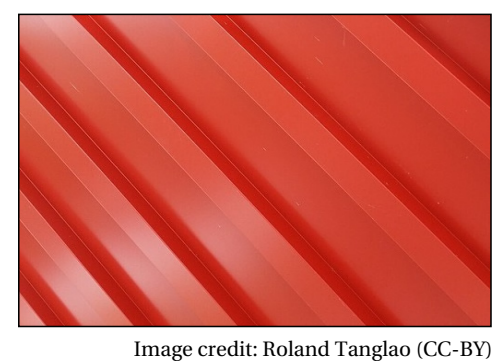

\title{
Technology Commercialization and Entrepreneurship
}

Welcome to the January issue of the Technology Innovation Management Review. We welcome your comments on the articles in this issue as well as suggestions for future article topics and issue themes.

Editorial: Technology Commercialization and Entrepreneurship Chris McPhee, Ferran Giones, and Dev K. Dutta

Strategy-as-Process in a Technology Venture: A Case Study of Pivots,

Pauses, Partners, and Progress Andrew G. Earle, Michael J. Merenda, and J. Matthew Davis

Alliances in Financial Ecosystems: A Source of Organizational Legitimacy for Fintech Startups and Incumbents Christopher Svensson, Jakob Udesen, and Jane Webb

Are High-Tech Companies More Competitive Than Others? An Empirical Study of Innovative and Exporting French SMEs Manon Enjolras, Mauricio Camargo, and Christophe Schmitt

The Effect of Digitalization on the Commercialization Process of HighTechnology Companies in the Life Sciences Industry Saheed A. Gbadegeshin

E-Leadership in Small and Medium-Sized Enterprises in the Developing World Maksim Belitski and Bain Liversage

Author Guidelines

.




\section{Publisher}

The Technology Innovation Management Review is a monthly publication of the Talent First Network.

\section{ISSN}

1927-0321

\section{Editor-in-Chief}

Chris McPhee

\section{Advisory Board}

Tony Bailetti, Carleton University, Canada

Peter Carbone, Ottawa, Canada

Parm Gill, Gill Group, Canada

Leslie Hawthorn, Red Hat, United States

Michael Weiss, Carleton University, Canada

\section{Review Board}

Tony Bailetti, Carleton University, Canada

Peter Carbone, Ottawa, Canada

Parm Gill, Gill Group, Canada

G R Gangadharan, IBM, India

Mohammad Saud Khan, Victoria University of

Wellington, New Zealand

Seppo Leminen, Pellervo Economic Research and Aalto University, Finland

Colin Mason, University of Glasgow, United Kingdom

Steven Muegge, Carleton University, Canada

Jennifer Percival, University of Massachusetts, United States

Risto Rajala, Aalto University, Finland

Punit Saurabh, Nirma University, India

Sandra Schillo, University of Ottawa, Canada

Marina Solesvik, Nord University, Norway

Stoyan Tanev, Carleton University, Canada

Michael Weiss, Carleton University, Canada

Mika Westerlund, Carleton University, Canada

Blair Winsor, Memorial University, Canada

(C) $2007-2019$

Talent First Network

www.timreview.ca

\section{Overview}

The Technology Innovation Management Review (TIM Review) provides insights about the issues and emerging trends relevant to launching and growing technology businesses. The TIM Review focuses on the theories, strategies, and tools that help small and large technology companies succeed.

Our readers are looking for practical ideas they can apply within their own organizations. The TIM Review brings together diverse viewpoints - from academics, entrepreneurs, companies of all sizes, the public sector, the community sector, and others - to bridge the gap between theory and practice. In particular, we focus on the topics of technology and global entrepreneurship in small and large companies.

We welcome input from readers into upcoming themes. Please visit timreview.ca to suggest themes and nominate authors and guest editors.

\section{Contribute}

Contribute to the TIM Review in the following ways:

- Read and comment on articles.

- Review the upcoming themes and tell us what topics you would like to see covered.

- Write an article for a future issue; see the author guidelines and editorial process for details.

- Recommend colleagues as authors or guest editors.

- Give feedback on the website or any other aspect of this publication.

- Sponsor or advertise in the TIM Review.

- Tell a friend or colleague about the TIM Review.

Please contact the Editor if you have any questions or comments: timreview.ca/contact

\section{About TIM}

The TIM Review has international contributors and readers, and it is published in association with the Technology Innovation Management program (TIM; timprogram.ca), an international graduate program at Carleton University in Ottawa, Canada. 


\section{Editorial:}

\section{Technology Commercialization and Entrepreneurship Chris McPhee, Editor-in-Chief Ferran Giones and Dev K. Dutta, Guest Editors}

\section{From the Editor-in-Chief}

Welcome to the January 2019 issue of the Technology Innovation Management Review. This month's editorial theme is Technology Commercialization and Entrepreneurship, and it is my pleasure to introduce our guest editors: Ferran Giones from the University of Southern Denmark and Dev K. Dutta from the University of New Hampshire in the United States.

For future issues, we are accepting general submissions of articles on technology entrepreneurship, innovation management, and other topics relevant to launching and growing technology companies and solving practical problems in emerging domains. Please contact us (timreview.ca/contact) with potential article topics and submissions, and proposals for future special issues.

Finally, we invite you to attend ISPIM Connects Ottawa (ispim-connects-ottawa.com), which will be held in Ottawa, Canada, from April 7-10, 2019. ISPIM Connects Ottawa is a three-day event that will bring together worldrenowned innovation managers, researchers, and business and thought leaders to share insights on specific local and global innovation challenges as well as general innovation management hot-topic. The TIM Review and its associated academic program at Carleton University, the TIM Program (timprogram.ca), are proud to be the local hosts of the event in collaboration with other partners.

\section{Chris McPhee}

Editor-in-Chief

\section{From the Guest Editors}

This special issue explores research questions at the intersection of technology commercialization and entrepreneurship. Specifically, our intent was to invite articles that examine the overlaps and complementarities between these two activities. In combination, technology commercialization with entrepreneurship brings to fruition the process of introducing into a market a new tool or a new application for an existing tool (Markman et al., 2008) and the venture-creation process to exploit an entrepreneurial opportunity (Davidsson, 2015).

Not all startups are led by technology entrepreneurs (Bailetti, 2012; Giones \& Brem, 2017a; Wallin et al., 2016). However, in disruptive environments, we increasingly notice the adoption of digital technologies to implement startup business models (von Briel et al., 2018; Westerlund et al., 2014) or organizational structures (Nambisan, 2016). So, in the end, technology commercialization and entrepreneurship often become intertwined in a complex process of co-evolution, resulting in the emergence of new technologies as well as entrepreneurial activity (Giones \& Brem, 2017b).

Take, for instance, the developments around some recent digital technologies such as social media and blockchain. Some entrepreneurs have engaged in developing applications and then bringing them to the market with a focus on overcoming the technology commercialization challenges; others have utilized these new technologies as external enablers for their new venture ideas (Davidsson et al., 2018). A similar pattern can be observed relating to clean-tech (Bjornali et al., 2017), nanotech (Woolley, 2014), or the drone industry (Giones \& Brem, 2017b). Interestingly, micro-level dynamics between promising technologies and entrepreneurs can contribute to the successful creation of ecosystems (Spigel \& Harrison, 2017), with significant regional impact, leading even to the emergence of new industries (Alvarez et al., 2015; Forbes \& Kirsch, 2011).

In order to provide an informed perspective and useful insights to researchers and practitioners, we have organized the contributions in this special issue within a 


\title{
Editorial: Technology Commercialization and Entrepreneurship
}

\author{
Chris McPhee, Ferran Giones, and Dev K. Dutta
}

framework integrating technology commercialization and entrepreneurship. Our objective is to make this framework a reference for future researchers and practitioners intending to examine these issues further.

\section{Bringing together technology commercialization and entrepreneurship}

The intersection of technology commercialization and entrepreneurship captures a scenario where entrepreneurs, potentially, have an advantage over established players when bringing novel technologies to market. Novelty is an advantage, even if it also makes survival harder (Hyytinen et al., 2015).

From the viewpoint of technology commercialization, these are often situations where there either is an emergent technology without a clear application or market, or there is a technology that is new to a specific market or industry. Emerging technologies include new promising insights from science and engineering that are being developed as tools that could potentially change the current state of the art (Rotolo et al., 2015). At the other extreme, existent technologies repurposed for new applications in new markets are defined as technology exaptations (Andriani et al., 2017; Andriani \& Cattani, 2016). They are often the more prevalent form of technology commercialization among digital entrepreneurs who recombine existent technologies for a new use. Therefore, we propose to divide the technology commercialization axis between "emerging technology innovations" and "exapted technologies and digital innovations" as being, a priori, sources of substantial differences in the technology commercialization process (see Table 1).

From the intersecting viewpoint of entrepreneurship, we know that founder characteristics and the new venture's team composition have an influence on the identification of an idea and its exploitation as an opportunity (Klotz, et al., 2013; Unger et al., 2011). We also know the ways in which the business model (Foss \& Saebi, 2017), the firm's strategy (Gans et al., 2018), the strategic orientation and learning (Dutta \& Crossan, 2005; Dutta \& Hora, 2017), and the ecosystem where they are embedded (Drori \& Wright, 2018; Kohler, 2016; Mian et al., 2016), can make a difference. Finally, we also know that there are overarching institutional, network, and societal elements that can have an impact on technology entrepreneurship activities, for instance, the regulation approaches (Gurses \& Ozcan, 2015) or regional innovation policy choices (Clayton et al., 2018; Sorenson, 2018). Thus, we divide the entrepreneurship axis (see Table 1) using three broad levels that include micro-, meso-, and macro-level components of the phenomenon.

The juxtaposition of these two viewpoints generates the opportunity to identify specific research areas that can contribute to advances in both domains by identifying practice-oriented problems (i.e., What should I consider in my specific situation?) and academic research problems (i.e., How could I introduce technology commercialization challenges in my entrepreneurship research?). We have added, only for illustrative purposes, possible research questions or scenarios that can inspire future work on the topic (see Table 1).

This special issue of the TIM Review takes the first steps towards addressing these research gaps. The articles in this issue introduce perspectives from managers leading their organizations, new firms (startups), and maturing firms (SMEs). The articles show how digitalization has permeated the different decision-making spheres across a diversity of contexts. The interplay of technology commercialization and entrepreneurship processes goes beyond the growth pains of high-tech firms. At the same time, the diversity of contexts and cases included in the special issue capture the complexity of the phenomenon and the relevance this has for technology entrepreneurs and innovation managers.

First, Andrew G. Earle, Michael J. Merenda, and J. Matthew Davis from the University of New Hampshire in the United States explore the case of a technology venture in the "green energy" industry to identify tools that entrepreneurs can use to overcome new venture development transitions. The authors address the question of "how do entrepreneurs navigate key transition points in the phases of the technology commercialization process?" They focus on the case of an emerging technology from the entrepreneur's perspective (microlevel). Their findings highlight the non-linearity of emerging technology commercialization, emphasizing the value of taking "strategic pauses" that allow the firm to pivot or explore new partnerships. The authors also introduce suggestions on how tech firms can prepare to more effectively navigate these transitions.

In the second article, Christopher Svensson, Jakob Udesen, and Jane Webb from Chalmers University of Technology, Sweden, study how fintech startups and incumbents build legitimacy in the financial ecosystem. The authors explore the perspective from the viewpoints of both new entrants (15 fintech startups) as well 


\section{Editorial: Technology Commercialization and Entrepreneurship}

\section{Chris McPhee, Ferran Giones, and Dev K. Dutta}

Table 1. A practice-oriented research framework for technology commercialization and entrepreneurship

\begin{tabular}{|c|c|c|c|}
\hline $\begin{array}{l}\text { Technology } \\
\text { Commercialization }\end{array}$ & $\begin{array}{c}\text { Micro-Level } \\
\text { (Entrepreneur and team) }\end{array}$ & $\begin{array}{c}\text { Meso-Level } \\
\text { (Firm and ecosystems) }\end{array}$ & $\begin{array}{c}\text { Macro-Level } \\
\text { (Region and policy) }\end{array}$ \\
\hline $\begin{array}{l}\text { Technologies with an } \\
\text { uncertain market: } \\
\text { Emerging Technology } \\
\text { Innovations }\end{array}$ & $\begin{array}{l}\text { - When and how do scientists } \\
\text { and inventors develop } \\
\text { emerging technological } \\
\text { innovations? } \\
\text { - How do individual biases, } \\
\text { learning, or preferences } \\
\text { impact the exploitation of } \\
\text { emerging technologies? } \\
\text { - When do teams outperform } \\
\text { individuals in the search for } \\
\text { the "next big thing"? } \\
\text { - To what extent could the } \\
\text { hype surrounding radical } \\
\text { new technologies reduce or } \\
\text { stymie low-tech or generic } \\
\text { entrepreneurial activity? }\end{array}$ & $\begin{array}{l}\text { - How can the tensions and } \\
\text { challenges of the new } \\
\text { venture development in } \\
\text { disruptive environments be } \\
\text { modelled? } \\
\text { - What are the antecedents } \\
\text { and consequences of } \\
\text { market strategy choices with } \\
\text { regard to emerging } \\
\text { technologies? } \\
\text { - How do entrepreneurial } \\
\text { ecosystems contribute to } \\
\text { the development of } \\
\text { emerging technology-based } \\
\text { entrepreneurship? }\end{array}$ & $\begin{array}{l}\text { - How can policy makers } \\
\text { balance their current } \\
\text { economic initiatives and } \\
\text { also facilitate the adoption } \\
\text { of unproven and risky } \\
\text { emerging technologies? } \\
\text { - When does public funding } \\
\text { contribute to the future } \\
\text { growth of new technology- } \\
\text { based entrepreneurship? } \\
\text { What makes a promising } \\
\text { technology from the policy } \\
\text { or regional perspective? } \\
\text { - Are there rules, or } \\
\text { innovation policy } \\
\text { instruments, that favour the } \\
\text { creation of new } \\
\text { entrepreneurial ecosystems? }\end{array}$ \\
\hline $\begin{array}{l}\text { Technologies for new } \\
\text { market application: } \\
\text { Exapted Technologies } \\
\text { and Digital Innovations }\end{array}$ & $\begin{array}{l}\text { - How do individual digital } \\
\text { competences (of the } \\
\text { founder or CEO) enhance } \\
\text { the firm capabilities to } \\
\text { generate digital } \\
\text { innovations? } \\
\text { - How does the digitization of } \\
\text { organizational processes } \\
\text { and systems change the } \\
\text { individual and team } \\
\text { entrepreneurial activities? } \\
\text { - To what extent does exapted } \\
\text { innovation attract different } \\
\text { types of individuals (i.e., } \\
\text { though reduced failure costs } \\
\text { or social stigma)? }\end{array}$ & $\begin{array}{l}\text { - How do firms capture } \\
\text { attention and build } \\
\text { legitimacy in contexts } \\
\text { characterized by } \\
\text { "information overload"? } \\
\text { - How can growth models } \\
\text { capture the differences } \\
\text { across new venture's } \\
\text { business models, } \\
\text { innovation platforms, or } \\
\text { ecosystems? } \\
\text { - How do partnerships with } \\
\text { established players } \\
\text { accelerate growth? Are there } \\
\text { any detrimental effects? }\end{array}$ & $\begin{array}{l}\text { - How do product-technology } \\
\text { life-cycles reconcile with } \\
\text { technology knowledge } \\
\text { spillovers to new } \\
\text { markets/industries? } \\
\text { - How can policy makers } \\
\text { (possibly) contribute to the } \\
\text { generation of new industries } \\
\text { while maintaining their } \\
\text { regions' knowledge-based } \\
\text { advantages? }\end{array}$ \\
\hline
\end{tabular}




\title{
Editorial: Technology Commercialization and Entrepreneurship
}

\author{
Chris McPhee, Ferran Giones, and Dev K. Dutta
}

as the incumbents (established financial firms) in terms of their response to regaining their organizational legitimacy. The focus is on one of the fascinating digital innovations using a firm perspective (meso-level). Their findings expand the implications of legitimacy theory in contexts where regulatory frameworks mediate the social and economic impact of digital innovations. The authors provide specific insights as to how new digital entrepreneurs can build legitimacy in highly regulated and competitive contexts.

Next, Manon Enjolras, Mauricio Camargo, and Christophe Schmitt from the Université de Lorraine, France, investigate the effects of technology intensity on the growth and internationalization of SMEs. The authors explore the consequences of technology commercialization from a firm perspective by answering the question: Does an SME's high technology intensity result in high innovativeness and export performance? The authors build on the observation of nine different SMEs with different levels of technology intensity and innovation types to extract potential profiles that connect technology commercialization outcomes and innovation. The findings suggest that a long-term implication for firms with high technology intensity is that they sustain a focus on product innovations, looking for "the next big thing" using emerging technologies. In contrast, firms with low technology intensity are more prone to specializing in process innovations, looking at options to recombine existing technologies to find solutions that address existing problems. The authors discuss the implications of such configurations for the long-term growth and internationalization of the firms.

Then, Saheed A. Gbadegeshin from the University of Turku, Finland, investigate how digitalization has changed the technology commercialization processes in the life sciences industry. The author explores this question from the angle of new drugs, medical devices, and e-health companies. The article takes a firm, ecosystem and regional perspective into account (mesolevel and macro-level) to explore how digitalization changes the technology commercialization of digital innovations and emerging technologies in a specific in- dustry (life sciences). The participation of a diversity of firms and stakeholders allows Gbadegeshin to extract common and specific insights. Common to the different types of technology commercialization processes is that lower costs and higher flexibility lead to more iterative processes and adoption of agile business model approaches across the industry. The article also presents specific examples of the downside of digitalization, for instance, related to cybersecurity or hacking threats.

The final article, by Maksim Belitski and Bain Liversage from the University of Reading in the United Kingdom, describes how digital technologies and eleadership skills influence the development of SMEs. The authors use the context of an emerging economy to study how transformation and e-leadership in SMEs can help to create and capture value using digital technologies. The article takes the perspective of the SME manager (micro-level) to identify what e-leadership capacities contribute to the exploitation of digital innovations. The authors use a mixed-methods approach (interviews and a survey) to gather insights on what it means to introduce transformational e-leadership and how this can have an impact on the development and growth of the SME. They discuss how the study findings extend the impact of digitalization beyond technology commercialization and entrepreneurship, noting that, as firms mature, it becomes necessary to realign the new technologies' potential with business strategy.

Taken together, the contributions to this special issue of the TIM Review provide a first step to address the research opportunities at the intersection of technology commercialization and entrepreneurship. They provide a sample of perspectives with different units of analysis and a rich combination of research methods. The international background of the authors as well as their respective studies indicate the interest in the topic as well as its relevance at a global scale, highlighting practiceoriented responses to what is a complex but promising and growing area of research.

\section{Ferran Giones and Dev K. Dutta Guest Editors}




\section{Editorial: Technology Commercialization and Entrepreneurship}

\section{Chris McPhee, Ferran Giones, and Dev K. Dutta}

\section{About the Editors}

Chris McPhee is Editor-in-Chief of the Technology Innovation Management Review. Chris holds an MASc degree in Technology Innovation Management from Carleton University in Ottawa, Canada, and $\mathrm{BScH}$ and MSc degrees in Biology from Queen's University in Kingston, Canada. He has 20 years of management, design, and content-development experience in Canada and Scotland, primarily in the science, health, and education sectors. As an advisor and editor, he helps entrepreneurs, executives, and researchers develop and express their ideas.

Ferran Giones is an Assistant Professor at the University of Southern Denmark in Sønderborg. He received his PhD from La Salle - Ramon Llull University in Barcelona, Spain. His research field is technology entrepreneurship, where he explores how and when technological progress transforms into entrepreneurial activity, and how this entrepreneurial activity results in sustainable organizations and innovative ecosystems.

Dev K. Dutta is an Associate Professor of Strategic Management and Entrepreneurship in the Management Department at the University of New Hampshire in the United States. His research and teaching focus on the intersection of entrepreneurship and innovation, especially the way these concepts apply at the firm and ecosystem levels. Dev has over 25 research publications in his field in peer-reviewed journals as well as books, book chapters, and research monographs. He also holds national certifications as an academic coach and facilitator in technology entrepreneurship, innovator mindset, lean launch pad, and design thinking (MIT and Stanford DSchool). Before joining academia, Dev worked for 15 years as a corporate strategy consultant for several large Indian IT multinationals.

\section{References}

Alvarez, S. A., Young, S. L., \& Woolley, J. L. 2015. Opportunities and Institutions: A Co-Creation Story of the King Crab Industry. Journal of Business Venturing, 30(1): 95-112. https://doi.org/10.1016/j.jbusvent.2014.07.011

Andriani, P., Ali, A., \& Mastrogiorgio, M. 2017. Measuring Exaptation and Its Impact on Innovation, Search, and Problem Solving. Organization Science, 28(2): 320-338. https://doi.org/10.1287/orsc.2017.1116

Andriani, P., \& Cattani, G. 2016. Exaptation as Source of Creativity, Innovation, and Diversity: Introduction to the Special Section. Industrial and Corporate Change, 25(1): 115-131. https://doi.org/10.1093/icc/dtv053

Bailetti, T. 2012. Technology Entrepreneurship: Overview, Definition, and Distinctive Aspects. Technology Innovation Management Review, 2(2): 5-12. https://doi.org/10.22215/timreview/520

Bjornali, E. S., Giones, F., \& Billström, A. 2017. Reveal or Conceal? Signaling Strategies for Building Legitimacy in Cleantech Firms. Sustainability, 9(10): 1-19.

https://doi.org/10.3390/su9101815

Clayton, P., Feldman, M., \& Lowe, N. 2018. Behind the Scenes: Intermediary Organizations that Facilitate Science Commercialization through Entrepreneurship. Academy of Management Perspectives, 32(1): 104-124. https://doi.org/10.5465/amp.2016.0133

Davidsson, P. 2015. Entrepreneurial Opportunities and the Entrepreneurship Nexus: A Re-Conceptualization. Journal of Business Venturing, 30(5): 674-695. https://doi.org/10.1016/j.jbusvent.2015.01.002

Davidsson, P., Recker, J., \& von Briel, F. 2018. External Enablement of New Venture Creation: A Framework. Academy of Management Perspectives.

https://doi.org/10.5465/amp.2017.0163

Drori, I., \& Wright, M. 2018. Accelerators: Characteristics, Trends and the New Entrepreneurial Ecosystem. In M. Wright \& I. Drori (Eds.), Accelerators: 1-20. Cheltenham, UK: Edward Elgar Publishing. https://doi.org/10.4337/9781786434098.00005

Dutta, D. K., \& Crossan, M. M. 2005. The Nature of Entrepreneurial Opportunities: Understanding the Process Using the 4I Organizational Learning Framework. Entrepreneurship Theory and Practice, 29(4): 425-449. https://doi.org/10.1111/j.1540-6520.2005.00092.x

Dutta, D. K., \& Hora, M. 2017. From Invention Success to Commercialization Success: Technology Ventures and the Benefits of Upstream and Downstream Supply-Chain Alliances. Journal of Small Business Management, 55(2): 216-235. https://doi.org/10.1111/jsbm.12334

Fini, R., Rasmussen, E., Wiklund, J., \& Wright, M. 2018. Theories From the Lab: How Research on Science Commercialization Can Contribute to Management Studies. Journal of Management Studies.

https://doi.org/10.1111/joms.12424 


\section{Editorial: Technology Commercialization and Entrepreneurship}

\section{Chris McPhee, Ferran Giones, and Dev K. Dutta}

Fisher, G., Kuratko, D. F., Bloodgood, J. M., \& Hornsby, J. S. 2017. Legitimate to Whom? The Challenge of Audience Diversity and New Venture Legitimacy. Journal of Business Venturing, 32(1): $52-71$.

https://doi.org/10.1016/j.jbusvent.2016.10.005

Forbes, D. P., \& Kirsch, D. A. 2011. The Study of Emerging Industries: Recognizing and Responding to Some Central Problems. Journal of Business Venturing, 26(5): 589-602. https://doi.org/10.1016/j.jbusvent.2010.01.004

Foss, N. J., \& Saebi, T. 2017. Business Models and Business Model Innovation: Between Wicked and Paradigmatic Problems. Long Range Planning, 51(1): 9-21.

https://doi.org/10.1016/j.lrp.2017.07.006

Gans, J. S., Scott, E. L., \& Stern, S. 2018. Strategy for Start-Ups. Harvard Business Review, 96(3): 44-52.

Giones, F., \& Brem, A. 2017a. Digital Technology Entrepreneurship: A Definition and Research Agenda. Technology Innovation Management Review, 7(5): 44-51. https://doi.org/10.22215/timreview1076

Giones, F., \& Brem, A. 2017b. From Toys to Tools: The Co-Evolution of Technological and Entrepreneurial Developments in the Drone Industry. Business Horizons, 60(6): 875-884.

https://doi.org/10.1016/j.bushor.2017.08.001

Gurses, K., \& Ozcan, P. 2015. Entrepreneurship in Regulated Markets: Framing Contests and Collective Action to Introduce Pay TV in the U.S. Academy of Management Journal, 58(6): 1709-1739. https://doi.org/10.5465/amj.2013.0775

Hyytinen, A., Pajarinen, M., \& Rouvinen, P. 2015. Does Innovativeness Reduce Startup Survival Rates? Journal of Business Venturing, 30(4): 564-581.

https://doi.org/10.1016/j.jbusvent.2014.10.001

Klotz, A. C., Hmieleski, K. M., Bradley, B. H., \& Busenitz, L. W. 2013. New Venture Teams: A Review of the Literature and Roadmap for Future Research. Journal of Management, 40(1): 226-255. https://doi.org/10.1177/0149206313493325

Kohler, T. 2016. Corporate Accelerators: Building Bridges Between Corporations and Startups. Business Horizons, 59(3): 347-357. https://doi.org/10.1016/j.bushor.2016.01.008

Markman, G. D., Siegel, D. S., \& Wright, M. 2008. Research and Technology Commercialization. Journal of Management Studies, 45(8): 1401-1423.

https://doi.org/10.1111/j.1467-6486.2008.00803.x

Mian, S., Lamine, W., \& Fayolle, A. 2016. Technology Business Incubation: An Overview of the State of Knowledge. Technovation, 50-51: 1-12.

https://doi.org/10.1016/j.technovation.2016.02.005
Nambisan, S. 2016. Digital Entrepreneurship: Toward a Digital Technology Perspective Of Entrepreneurship. Entrepreneurship Theory and Practice, 41(6): 1029-1055. https://doi.org/10.1111/etap.12254

Rotolo, D., Hicks, D., \& Martin, B. R. 2015. What Is an Emerging Technology? Research Policy, 44(10): 1827-1843. https://doi.org/10.1016/j.respol.2015.06.006

Sorenson, O. 2018. Social Networks and the Geography of Entrepreneurship. Small Business Economics, 51(3): 527-537. https://doi.org/10.1007/s11187-018-0076-7

Spigel, B., \& Harrison, R. 2017. Toward a Process Theory of Entrepreneurial Ecosystems. Strategic Entrepreneurship Journal, 12(1): 151-168. https://doi.org/10.1002/sej.1268

Unger, J. M., Rauch, A., Frese, M., \& Rosenbusch, N. 2011. Human Capital and Entrepreneurial Success: A Meta-Analytical Review. Journal of Business Venturing, 26(3): 341-358. https://doi.org/10.1016/j.jbusvent.2009.09.004

von Briel, F., Davidsson, P., \& Recker, J. 2018. Digital Technologies as External Enablers of New Venture Creation in the IT Hardware Sector. Entrepreneurship Theory and Practice, 42(1): 47-69. https://doi.org/10.1177/1042258717732779

Wallin, A., Still, K., \& Henttonen, K. 2016. Entrepreneurial Growth Ambitions: The Case of Finnish Technology Startups. Technology Innovation Management Review, 6(10): 5-16. https://doi.org/10.22215/timreview/1023

Westerlund, M., Leminen, S., \& Rajahonka, M. 2014. Designing Business Models for the Internet of Things. Technology Innovation Management Review, 4(7): 5-14. https://doi.org/10.22215/timreview/807

Woolley, J. L. 2014. The Creation and Configuration of Infrastructure for Entrepreneurship in Emerging Domains of Activity. Entrepreneurship Theory and Practice, 38(4): 721-747. https://doi.org/10.1111/etap.12017

Citation: McPhee, C., Giones, F., \& Dutta., D. K. 2019. Editorial: Technology Commercialization and Entrepreneurship. Technology Innovation Management Review, 9(1): 3-8.

http://doi.org/10.22215/timreview/1207

Keywords: technology, entrepreneurship, commercialization, startups, ventures, SMEs, innovation, management, framework, legitimacy, technology intensity, internationalization, digitalization, e-leadership 


\title{
Strategy-as-Process in a Technology Venture: A Case Study of Pivots, Pauses, Partners, and Progress
}

\author{
Andrew G. Earle, Michael J. Merenda, and J. Matthew Davis
}

\author{
"We thought we were being 'disruptive'. Time will tell if ") \\ we were, in fact, just being stubborn.
}

Founder of the technology venture featured in this study

\begin{abstract}
Technology commercialization is an often nonlinear process that tends to pass through various "stages" or "phases" as a venture attempts to shepherd a technology from the laboratory to marketplace. Between these phases are "junctures" or "transitions" that present particular challenges for entrepreneurs as they often comprise fundamental changes to the venture instead of simply scaled versions of previous challenges. In this study, we use a participantobserver methodology to deeply explore how a technology venture in the renewable energy sector negotiated these transitions. Our findings highlight the development of a "repertoire" of tools entrepreneurs can use to help successfully negotiate these transitions.
\end{abstract}

\section{Introduction}

Technology entrepreneurship is defined as "an investment in a project that assembles and deploys specialized individuals and heterogeneous assets that are intricately related to advances in scientific and technological knowledge for the purpose of creating and capturing value for a firm" (Bailetti, 2012). Commercialization is "the process of acquiring ideas, augmenting them with complementary knowledge, developing and manufacturing saleable goods, and selling goods in a market" (Mitchell \& Singh, 1996). Both of these closely related concepts are critical to developing science-based solutions to seemingly intractable social problems and sustaining firm competitiveness in technology-driven industries (Katila, 2002; Prahalad, 2011).

Past technology entrepreneurship research revealed barriers to commercialization such as the "Valley of Death" in which a given technology fails to make it to market because many funding sources focus on scientific novelty (such as grants for basic scientific research) and do not support the type of translational research needed to make such a technology attractive to private investors (Auerswald \& Branscombe, 2003). Similarly, researchers have highlighted "chasms" like that between enthusiastic groups of early adopters and the mass market that ultimately determine a venture's success (Moore, 1999).
Beyond these well-established barriers, researchers have found other, often subtler, obstacles including the difficulty in effectively traversing the conflicting logics of scientific research and market-focused commercialization (Vohora et al., 2004). Furthermore, these barriers often require fundamentally different managerial approaches rather than representing scaled-up versions of the same problem. For example, Fisher and colleagues (2016) demonstrate how institutional pressures vary, leading to legitimacy challenges as technology-focused ventures make their way from the laboratory to the market. Despite all of these laudable research efforts, technology commercialization remains challenging, and empirical evidence shows that very few inventions navigate this perilous transition to become true innovations (Markman et al., 2008; Moser, 2005).

In this study, we build on this research, while also taking a different methodological approach to understanding the technology commercialization process. By taking studies outlining increasingly nuanced views of the stages and phases of technology commercialization as showing the "contours" (Rasmussen, 2011) of this process, we examine how technology entrepreneurs deploy various tools in the transition between these phases. In so doing, we respond to calls for entrepreneurship researchers to engage in process-centered, longitudinal, and market-oriented studies of emergence 


\section{Strategy-as-Process in a Technology Venture: A Case Study of Pivots, Pauses, Partners, and Progress Andrew G. Earle, Michael J. Merenda, and J. Matthew Davis}

under conditions of uncertainty (Davidsson, 2003). This approach both helps add a dimension of "how" to the "what" examined in these previous studies, and it provides more concrete guidance to those directly involved in the technology commercialization process.

Previous research has provided limited guidance on negotiating transition points between stages of the commercialization process (Neergard, 2003; Rasmussen, 2011) and these transitions are still not well understood more generally (Fisher et al., 2016). A result, we use a qualitative inductive methodological approach, featuring participant observation, in an effort to gain deeper insights into our research question: how do entrepreneurs navigate key transition points in the phases of the technology commercialization process? Our goal in this study is to contribute to opening the "black box" of these transition points to better understand the tools used in these efforts by technology ventures.

In service of this goal, we first offer a focused literature review on stage-based models of entrepreneurship with particular attention paid to the consequences for technology commercialization contexts. Second, we present our case analysis of a technology commercialization venture in the promising area of sensors and data analytics used in renewable energy systems. Our analysis of this case unveiled a repertoire of tools the venture used when navigating its technology commercialization path and associated critical transition points. This notion of a repertoire from which actors can select is well established in research on organizational culture (e.g., Swidler, 1986) and has more recently been adapted to the context of product innovation (e.g., Seidel \& O'Mahony, 2014).

While some of these "tools" we observed have received increasing attention in both popular and academic outlets - such as "pivoting" (Crilly, 2018; Reis, 2011) - others such as strategic pauses are less developed within the literature. Mintzberg and Waters (1982) highlight the importance of "periods of pause, following periods of sprinting" for organizations to "remain viable" more generally, but they do not apply this concept to technology commercialization or early-stage ventures. Furthermore, our methods allow us to take a more holistic view of these tools so instead of examining whether or not a given tool is effective on average across a large population of ventures; we are able, for example, to examine the nuanced relationship between pivoting and pausing in the context of this particular case.

\section{Previous Research}

One of the foundational observations in research on technology commercialization (and entrepreneurship more generally) is that it is inherently $a$ process rather than an event or trait (Davidsson, 2003). As such, researchers have endeavoured to better understand this process by focusing on its progression from scientific discovery to marketable product. In an extreme but instructive example, Rothaermel and Deeds (2004) studied the technology commercialization process in the pharmaceutical industry. Here, chemical compounds are screened through numerous "models" (ranging from simple organisms to mice to human subjects) to assess a compound's feasibility as a pharmaceutical. Of course, the highly regulated and broadly linear technology commercialization process in the pharmaceutical industry likely represents an extreme case; however, the overarching idea remains the same: scientific discoveries must be tested and refined to eventually become commercialized products.

In another example, Dewald and Fromhold-Eisebith (2015) examined the photovoltaic (PV) industry's formation from its birth in the 1950s to its maturation in the 2000s. The researchers studied this industry through the lens of technological innovation systems, specifically sustainability-oriented technology. Their empirical study demonstrated "an expedient combination" of "territorial innovation system" approaches (regional, national, supranational, and international spaces) and its connections with major process-oriented fields (R\&D, knowledge development, technology production, market formation, and policy). The authors postulate that technology innovation systems are rescaled in time and space through the dynamic convergence of the different process fields and a focus on the convergence of technology innovation systems and national institutional systems by aligning technology with strengths of the national innovation system (e.g., prevalence of a nation's leading industries, technologies, and expertise). Whether it takes place at the macro- (institutional and policy), mezzo- (industry), or micro- (firm) level of analysis, this area of research has shown that, in addition to experiencing a nonlinear technology commercialization process, nascent technology entrepreneurs face the dynamic interplay of markets (e.g., industry maturation, legacy effects, and fights over standards and practices), technology development and integration (e.g., symbiotic relationships), and psychological (reliance on heuristic and mental models) challenges. 


\section{Strategy-as-Process in a Technology Venture: A Case Study of Pivots, Pauses, Partners, and Progress Andrew G. Earle, Michael J. Merenda, and J. Matthew Davis}

In addition to outlining high-level patterns, the literature illustrates that entrepreneurial ventures pass through several phases and confront critical junctures in their development. The literature also reveals that the intricacies and challenges faced by entrepreneurial ventures are similar regardless of industry or firm size. At each phase, ventures face strategic, financial, managerial, and organizational challenges, as well as issues with resource limitations and transition challenges (Churchill \& Lewis, 1983; Eggers et al., 1994). More specific to the technology-based venture context, Vohora and colleagues (2003) found the commercialization processes for spinouts based on university-generated technologies are also non-linear, often skipping stages or regressing to an earlier stage. These and other researchers found that early decisions and mistakes in this process can lead to substantial opportunity costs, including longer time to market, lost revenue, and lack of external investment (Eisenhardt \& Martin, 2000; Galunic \& Eisenhardt, 2001; Teece et al., 1997).

More recently, researchers have examined punctuated paths of technology commercialization and have argued that this process is more than merely refining a technology or searching for market alignment. For example, Fisher and colleagues (2016) develop a model in which new ventures based on university-generated technologies must traverse multiple "legitimacy thresholds" in which institutional pressures on the new venture change dramatically, thereby providing evidence that scaling requires a more systematic change to a venture than just doing more of the same, but on a larger scale.

\section{Methods}

To examine our research question, we employ a casebased methodology (Yin, 1989) to gain deeper insight into the tools and tactics used by technology-oriented entrepreneurs as they negotiate transition points (Figure 1) in the development of their ventures. Yin (1981) argues that case-based approaches are wellsuited to "attempt to examine: (a) a contemporary phenomenon in its real-life context, especially when (b) the boundaries between phenomenon and context are not clearly evident." This description fits our case study as we are examining the early stages of a new venture's evolution and focusing on the processes inherent in entrepreneurial activities (Davidsson, 2003). Specifically, we examine what Rasmussen (2011) classifies as the "teleological" processes of entrepreneurship, which aim to describe how entrepreneurs "are able to drive the project forward in a purposeful, or teleological, way" related to strategic decision making (Poole \& Van de Ven, 2004), adaptive learning (March \& Olsen, 1976), and the practice of strategy (Jarzabkowski, 2004).

In addition to adopting this exploratory case-based method, we also benefit from having a participant observer on our author team. Observation, including by participants, is employed in several disciplines as a technique to collect personal perspectives and cultural data in qualitative research (Kawulich, 2005). This design allows us unique access to understanding the "hows" and the "whys" of this case and has appeared

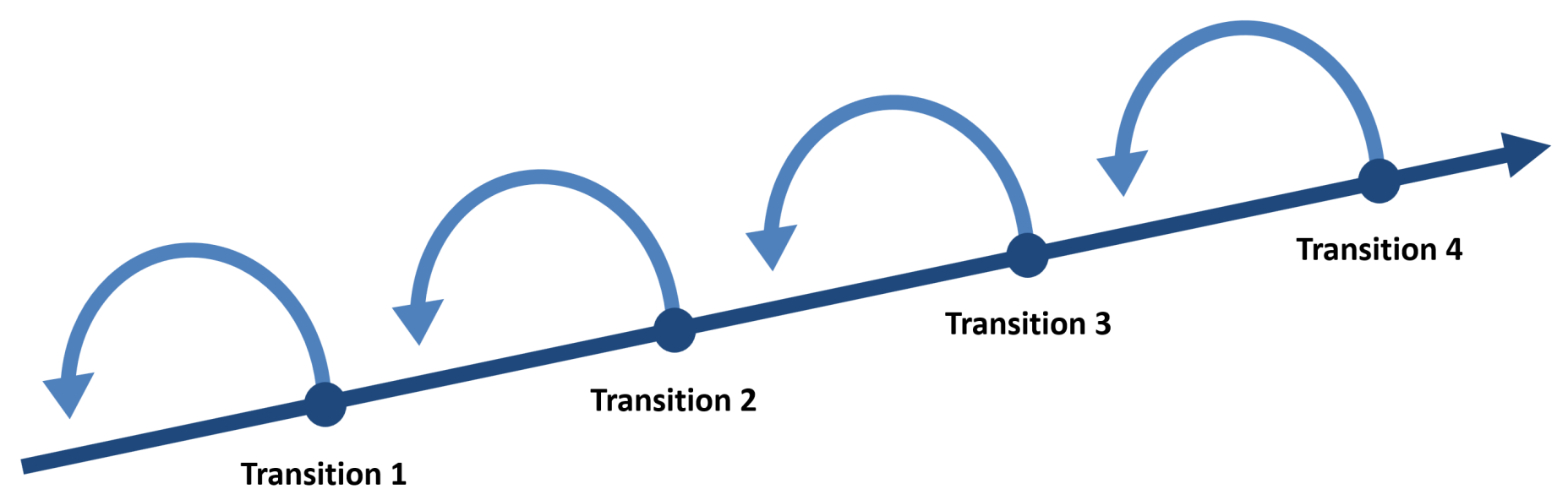

Figure 1. The recursive technology commercialization process with a focus on transitions 


\section{Strategy-as-Process in a Technology Venture: A Case Study of Pivots, Pauses, Partners, and Progress Andrew G. Earle, Michael J. Merenda, and J. Matthew Davis}

in related areas of research, such as examining the evolution of entrepreneurial networks (Jack et al., 2010). Furthermore, using a participant-observer approach for data collection helps answer calls for entrepreneurship research to more squarely focus on questions of emergence, as well as those of process (Davidsson, 2003).

\section{Case Selection and Setting}

We selected our case study based on access and its theoretical alignment with our research question. We believe our case excels at its alignment with our research question as it focuses on an early stage, but not a nascent, venture (having been founded in 2011). Therefore, it maps to early parts of stage-based models of technology entrepreneurship but also has existed long enough to offer a genuinely longitudinal perspective on the venture's evolution.

We also examined this venture "midstream" in its development (i.e., it is still an operating company). This timing allows us a unique vantage point in that we are not capturing prospective thoughts about what a potential founder might do, but a retrospective view on what a founder actually did in creating and managing their venture. As such, we are also not waiting for the ultimate outcome of the venture to study its evolution. As a result, such a midstream case selection helps avoid "survivorship" bias endemic in entrepreneurship research and contributes to "real-time" study of new venture processes (Carter et al., 1996).

The setting for our case is a technology venture called Energy Sensors LLC (a pseudonym). Energy Sensors' core product is a monitoring system (with hardware and software components) that can either be retrofitted to existing, or be integrated into new, geothermal heating and cooling systems. This technology allows system owners real-time analytics to assess the performance of their systems, replacing the guesswork and proxy measures that had been common industry practices. As such, Energy Sensors fits squarely with Bailetti's (2012) definition of technology entrepreneurship and other common definition of entrepreneurship more generally (e.g., Davidsson, 2003; Kirzner, 1983).

To help map Energy Sensors' journey to the phasebased frameworks described earlier, we asked our participant observer and Energy Sensors' founder to write an annotated timeline of critical events in his venture's formation and evolution. Once we had this more general timeline in place, we asked our participant observer to map the company's journey across the relevant phases to better illuminate how these transitions occurred. The timelines and additional conversations led to the development of an interview guide for collecting the founder's perceptions, observations, and experiences in starting and managing Energy Sensors. Based on this initial narrative, we then iterated through rounds of clarification, refinement, follow-on questions, and feedback from our participant observer. Given that we are particularly interested in the founder's navigation through the stages of his entrepreneurial journey, our questions and clarifications focused primarily on the critical junctures between phases.

\section{Case Study: Energy Sensors, LLC}

Energy Sensors was founded on the promise of widespread adoption of geothermal heat pump (GHP) technology as a critical element in reducing greenhouse gas emissions. Although changes in public policy to support renewable energy sources would be helpful, the founders believed market forces would ultimately drive large-scale adoption of GHP systems.

Energy Sensors' initial value proposition centered on the significant cost savings its technology could provide to GHP system operators and original equipment manufacturers (OEMs). For example, as a more efficient energy source, it was estimated that GHP technologies could deliver the same heating and cooling benefit for about half the cost of other heating and cooling methods. With this potential for energy savings in mind, Energy Sensors' initial value proposition mirrored that of the solar energy industry. Based on our participant-observer's annotated timeline of critical events in his venture's evolution, and his responses to the interview guide, we identified three phases and three sub-phases of this particular technology commercial process:

Phase 0 (2009-2010): R\&D, Idea, Discovery

Phase 1 (2011): Targeting, Customer Value Proposition Development

Phase 2 (2012-2016): Technology Application Phase 2a (Early 2012): Product Launch, Acquiring Resources, Trust Building

Phase 2b (Late 2012-2016): Re-Framing Technology and New Customers

Phase 2c (Late 2016): Fostering Collaborative Relationships

Phase 3 (2016): Quest for Profits 


\section{Strategy-as-Process in a Technology Venture: A Case Study of Pivots, Pauses, Partners, and Progress Andrew G. Earle, Michael J. Merenda, and J. Matthew Davis}

\begin{abstract}
Phase 0
Energy Sensors began based on our participant-observer's desire to apply his scientific work and interests in groundwater systems and data collection to solve similar problems related to heat flows associated with geothermal heat pumps (GHP). The founder's research interests coupled with his interests in serving the broader community as a scientist and researcher at a major research institution, and his financial motivation/job creation with a family business also acted as catalysts for phase 0. The founder launched Energy Sensors as a private entity separate from the university. He funded the startup and its initial intellectual property with his private funds and his co-founders' small equity investments.
\end{abstract}

The founder stated:

"There are many analogies in the status of GHP technology today and groundwater resource development. Both require a convergence of technology, motivated users/decision makers, and state and federal policies that enable market penetration (mainly in the form of infrastructure). While we see the necessary ingredients emerging for a GHP 'revolution', both the confidence in and awareness of the technology are lacking. Energy Sensors is working to develop technologies that will help overcome these barriers - specifically, cost-effective, and scalable monitoring and verification."

\section{Phase 1}

Phase I initiated Energy Sensors' investigation of commercialization opportunities for its GHP monitoring technology hardware and software. In 2011, the founder launched Energy Sensors, LLC. He wrote:

"Initial conception and product development (Spring/Summer 2011) included me and my wife as co-founders. Early on (Fall 2011), we brought on two engineers with some business and product development experience. Both had BS degrees in Mechanical Engineering and MBAs, and while in the MBA program, they started a small product development entity. They paid a nominal amount for approximately 10\% equity each. One had experience in the HVAC industry and ran a small business, while the other had experience in the development of electronics with connections in that field with some providers that we used in that space."

Critical to navigating this phase was an assessment of the technological viability of the initial hardware and software applications to determine if they could be commercially exploited; and, if so, how could they best create value? During this phase, Energy Sensors experienced technical and market uncertainties, capital constraints, and sometimes strained relationships with gatekeeping customers (e.g., GHP installers), all of which challenged Energy Sensors' ability to gain market traction and cash flow to cover rising start-up costs. To set the business on a path toward positive returns, the founders sought assistance through the local SCORE chapter and the state's Small Business Development Center (SBDC). The founder emphasized that a critical resource constraint was the limited time he could devote to the venture while maintaining his fulltime university position:
"It has been difficult to get others to really dig in- it is really hard to get something off the ground when you have a job and family. With a nine- month faculty appointment, I had one day a week for 'consulting', and nights, weekends, holidays, and summers for Energy Sensors, but that meant lost revenue to support family."

\section{Phase 2a}

In 2012, Energy Sensors released its initial product and began acquiring additional technical and professional expertise. This included a well-established GHP system design engineer with his own firm; a lead software developer; a marketing expert with a strong online presence in solar photovoltaic space; and a person with finance and project management skills who eventually became its part-time CEO. All hires were part-time and were incentivized through the adoption of a profit interest equity agreement. Still, the founder noted:

\section{"We had, and have, a pretty good team. With that said, they all have jobs, families, and other com- mitments, so getting what we need when we need it has been challenging."}

\section{Phase 2b}

Even with the added hires, Energy Sensors struggled to find the right technology applications for "paying" customers. This led to the founder's further investigation into the technical limitations of the company's software and monitoring system. During this phase, the founder noted that Energy Sensors experienced two major shifts in its trajectory. First, it moved from offering "customized" technology solutions to diverse customer needs to circling back to a more optimal set of standardized technology options. As company champion, the founder viewed the technology development 


\section{Strategy-as-Process in a Technology Venture: A Case Study of Pivots, Pauses, Partners, and Progress Andrew G. Earle, Michael J. Merenda, and J. Matthew Davis}

process as a learning opportunity, responding:

"We learned a lot through this real-time product development. I became the de facto GHP representative on the ASTM committee developing a heat meter standard for the U.S. The GHP industry would often call on me to work with State Energy Offices for consultation (mostly free). Collectively, this has established Energy Sensors as an objective expert in monitoring and verification (M\&V) of GHP systems."

The second trajectory change was repositioning the business by identifying and targeting a different set of paying customers and executing a "single customer development strategy". The founder explained:

"With limited resources, it is difficult to sustain a multi-front effort. Our initial target was the GHP system installer (residential, light commercial systems). We spent most of our effort on getting to installers. We joined the regional professional network and gave presentations at their annual meetings. Eventually, I ended up on the Board of Directors. While there was a great deal of mutual respect, they were not interested in our product/service and for reasons we now understand. We thought we were 'disruptive'. Time will tell if, in fact, we were just being stubborn. Our relationship with installers has been invaluable because we have earned their confidence and also learned A LOT [emphasis added by founder] about GHP technology and the industry."

\section{Phase 2c}

In this phase, the founder recognized the importance of Energy Sensors' involvement in regional sustainability efforts and GHP efforts that included many state agencies, suppliers, OEMs, practitioners, financial institutions, and other value chain players (mirroring past findings on the importance of national and regional institutions, and technology innovation systems). This collaborative participation and partnering proved critically important in the founder's success in both justifying and informing Energy Sensors' second round of R\&D through a United States Department of Energy (DOE) grant. The founder described his general approach in navigating transitions between phases $2 \mathrm{~b}$ to $2 \mathrm{c}$ :

"One big change is that, from Phase $2 b$ to $2 c$, we relied on a federal grant (DOE's Small Business Technology Transfer - STTR: Phase I). Co-founders committed to not go through additional fundraising sources or use personal funds. We reached the

\begin{abstract}
'break even' mark in 2014, and the rule was: no more debt. If an investor showed up at our door offering funds and expertise and willingness to lead, then we would reconsider, but we didn't want to be obligated to more people without having enough resources to really pull it off."
\end{abstract}

He continued:

\begin{abstract}
"Luckily, the DOE put out an SBIR/STTR topic that aligned with what we thought needed to be done and what we had established ourselves as being capable of doing; so we were successful in Phase I (SBIR/STTR: Phase I round). The Phase II application was not successful, but we were close to having a new product. We are exploring other opportunities to potentially get us to profitability."
\end{abstract}

What was evident in the founder's efforts to navigate critical junctures in the technology commercialization process was a great deal of change resulting from the continuous learning experienced by Energy Sensors' entrepreneurial team. This included interacting, partnering, and collaborating with customers, suppliers, investors, governmental agencies, and others in the sustainability and GHP industry clusters (i.e., the technological innovation system). Continuous learning and building trust enabled Energy Sensors to breakeven in 2014. This technology and business stabilization better positioned the company toward profits and value capture, with the founder observing: "most of 2016 we paused in pushing sales and began to work on building a market with larger stakeholders".

\section{Findings}

Figure 2 provides a conceptual model based on this case study. This model shows the contours of Energy Sensors' evolution and highlights the tools the company employed in its efforts to navigate critical junctures in the technology commercialization process. For simplicity, the linear path by which ventures move directly from one stage to the next was omitted (and was not something we observed in the case of Energy Sensors). As Energy Sensors approached the transition between phase 1 and phase 2, it had several alternative paths. It could pivot (represented by the broad-dash line) and enter a recursive part of the process, returning it to phase 1 (or earlier) in an effort to discover a more viable technology and market opportunity. This would have transitioned the founder back to continued $R \& D$, technology development, and idea formation. The founder observed: 


\section{Strategy-as-Process in a Technology Venture: A Case Study of Pivots, Pauses, Partners, and Progress Andrew G. Earle, Michael J. Merenda, and J. Matthew Davis}

"Let's use what we've learned, the relationships that we've built, and try to solve this problem again - back to the drawing board, but in a much better position than before. I don't think our initial trajectory/strategy was wrong and I don't think anyone could have known then what we know now, so it's not a sense of 'Shucks, we miscalculated, let's go in a different direction."”

A second technique used by the founder was to partner and problem solve with a previously uninvolved party (in this case, the university) in the DOE grant application process. This effort, as represented by the narrowdash line in Figure 2, resulted in receiving an SBIR/STTR Phase I DOE grant. The partnership and grant became the catalyst needed to navigate the transition from phase $2 \mathrm{~b}$ to $2 \mathrm{c}$.

A third technique (represented in Figure 2 by the circle at the end of the main venture path) utilizes a purposeful pause to reassess the challenge of transitioning to the upcoming phase. For conceptual clarity, these alternative paths are visualized in Figure 2 as separate techniques. However, these could also be used in concert as when the founder reported using a pause to enable a broader search for more capable partners:

"In late 2016, when we had come to the realization that our technology was not sufficient to meet the need that we had set out to address (cost-effective, scalable, GHP systems), we were going to shut it [Energy Sensors] down. When the SBIR/STTR topic was released in October 2016, it gave us one more shot to use what we had learned and see if we could pull it off. That was also an opportunity to formalize a university-Energy Sensors partnership."

Figure 2 suggests that transitions are more than merely a test of a venture "as is" where the more viable ones are filtered out from the less viable ones, or a proverbial locked "gate" that ventures slam up against and must rapidly pivot to find the right "key." Instead, transitions offer an occasion to pause, refit, reinforce, and refocus for subsequent stages of the technology commercialization process, which may look very different from previous ones.

"In fact, our redirection/reinvention has relied upon data that has been collected over the past several years - so there is no way that we could do what we are doing now without the initial 'failure."

Beyond the specific techniques used by Energy Sensors to engage with these transitions, Figure 2 suggests the utility of thinking beyond the "process" of technology commercialization to viewing it as a bundle of iterative and mutually interdependent "processes." The founder describes it as:

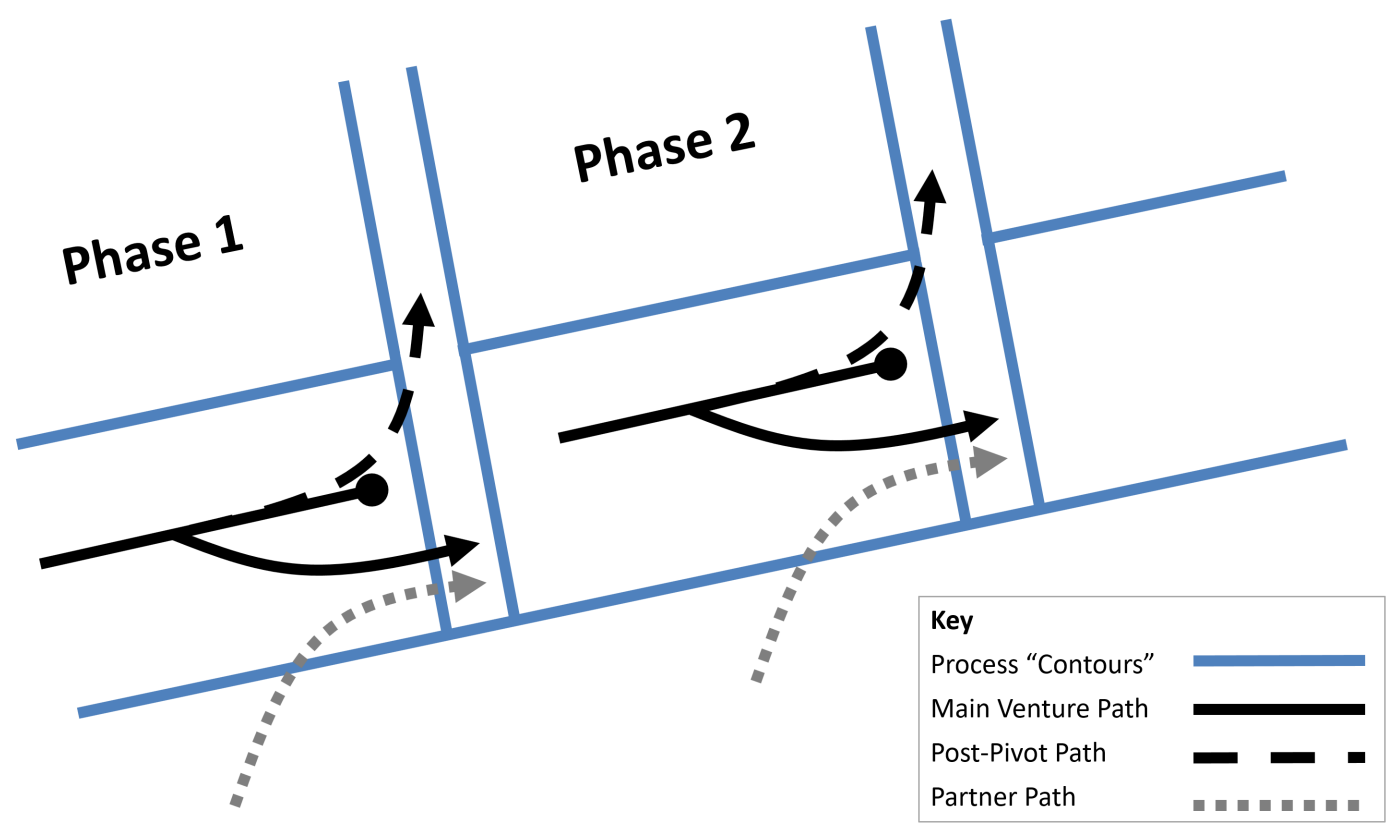

Figure 2. Transition repertoire model of how a company navigates critical junctures in the technology commercialization process 


\section{Strategy-as-Process in a Technology Venture: A Case Study of Pivots, Pauses, Partners, and Progress Andrew G. Earle, Michael J. Merenda, and J. Matthew Davis}

\begin{abstract}
"[A]n iterative process that remained focused on the end goal of increasing market penetration of renewable energy. The technology has been characterized as a necessary enabling technology, and there is an ongoing process of identifying what the needs of the market are and whether or not the technology can meet those needs."
\end{abstract}

\section{Discussion}

Our case study echoes previous findings by illustrating that navigating key transitions is more complicated than merely forging ahead linearly or quickly pivoting back through a given phase of development. Instead, we observed an entrepreneur working to build a repertoire of techniques to assist in managing these transitions. Within this repertoire, pivoting (as outlined in the lean startup methodology, [Reis, 2011]) is something increasingly common in technology-based ventures. However, pivoting was one of several approaches employed by Energy Sensors when navigating this technology commercialization process. For example, Energy Sensors transitioned from a retrofit-focused technology application (i.e., adding its solution to installed GHPs) to potentially partnering with utilities interested in the company's expertise in interpreting data. Thus, Energy Sensors had to pause and wait for these new customers to be ready to adopt their more advanced innovations.

This type of "strategic pause" mirrors recent attention on the importance of timing in entrepreneurial success as highlighted in popular outlets such as TED Talks (e.g., Bill Gross' 'The Single Biggest Reason Why Startups Succeed") and business-press books (e.g., Adam Grant's Originals). As with our findings regarding pivots, strategic pausing does not imply waiting for the sake of waiting; it is that intentional pausing and careful monitoring of how partners or customers are "catching up" that is a critical skill for technology entrepreneurs to have in their commercialization repertoires.

The third part of the repertoire featured in this case focuses on partnering. As with pivoting, technology entrepreneurs' need to find strategic partners is not new. However, our case highlights the need to not only partner in general, but also continually refine a venture's partnership capabilities given that such partnerships may not always follow a specific formula (Dewald \& Fromhold-Eisebith, 2015). The temporal and spatial dynamics found in the larger institutional systems (such as at the national level) and technology innovation systems reveals the usefulness of pausing and purposefully searching for particular partners in the technology commercialization process. For example, Energy Sensors first focused on investors and only later did it turn toward other partners such as standards-making bodies, universities, and key industry players (OEMs, suppliers, and utilities).

Given that we do not yet know the ultimate outcome of Energy Sensors as a venture, we are not advocating that other technology entrepreneurs necessarily follow this particular path. However, Energy Sensors does provide an example of a non-obvious partnering pattern while highlighting "why" effectively partnering with a range of actors found in a technology innovation system is an essential part of any venture's repertoire. As a venture approaches critical junctures, reframing its approach to partnerships may prove an essential tool for navigating these transitions. For example, Energy Sensors recast GHP installers from stuck-in-their-ways traditionalists in need of "disruption" to "invaluable" partners with whom the company needed to build trust and confidence.

\section{Future Research}

This exploratory study captures our participant-observer's experiences in navigating critical junctures over several phases in the technology commercialization process. Inherent to this methodological approach is a tradeoff between the depth of access to the entrepreneur's "behind the scenes" perspective on the earliest phases of their venture and more immediately generalizable findings. As such, we view this study as an earlystage effort in casting light on (especially the earliest) interstices in the technology commercialization process and its main contribution being a set of questions on transitional repertoires that we hope will be more fully elaborated, and eventually empirically tested, in future research.

As an immediate next step, a multiple case-study design (or triangulation within this particular case) could do more to suggest a generalizable model of the process we have observed here. For Energy Sensors, its process was influenced by the dynamic nature and interplay of external (e.g., institutional and industry technical, social, political, legal) and internal (e.g., technology development, market identification) factors that likely shape all such technology commercialization processes. However, whether the repertoire that Energy Sensors developed and deployed represents a common set of tools for entrepreneurs remains an open question. Building on this effort to add breadth to the depth offered in this 


\section{Strategy-as-Process in a Technology Venture: A Case Study of Pivots, Pauses, Partners, and Progress Andrew G. Earle, Michael J. Merenda, and J. Matthew Davis}

case study, a survey of technology entrepreneurs on their experiences with the early stages of the commercialization process would also help support the generalizability (or lack thereof) of our case-based findings.

Beyond these methods-based suggestions, future research could also consider not just what is available in an entrepreneur's repertoire (pivoting, pausing, and partnering, in the case of Energy Sensors) but under what circumstance each of these could be used, alone or in concert, to help ventures successfully navigate transitions and set them up for success in the next phases of their development. Such a study would require going beyond our largely exploratory and descriptive approach to testing the impact of variation in repertoire use on firm performance or other indicators of new venture success (e.g., user adoption, equity investment).

\section{Conclusions}

As with any case-based research, our goal was not to define or test the optimal technology commercialization process. Instead, we utilized a participant-observer methodology to gain deep insight "behind the scenes" on a portion of the technology commercialization process not often captured in past research. Specifically, we examined how a technology entrepreneur conceptualized, negotiated, and managed early-stage transition points in their technology commercialization process. Instead of testing a predefined model, we used this perspective to uncover new ideas and patterns that have the potential to both inform future quantitative research and provide practicing entrepreneurs with some options to consider as they face the same transitions as Energy Sensors.

Our findings indicate that developing a "repertoire" of techniques, including pivoting and pausing, before attempting to traverse key transition points is a useful (and actionable) practice for technology-focused entrepreneurs. Our research also suggests that entrepreneurs should develop and practice each technique in this repertoire so when the venture's development calls for its use, it will be reasonably well mastered before it is truly needed.
For the technology entrepreneur, becoming comfortable with pivoting or partnering aligns well with mastering routines that can contribute to the success of an organization. In contrast, practicing pausing may sound less intuitive. However, in a world with mantras like "move fast and break things" or "fail fast, fail often" which celebrates traits like "single-mindedness" and "obsession," an ability to execute a disciplined, focused, intentional, and strategic pause may be precisely the kind of thing many entrepreneurs need in their repertoires to help set them apart, spur further innovation, and take stock of their surroundings. In conclusion, we view this study as one modest contribution to provide a more operational perspective to both active and potential technology-focused entrepreneurs who need effective tools to navigate the currents, shoals, and reefs inherent in the technology commercialization process.

\section{About the Authors}

Andrew Earle is an Assistant Professor of Strategic Management and Entrepreneurship in the Paul College of Business and Economics at the University of New Hampshire in the United States. His research interests grow out of a long-held fascination with the transformational power of new technologies. The core of his research program is developing new ways of understanding how technologies move from initial invention to marketable products and how this process affects and informs the strategies of participating organizations.

Michael J. Merenda is a Professor of Strategic Management and Entrepreneurship in the Paul College of Business and Economics at the University of New Hampshire in the United States. His focus is on problem-solving, critical inquiry, and strategic thinking as it applies to strategic management and entrepreneurial education.

J. Matthew Davis is an Associate Professor of Earth Sciences at the University of New Hampshire in the United States. His research focuses on hydrology and water resources. 


\section{Strategy-as-Process in a Technology Venture: A Case Study of Pivots, Pauses, Partners, and Progress Andrew G. Earle, Michael J. Merenda, and J. Matthew Davis}

\section{References}

Auerswald, P. E., \& Branscomb, L. M. 2003. Valleys of Death and Darwinian Seas: Financing the Invention to Innovation Transition in the United States. The Journal of Technology Transfer, 28(3-4): 227-239. https://doi.org/10.1023/A:1024980525678

Bailetti, T. 2012. Technology Entrepreneurship: Overview, Definition, and Distinctive Aspects. Technology Innovation Management Review, 2(2): 5-12.

http://doi.org/10.22215/timreview/520

Carter, N. M., Gartner, W. B., \& Reynolds, P. D. 1996. Exploring StartUp Event Sequences. Journal of Business Venturing, 11(3): 151-166. https://doi.org/10.1016/0883-9026(95)00129-8

Churchill, N. C., \& Lewis, V. I. 1983. The Five Stages of Small Business Growth. Harvard Business Review, 61: 30-50.

Crilly, N. 2018. 'Fixation' and 'The Pivot': Balancing Persistence with Flexibility in Design and Entrepreneurship. International Journal of Design Creativity and Innovation, 6(1-2): 52-65. https://doi.org/10.1080/21650349.2017.1362359

Davidsson, P. 2003. The Domain of Entrepreneurship Research: Some Suggestions. In J. Katz \& D. Shepherd (Eds), Cognitive Approaches to Entrepreneurship Research: Advances in Entrepreneurship, Firm Emergence and Growth, Vol. 6: 315-372. Bingley, UK: Emerald Group Publishing Limited.

Dewald, U., \& Fromhold-Eisebith, M. 2015. Trajectories of Sustainability Transitions in Scale-Transcending Innovation Systems: The Case of Photovoltaics. Environmental Innovation and Societal Transitions, 17: 110-125.

https://doi.org/10.1016/j.eist.2014.12.004

Eisenhardt, K. M., \& Martin, J. A. 2000. Dynamic Capabilities: What Are They? Strategic Management Journal, 21(10-11): 1105-1121. https://doi.org/10.1002/10970266(200010/11)21:10/11<1105::AID-SMJ133>3.0.CO;2-E

Eggers, J. H., Leahy, K. T., \& Churchill, N. C. 1994. Stages of Small Business Growth Revisited: Insights into Growth Path and Leadership/Management Skills in Low- and High-Growth Companies. In W. D. Bygrave (Ed.), Frontiers of Entrepreneurship Research: 131-144. Babson Park, MA: Babson College.

Fisher, G., Kotha, S., \& Lahiri, A. 2016. Changing with the Times: An Integrated View of Identity, Legitimacy, and New Venture Life Cycles. Academy of Management Review, 41(3): 383-409. https://doi.org/10.5465/amr.2013.0496

Galunic, D. C., \& Eisenhardt, K. M. 2001. Architectural Innovation and Modular Corporate Forms. Academy of Management Journal, 44(6): 1229-1249.

https://doi.org/10.5465/3069398

Grant, A. 2017. Originals: How Non-Conformists Move the World. New York: Penguin.

Gross, B. 2015. The Single Biggest Reason Why Startups Succeed. TED, March 2015.

https://www.ted.com/talks/bill_gross_the_single_biggest_reason_ why_startups_succeed

Jack, S., Moult, S., Anderson, A. R., \& Dodd, S. 2010. An Entrepreneurial Network Evolving: Patterns of Change. International Small Business Journal, 28(4): 315-337. https://doi.org/10.1177/0266242610363525
Jarzabkowski, P. 2004. Strategy as Practice: Recursiveness, Adaptation, and Practices-in-Use. Organization Studies, 25(4): 529-560. https://doi.org/10.1177/0170840604040675

Kawulich, B. B. 2005. Participant Observation as a Data Collection Method. Qualitative Social Research, 6(2): 43. http://dx.doi.org/10.17169/fqs-6.2.466

Katila, R. 2002. New Product Search Over Time: Past Ideas in Their Prime? Academy of Management Journal, 45(5): 995-1010. https://doi.org/10.5465/3069326

Kirzner, I. M. 1983. Entrepreneurs and the Entrepreneurial Function: A Commentary. In J. Ronen (Ed.), Entrepreneurship. Lexington, MA: Lexington Books.

March J. G., \& Olsen, J. P. 1976. Ambiguity and Choice in Organizations. Bergen, Norway: Universitetsforlaget.

Markman, G., Siegel, D., \& Wright, M. 2008. Research and Technology Commercialization. Journal of Management Studies, 45(8): 1401-1423. https://doi.org/10.1111/j.1467-6486.2008.00803.x

Mintzberg, H., \& Waters, J. A. 1982. Tracking Strategy in an Entrepreneurial Firm. Academy of Management Journal, 25(3): 465-499. https://doi.org/10.1111/j.1741-6248.1990.00285.x

Mitchell, W., \& Singh, K. 1996. Survival of Businesses Using Collaborative Relationships to Commercialize Complex Goods. Strategic Management Journal, 17(3): 169-195. https://doi.org/10.1002/(SICI)1097-0266(199603)17:3<169::AIDSMJ801>3.0.CO;2-\#

Moore, G. A. 1991. Crossing the Chasm: Marketing and Selling HighTech Products to Mainstream Customers. New York, NY: Harper Business.

Moser, P. 2005. How Do Patent Laws Influence Innovation? Evidence from Nineteenth-Century World's Fairs. The American Economic Review, 95(4): 1214-1236. http://dx.doi.org/10.1257/0002828054825501

Neergaard, H. 2003. The Process of Entrepreneurship: A Managerial and Organizational Journey. In C. Steyaert \& D. Hjorth (Eds.), New Movements in Entrepreneurship: 160-176. Cheltenham, UK: Edward Elgar.

Poole, M. S., \& Van de Ven, A. H. 2004. Theories of Organizational Change and Innovation Processes. In A. H. Van de Ven \& M. S. Poole (Eds.), Handbook of Organizational Change and Innovation: 374-397. Oxford, UK: Oxford University Press.

Prahalad, C. K. 2012. Bottom of the Pyramid as a Source of Breakthrough Innovations. Journal of Product Innovation Management, 29(1): 6-12. https://doi.org/10.1111/j.1540-5885.2011.00874.x

Rasmussen, E. 2011. Understanding Academic Entrepreneurship: Exploring the Emergence of University Spin-Off Ventures Using Process Theories. International Small Business Journal, 29(5): 448-471.

https://doi.org/10.1177/0266242610385395

Ries, E. 2011. The Lean Startup: How Today's Entrepreneurs Use Continuous Innovation to Create Radically Successful Businesses. New York: Crown Books. 


\section{Strategy-as-Process in a Technology Venture: A Case Study of Pivots, Pauses, \\ Partners, and Progress Andrew G. Earle, Michael J. Merenda, and J. Matthew Davis}

Rothaermel, F. T., \& Deeds, D. L. 2004. Exploration and Exploitation Alliances in Biotechnology. Strategic Management Journal, 25(3): 201-221.

https://doi.org/10.1002/smj.376

Seidel, V. P., \& O’Mahony, S. 2014. Managing the Repertoire: Stories, Metaphors, Prototypes, and Concept Coherence in Product Innovation. Organization Science, 25(3): 691-712.

https://doi.org/10.1287/orsc.2013.0879

Swidler, A. 1986. Culture in Action: Symbols and Strategies. American Sociological Review, 51(2): 273-286.

https://doi.org/10.2307/2095521

Teece, D. J., Pisano, G., \& Shuen, A. 1997. Dynamic Capabilities and Strategic Management. Strategic Management Journal, 18(7): 509-533.

https://doi.org/10.1002/(SICI) 1097-0266(199708)18:7<509::AID-

SMJ882>3.0.CO;2-Z

Vohora, A., Wright, M., \& Lockett, A. 2004. Critical Junctures in the Development of University High-Tech Spinout Companies. Research Policy, 33(1): 147-175.

https://doi.org/10.1016/S0048-7333(03)00107-0

Yin, R. K. 1981. The Case Study Crisis: Some Answers. Administrative Science Quarterly, 26(1): 58-65.

https://doi.org/10.2307/2392599

Yin, R. K. 1989. Case Study Research: Design and Methods, Vol. 5. Newbury Park, CA: Sage.

Citation: Earle, A. G., Merenda, M. J., \& Davis, J. M. 2019.

Strategy-as-Process in a Technology Venture: A Case

(cc) BY

Study of Pivots, Pauses, Partners, and Progress

Technology Innovation Management Review, 9(1): 9-19.

http://doi.org/10.22215/timreview/1208

Keywords: innovation systems, technology

commercialization, process research, technology

entrepreneurship, managing critical junctures and

transitions 


\title{
Alliances in Financial Ecosystems: A Source of Organizational Legitimacy for Fintech Startups and Incumbents
}

\author{
Christopher Svensson, Jakob Udesen, and Jane Webb
}

\author{
(6 Banks are not only going to compete with each other") \\ and fintech startups. We're probably also going to have \\ to compete with Amazon, Google, and Apple. Maybe \\ there's going to come a time when all the former rivals \\ will come together.
}

Investment Manager of a Swedish Venture Capitalist Firm (Interviewed for this study)

\begin{abstract}
Financial ecosystems are transforming around new financial technology, or "fintech". As such ecosystems transform, the basis for being seen as legitimate also changes for all actors. Thus, alliances between actors within financial ecosystems are increasingly formed to help gain, maintain, and repair organizational legitimacy. From interviews with fintech startups in Sweden and with venture capitalist firms investing in fintech startups in Sweden, we explore the intertwined quests for organizational legitimacy in a transforming financial ecosystem. As Swedish fintech startups seek to establish a sense of their legitimacy, simultaneously incumbents seek to maintain and repair their organizational legitimacy. Adopting a legitimacy-based view of strategic alliances, we set out the aspects of organizational legitimacy that incumbents and fintech startups look for in a potential partner and how these aspects meet the legitimacy needs of each partner. We argue that alliances further enhance the organizational legitimacy of both fintech startups and incumbents.
\end{abstract}

\section{Introduction}

Recently the surge in new financial technology fintech - has come under increasing attention. Some paint fintech startups as disruptive forces about to revolutionize financial services with major improvements in efficiency, customer centeredness, and informedness (Gomber et al., 2018). Others see this as fintech 3.0 , an era where an increased number of actors provide financial services and develop technology faster (Arner et al., 2016). Various understandings of the current fintech trends are twinned with ambiguity over just what the term fintech actually covers (Gromek, 2018). A straightforward definition of fintech is "companies... that combine financial services with modern, innovative technologies..., offer[ing] Internet-based and application-oriented products" (Dorfleitner et al., 2017). Offerings of fintech startups relate to a broad range of categories, but particularly to automated wealth management, customized insurance, peer-to- peer lending, new payment solutions, crowdfunding, and the trading of stocks (Lee \& Shin, 2018).

The financial ecosystem that fintech startups are helping transform also includes technology developers; government agencies and regulators; financial customers (both private and corporate customers); and traditional financial institutions (incumbents) (Lee \& Shin, 2018). Fintech startups need to take many of these actors into account when developing their services (CB Insights, 2018; Lee \& Shin, 2018). However, they confront a "liability of newness" (Stinchcombe, 1965) while struggling for visibility, influence, and legitimacy in a competitive market. As Payette (2014) details, legitimacy is particularly vital to the growth and survival of technology startups and yet managers often resort to improvising legitimacy-building tactics. Unquestionably, fintech startups engage in other challenges related to commercialization at the same time as legitimacy-building, such as raising awareness among 


\section{Alliances in Financial Ecosystems: A Source of Organizational Legitimacy for Fintech Startups and Incumbents Christopher Svensson, Jakob Udesen, and Jane Webb}

other actors in the financial ecosystem about the potential of new technologies; ensuring that products comply with relevant legislation such as the handling of personal data; and integrating products to cumbersome legacy systems. Here, we focus on how the need for organizational legitimacy of fintech startups relates to the organizational legitimacy needs of incumbents. Understanding how this dynamic may influence commercialization is vital for fintech startups.

We argue in this article that, as financial ecosystems transform, so too does the basis for being perceived as a legitimate actor. Drawing on an interview study, we provide a snapshot of experiences of Swedish fintech startups. We explore the relationship between attempts by fintech startups to establish a sense of their legitimacy and simultaneous attempts by incumbents to maintain and repair organizational legitimacy. Adopting a legitimacy-based view of strategic alliances, we set out the aspects of organizational legitimacy that incumbents and fintech startups look for in a potential partner and how these aspects meet the legitimacy needs of each partner. We argue that alliances further enhance the organizational legitimacy of both fintech startups and incumbents. We call for more research into how ecosystems transformed by technology entrepreneurship involve actors in intertwined quests for organizational legitimacy, and what this means for the commercialization of new technologies.

\section{A Relational Perspective on Technology Ecosystems}

Technological innovation and business model changes are reshaping entire industries (Giones \& Brem, 2017; Kumaraswamy et al., 2018). Such networks of interdependent firms are commonly labelled as business ecosystems (Iansiti \& Levien, 2004). With respect to fintech ecosystems, Lee and Shin (2018) conceptualize an ecosystem as an affiliation, where traditional industry boundaries have broken down, leading to interdependence and symbiotic relationships (Adner, 2017). With this starting point, innovation is understood as radically reconfiguring relationships between ecosystem members, leading to a need to consider how changes in ecosystems affect relationships between a variety of different actors. Understanding the impact of innovation on the relational interdependencies across ecosystems becomes necessary (Adner \& Kapoor, 2010; Dougherty, 2017; Sandström et al., 2014).

Such a relational approach helps reveal the dynamics between firms defending their position in an existing market and those attempting to disrupt it (Kumaraswamy et al., 2018). New ventures often have a relational dependency on incumbents, needing to access complementary resources from incumbents, but ecosystems are, of course, characterized by many differently motivated actors who respond differently to changes (Kumaraswamy et al., 2018). This means that introducing innovation is about "multilateral negotiations with multiple stakeholders that have potentially diverging preferences" (Sandström et al., 2014). We can understand disruption to industries as processual, rather than outcome-based, and as depending "on how the innovation is framed and experienced by the multiple actors involved at different times during the innovation's journey" (Kumaraswamy et al., 2018).

Felländer, Siri, and Teigland (2018) describe a phase in the Swedish financial ecosystem of innovation struggle (from 2007-2008 to mid-2016) and today's phase of partnership and client focus. They argue that there will likely be a new phase of positioning from 2020 driven by technology, in contrast to the earlier consumerdriven and regulations-driven phases. The future phase will be characterized by "a more networked structure with partnerships with fintech actors, while the client databases will be open and secure, enabling the co-creation of services" (Felländer et al., 2018). Moving towards such an era in the finance industry entails changing relationships between incumbents and fintech startups. Exploring how organizations can harness relationships to build sustained competitive advantage becomes important (Dyer \& Singh, 1998).

When considering interdependencies in an ecosystem, the complexity of converging and diverging interests cannot be underestimated. It is vital to understand that there are both "competitive and collaborative dynamics in fintech innovation" (Lee \& Shin, 2018). This means, for example, that fintech startups are less collaborative with incumbents when regulation is favourable for a startup to establish their business (Lee \& Shin, 2018). Even in acquisitions seen as a complementary process, where incumbents want to acquire the assets of a startup and a startup wants to be acquired in order to leverage an incumbent's capabilities, acquisition integration requires careful planning and execution (Carbone, 2011). Within the financial ecosystem, incumbents invest in fintech in a number of ways in addition to the straight route to acquiring or buying fintech (Lee \& Shin, 2018). In this article, we take the view that incumbents cannot take for granted that startups want to be acquired. 


\section{Alliances in Financial Ecosystems: A Source of Organizational Legitimacy for Fintech Startups and Incumbents Christopher Svensson, Jakob Udesen, and Jane Webb}

\section{Forms of Organizational Legitimacy}

This article is about how transformation in ecosystems around technology entrepreneurship changes the basis for being seen as a legitimate actor. Organizational legitimacy is "a generalized perception or assumption that the actions of an entity are desirable, proper, or appropriate within some socially constructed system of norms, values, beliefs, and definitions" (Suchman, 1995). It is "a reaction of observers to the organization as they see it" (Suchman, 1995). While legitimacy is often seen as an "asset", an organization is subject to an ongoing assessment by others of its legitimacy (Bitektine \& Haack, 2015). Suchman (1995) distinguishes between an organization operating in an appropriate manner and being appropriate, as well as whether legitimacy is considered on an episodic or continual basis.

Suchman (1995) identifies three forms of legitimacy pragmatic, moral, and cognitive - that each rest on a different behavioural dynamic. Pragmatic legitimacy is based on the self-interest of an organization's most immediate audience. Moral legitimacy hinges on the normative approval by an audience of an organization's actions and the extent to which the organization is perceived as "doing the right thing". This is about wider societal welfare rather than narrow self-interest. Both pragmatic and moral legitimacy are about discursive evaluation, where cost-benefit appraisals and ethical judgements are carried out through explicit public discussion. Cognitive legitimacy arises when an audience stops evaluating an organization and instead accepts it as necessary. Table 1 summarizes how Suchman (1995) conceptualizes organizational legitimacy. We use this as the first part of our analytical framework.

These forms of organizational legitimacy are in play both when pursuing continuity and when pursuing credibility, as well as when seeking active support and when seeking passive support from audiences. Continuity is about how an audience acts towards an organization, supporting the organization through their everyday actions and allowing the organization to persist. Credibility relates to how an audience understands an organization, considering an organization as worthier, more meaningful, more predictable, and

Table 1. Forms of organizational legitimacy set out by Suchman (1995)

\begin{tabular}{lll}
\hline Form of Legitimacy & Description \\
\hline Pragmatic & Exchange & An audience supports an organization's actions because they benefit from them. \\
\hline & Influence & An audience believes that an organization is responsive to their larger interests. \\
\hline Dispositional & $\begin{array}{l}\text { An audience associates an organization with particular attributes, such as being } \\
\text { trustworthy. }\end{array}$ \\
\hline Consequential & $\begin{array}{l}\text { An audience positively evaluates the generated output or accomplishments of the } \\
\text { organization. }\end{array}$ \\
\hline Procedural & $\begin{array}{l}\text { An organization complies with socially formed and accepted techniques, } \\
\text { procedures, and methodologies. }\end{array}$ \\
\hline Structural & $\begin{array}{l}\text { An organization has in place socially accepted structures that indicate a capacity to } \\
\text { perform specific types of work. }\end{array}$ \\
\hline Personal & $\begin{array}{l}\text { An audience associates an organization with charismatic individuals. } \\
\text { Comprehensibility }\end{array}$ & $\begin{array}{l}\text { An organization fits with available cultural models that provide plausible } \\
\text { explanations for the organization and its endeavours. }\end{array}$ \\
\hline Taken-for- & $\begin{array}{l}\text { An audience considers an organization as irreplaceable - for it not to exist would } \\
\text { be unthinkable. }\end{array}$ \\
\hline
\end{tabular}




\section{Alliances in Financial Ecosystems: A Source of Organizational Legitimacy for Fintech Startups and Incumbents Christopher Svensson, Jakob Udesen, and Jane Webb}

more trustworthy (Suchman, 1995). Ensuring continuity is perhaps of greatest importance to an incumbent, whereas gaining credibility is perhaps more important for startups. Both pursuing continuity and pursuing credibility are parts of whether an organization is assessed as legitimate by audiences.

\section{Strategic Alliances as a Source of Organizational Legitimacy}

There are various internal actions that companies can take to gain, maintain, and repair organizational legitimacy, such as employing experienced leaders and managers with previous knowledge from related fields or locating the company in proximity to a relevant talent pool and an industrial cluster (Rao et al., 2008). Another way that organizations can attempt to gain, maintain or repair organizational legitimacy is to engage in strategic alliances. A strategic alliance is an inter-organizational cooperation that enables the building of competitive advantages. Given that engaging in alliances is often integral to technology startups achieving competitive advantage (Dutta \& Hora, 2017), being perceived as an attractive partner is an important part of growing a startup. Such alliances provide, for example, customer knowledge and distribution channels (Aarikka-Stenroos \& Sandberg, 2012). However, alli- ances can also serve an important legitimating function for organizations and act as a means to an economic or competitive end (Dacin et al., 2007). The legitimating role of strategic alliances is itself a source of competitive advantage (Dacin et al., 2007), helping firms gain more from their innovation (Rao et al., 2008).

Table 2 summarizes the five legitimacy needs that Dacin, Oliver, and Roy (2007) set out as motivations for organizations to consider strategic alliances. We use this as the second part of our analytical framework. Partner selection for an alliance is driven by a variety of factors relevant to each organization's objectives that assess whether an alliance with a potential partner will meet legitimacy needs at the same time as a wider set of objectives (Dacin et al., 2007). For technology startups, organizational legitimacy and legitimacy for a product go hand in hand in commercialization processes, given that the firm and the digital technology are often indistinguishable for digital entrepreneurs (Ingram Bogusz et al., 2018). Technology startups, like any startups, have to balance conforming to expectations within an industry with being distinct (Navis \& Glynn, 2011). How an alliance could function to help a startup achieve "legitimate distinctiveness" - being similar enough and distinct enough - is something startups must consider. Incumbents can consider how an alliance could help

Table 2. Legitimacy needs and functions of strategic alliances set out by Dacin, Oliver, and Roy (2007)

\section{Legitimacy Need}

Market

The need for endorsement and receptiveness by government, suppliers, or customers; often faced by new firms
Legitimating Function of Alliance

Establishes or maintains rights to operate in a specific market with government, suppliers, or customers

Draws in prospective partners by demonstrated collaborative capabilities
Relational

The need to be perceived as an attractive alliance partner in an environment of intense competition for partners

\section{Social}

The need to be seen as socially responsible by stakeholders who closely monitor compliance with rules and expectations
The need for a new business activity to be endorsed internally
Enhances legitimacy as socially responsible with government agencies, local communities, public interest groups, or customers

Legitimates business activities in the eyes of corporate executives, boards, venture capitalist firms, and shareholders

Legitimates the alliance form while also helping meet other legitimacy needs
Alliance

The need for alliances to be endorsed, particularly in industries without a history of using alliances 


\section{Alliances in Financial Ecosystems: A Source of Organizational Legitimacy for Fintech Startups and Incumbents Christopher Svensson, Jakob Udesen, and Jane Webb}

them maintain organizational legitimacy and gain competitive advantage in an ecosystem transforming around new technologies.

\section{Methods}

\section{Research context}

This article draws on data from an explorative study about the growth of fintech startups in Sweden. The Nordic fintech sector is growing rapidly with annual investments of $€ 163$ million ( $\$ 250$ million CAD) during 2016, doubling the amount from 2014 (Jonsdottir et al., 2017). Sweden is currently the second largest fintech community in Europe. Swedish consumers are known to be early adopters of new technologies, with Sweden leading for over a decade in the uptake of online banking (Björn, 2018). In the past, the banks have worked together to introduce two successful fintech services: Swish, a payments service for transfer between private customers launched in 2012, and BankID, a digital identification service launched online in 2003 and on mobile in 2010. The launch of Swish occurred during an era that Felländer and co-authors (2018) see as the first phase of fintech in Sweden, when the banks awakened to the success of fintech startups such as Klarna and iZettle and cooperated with each other to introduce new technology. We carried out the research in the current phase of partnership and client focus, that in the next few years will likely give way to a phase of positioning, driven by technology and when client databases will be more open (Felländer et al., 2018).

\section{Data collection}

The study began during a conversation between two of the authors and the founders of a Swedish fintech startup. During that conversation, the founders repeatedly returned to the uncertainty they were facing about how to approach markets outside Sweden. Based on this, we chose to explore the internationalization experiences of Swedish fintech startups, focusing on partnership strategies. We interviewed representatives from fintech startups, as well as venture capitalist firms (VCs), because VCs are often involved at an early stage in the particularly capital-intensive area of fintech (Jonsdottir et al., 2017).

Two of the authors jointly carried out 19 interviews over four weeks (February to March 2018). Fifteen of these interviews were with fintech startups in Sweden, and four were with investors introduced to us by the fintech startups. The interviewees from startups were business developers, founders, or CEOs with strategic responsibility for the long-term vision of the startup. We identi- fied the startups by using the Nordic Tech List (2018). These startups were "new ventures developing software based financial services" (Dorfleitner et al., 2017) and: i) had received at least $€ 1 \mathrm{M}(\sim \$ 1.5 \mathrm{M}$ CAD) in funding; ii) had a corporate website in at least two languages; and iii) had been founded in Sweden. According to Lee and Shin's (2018) typology of the business models of fintech startups, the 15 interviewed fintech startups included: capital market (1), insurance (1), crowdfunding (1), wealth management (3) and payment (7). The remaining two fintech startups - one with software enabling the use of artificial intelligence, another with a product enabling authentication on a smartphone - combined elements of a fintech startup with a technology developer. We also interviewed four investors that were: i) based in Sweden; ii) investing in fintech startups, and iii) working with portfolio companies that had expanded outside Sweden. Two of the investors were from bank-owned VCs, one was from a bank investing in fintech startups, and one was from a general VC.

We developed the interview guide to invite reflections from each interviewee about the experience of initial internationalization efforts by Swedish fintech startups. In line with the explorative research design, the interviews were semi-structured to allow an interviewee to elaborate on aspects particularly important to them. The interviews each lasted 40-60 minutes and were recorded. One researcher asked the questions, while the other took notes. Immediately after each interview, the two researchers wrote up an interview summary. Later they transcribed all interviews.

\section{Data analysis}

Across the interviews were comments about establishing trust with other actors in the financial ecosystem and the need to work through incumbents, both in Sweden and in new markets. To zoom in on the interplay of organizational legitimacy of incumbents and fintech startups, we mapped how different actors in the financial ecosystem assessed a fintech startup, and how different actors in the financial ecosystem assessed an incumbent. Using Suchman's (1995) definition of organizational legitimacy, by audience we looked at: i) the norms, values, and beliefs and ii) desirable, proper, or appropriate actions. Our research design for understanding the experiences of fintech startups gave particular insights into how fintech startups assess the legitimacy of incumbents and how incumbents assess the legitimacy of fintech startups.

In the next section, we present interview snippets about why incumbents are interested in partnering 


\section{Alliances in Financial Ecosystems: A Source of Organizational Legitimacy for Fintech Startups and Incumbents Christopher Svensson, Jakob Udesen, and Jane Webb}

with fintech startups and why fintech startups are interested in partnering with incumbents. We emphasize the main points of each snippet in bold. The snippets illustrate the legitimacy needs of incumbents and fintech startups.

We then synthesize our analysis into a model of the desirable actions and attributes that fintech startups and incumbents look for in a partner. Next, we illustrate how fintech startups signaled trustworthiness to incumbents before outlining what we understand as the implications for fintech startups stemming from our findings about organizational legitimacy in financial ecosystems.

\section{A Wave of Innovation Transforming the Financial Ecosystem}

Why were established actors interested in partnering with fintech startups? What were the general legitimacy needs of incumbents? Interviewees spoke about how banks in Sweden are realizing that they need to transform their working processes. They spoke of a "wave of innovation" and of the change to the finance industry since new regulations (i.e., the EU's Payment Services Directive, or PSD2) had come into force. All of this challenged the ways that banks were used to working and how they maintained customer loyalty. This new picture of the financial ecosystem meant that banks were considering how to work with other actors. It was clear, however, that banks hoped to partner with fintech startups on their terms - by owning a controlling share of fintech startups.

A representative of a bank-owned VC said this about the impact of changing regulations:

"I believe that the traditional banks will encounter more and more challenges related to their way of doing business. They will be attacked from many different angles." (Investor D)

Such challenges to the banks' ways of working had had a positive impact on a wealth management startup, according to its CEO:

"Our sales process is becoming easier now as the banks are realizing that the regulations are changing. The banks have a big spending budget and their demand for innovation is increasing as they see that there will be new competitors as a consequence of PSD2... If you are a bank and I am PSD2-certified, then I can force you to give me your data." (Fintech Startup O)
The investment manager from a VC working specifically with fintech partnerships went further. He pointed to the potential of even greater cooperation within the financial ecosystem to block non-financial actors establishing themselves:

\section{"We need to understand that the wave of innova- tion that is coming means that banks are not only going to compete with each other and fintech startups. We're probably also going to have to compete with Amazon, Google, Apple, etc. Maybe there's going to come a time when all the former rivals will come together and say 'Oh my God. We have to do this or we're going to die."' (In- vestor B)}

There seemed to be two main reasons that incumbents wanted to partner with fintech startups, according to the interviewees. The first was about retaining legitimacy in the eyes of their customers:

"The banks care about their customers' long-term view of the bank. Five years from now, they want their customers to still look at them as legitimate service providers. They understand that they need to add new functionality." (Fintech Startup O)

The second explanation for why incumbents wanted to partner with startups was about moving to a more open banking system:
"An IT executive at [Swedish Bank] put it really well. He said that, up to now, they've tried to make their systems as closed and secure as pos- sible. Now they're facing demands to open up these systems and share them with everyone else. Those are two completely different mindsets. It's really clear that the banks are struggling to trans- ition from a closed community to an environ- ment where everything is shared." (Fintech Startup K)

Despite the interest in partnering with fintech startups, the banks expected to have control of fintech startups:

\section{"The banks are after innovation, but they also want revenue share and ownership in the fintech startup." (Fintech Startup K)}

One of the motivations of banks for such control may have been a wish to act cautiously due to their standing in the financial ecosystem and their fear of adverse customer impact: 


\section{Alliances in Financial Ecosystems: A Source of Organizational Legitimacy for Fintech Startups and Incumbents Christopher Svensson, Jakob Udesen, and Jane Webb}

\begin{abstract}
"Banks are in a situation where they're almost considered as government bodies. They simply cannot make decisions that could affect customers negatively." (Fintech Startup O)
\end{abstract}

From these interview snippets, we see that incumbents had legitimacy needs in terms of being seen as able to keep apace with the opening up of banking brought about by changing regulations and by fintech innovation. Their established status put them in need of maintaining legitimacy, rather than gaining legitimacy. This could be classified primarily as a need for market legitimacy, but with clear links also to investment legitimacy and to alliance legitimacy (Dacin et al., 2007). Through the right partner, an incumbent could validate the alliance form, as well as signal to a variety of stakeholders that the company had an intention to expand and improve current services to customers.

\section{A Long Journey for Approval}

Some of the interviewees represented a fintech startup where their business model was dependent on other actors within the financial ecosystem for access to infrastructure such as payment systems or authentication systems. For such fintech startups, acquisition and shared ownership were part of commercialization strategies. Beyond this, what were the reasons that fintech startups had for partnering with established actors? What were the general legitimacy needs of fintech startups? Interviewees emphasized how fintech startups were generally dependent on the banks, because the banks had standing akin to being government bodies. Banks had knowledge and expertise that could help fintech startups navigate regulatory frameworks. The banks were able to verify customer need for new services and open doors to partners and customers in new markets.

One manager at a bank investing in fintech, talked about what differentiated fintech startups from other technology-based startups:

"Based on the companies that we've previously invested in, it's always been a given that SaaS startups [Software as a Service] are 'born global' right from the start. For fintech companies, it's a different story because there are so many regulatory aspects that need to be considered. Fintech companies have to go through quite a long journey before they have a final product approved by the

Financial Authority." (Investor C)
An investment manager at a VC described why fintech startups depended on the banks:

"Fintech need the banks. They still need the banks because it's the banks that have the banking licenses." (Investor B)

Some interviewees emphasized the support they received to identify barriers to entry in different markets. Commonly, the main expertise that was mentioned as being invaluable to fintech startups was how to make sense of regulations. A senior advisor at a bank-owned VC spoke about how experience working with a number of fintech startups meant that the firm's lawyers were able to offer tailor-made advice:

"As we've navigated the regulatory frameworks for a while, we've learned how to apply them correctly to new products. I can use our lawyers, who have a thorough understanding of the frameworks, to supply knowledge to our portfolio companies." (Investor A)

Providing legal expertise was part of what a partnership with a fintech startup entailed for a bank. One interviewee put it like this:

"That's one huge advantage of collaborating with a bank - they possess a lot of knowledge and an army of lawyers if there was ever any legal complication. Since we have implemented our service in their platform, it's in their interest to help us." (Fintech Startup O)

Beyond complying with all the regulatory and procedural requirements of a bank or of national regulators, the interviewees also emphasized how incumbents provided access to customers both in Sweden and in other markets, and helped verify customer need:

"What helped us there, was that they introduced us to all their customers. We basically got to meet every big bank in the UK through our partner [a Swedish bank]." (Fintech Startup I)

"It's a huge advantage when you're working with such a big bank. They have resources to thoroughly verify the market demand. They would not have accepted us as a partner if they had not verified the need with their customers first. We assume that the incumbents have a good idea of what their customers want." (Fintech Startup O) 


\section{Alliances in Financial Ecosystems: A Source of Organizational Legitimacy for Fintech Startups and Incumbents Christopher Svensson, Jakob Udesen, and Jane Webb}

One interviewee from a payments fintech startup talked about how his company gained access to credit card customers through partnering with a bank:

"Through that partner [a bank], we secured a much cheaper customer acquisition cost. We didn't need to market ourselves to the same extent. We could rely a lot on the alliance with the bank who already had a customer base. They just went out to their customers and told them that we existed." (Fintech Startup I)

From these interview snippets, we see that fintech startups had legitimacy needs in terms of being seen to comply with regulations and to reach customers to validate the product. The status put them in need primarily of gaining market legitimacy (Dacin et al., 2007) as they tackled the "liability of newness" (Stinchcombe, 1965). There were links, too, to social legitimacy and investment legitimacy (Dacin et al., 2007), as fintech startups sought to be seen as compliant by regulators and to signal to investors the worth of their business through entering into a strategic alliance with an experienced partner.

\section{Intertwined Quests for Organizational Legitimacy}

The interviews provide insight into how the motivations for partnerships between incumbents and fintech startups are underpinned by legitimacy needs. From the primary need of market legitimacy for fintech startups and incumbents, it becomes clearer what makes each actor an attractive partner for the other. Figure 1 illustrates the complementary nature of the quests for organizational legitimacy that fintech startups and incumbents engage in. The figure depicts the desired actions and attributes associated with organizational legitimacy central in alliances between fintech startups and incumbents. These are the criteria for partner selection and show how the legitimacy needs of each actor relate. Joint accomplishments from the partnership enhance the organizational legitimacy for both partners with a variety of stakeholders, helping to meet a package of legitimacy needs of each partner. Below, we summarize the actions and attributes using Suchman's (1995) conceptualization of forms of organizational legitimacy. A key element of this representation is that the nature of gaining, maintaining, or repairing organizational

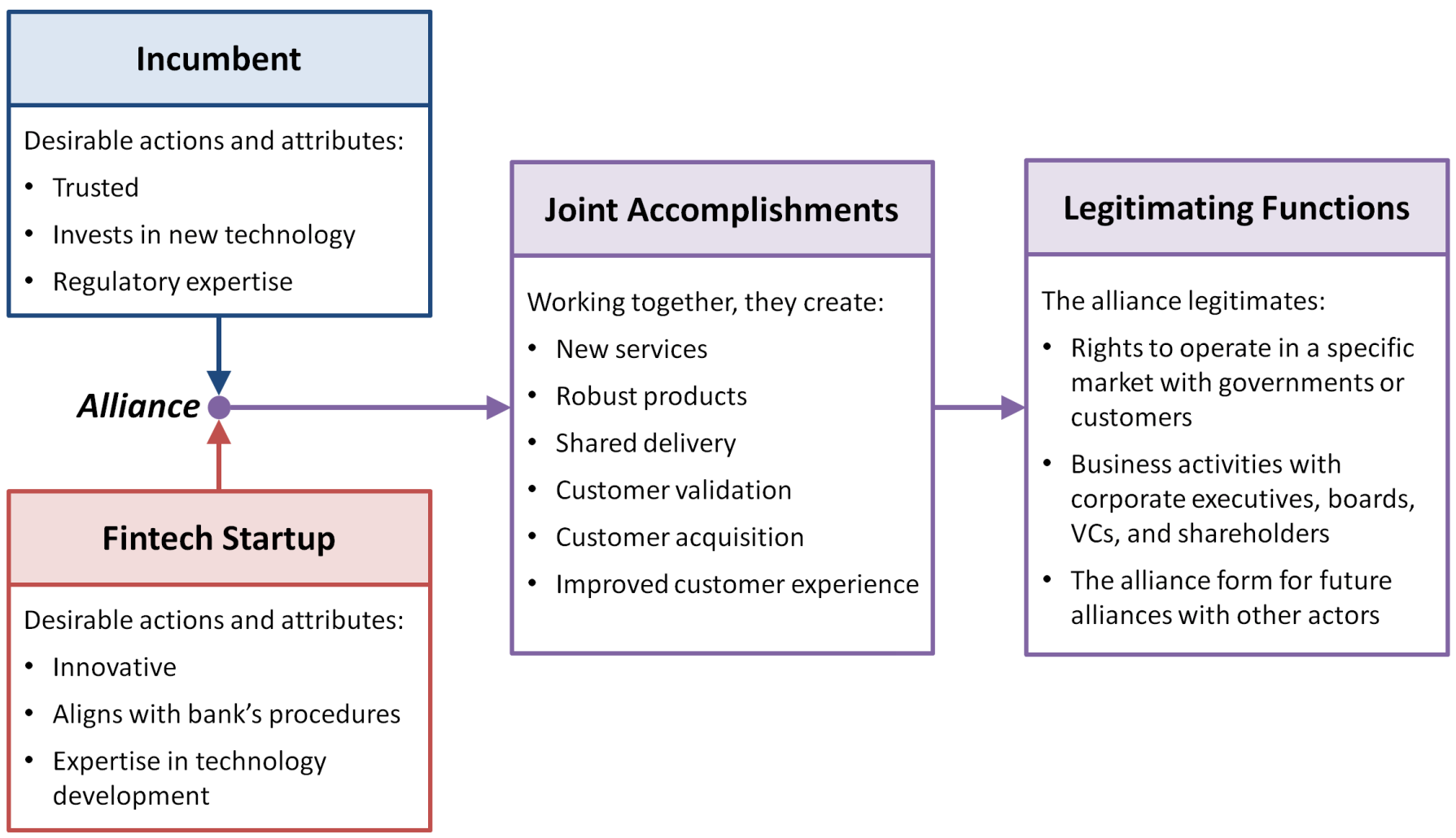

Figure 1. Legitimating functions of alliances between a fintech startup and an incumbent to meet organizational legitimacy needs of each partner 


\section{Alliances in Financial Ecosystems: A Source of Organizational Legitimacy for Fintech Startups and Incumbents Christopher Svensson, Jakob Udesen, and Jane Webb}

legitimacy, as Suchman (1995) describes, means that organizational legitimacy is not an "asset" that arises from a strategic alliance, but is subject to the ongoing assessment of an actor by various audiences.

\section{Dispositional legitimacy and taken-for-grantedness}

Incumbents associate a legitimate fintech startup with being innovative and having an ability to translate user input into new functionality. An incumbent's organizational legitimacy is enhanced through new or improved services and the connection to improved customer experience. For an incumbent to be perceived as legitimate by a fintech startup, it would have achieved a level of taken-for-grantedness that means it is trusted by customers. This shows a relationship between pursuing credibility (a fintech startup) and pursuing continuity (an incumbent). An alliance can help meet these legitimacy needs. Rather than considering that the legitimacy of an incumbent is "extended" to a startup as if an asset, it is more the case, we argue, that both partners in alliances can benefit from the positive assessment by others of the joint accomplishments with their partner.

\section{Influence legitimacy}

Both fintech startups and incumbents expect each other to be responsive to their larger interests. Fintech startups expect a legitimate incumbent to recognize the transforming financial ecosystem and a need to improve their services or to add new services. They expect an incumbent to respect a fintech startup's capacity to apply advanced technology that transforms financial services. Incumbents expect a legitimate fintech startup to be willing to align with their policies, procedures, and demands and respect an incumbent as an expert in following accepted rules and norms. This points to a shared understanding of the financial ecosystem, where both incumbents and fintech startups need to work together because their organizational legitimacy is based on different actions and expertise. We can understand here that there is not a straight case of fintech startups either fitting to the processes of incumbents or of disrupting processes. Instead, there is a process in between the two, given that both fintech startups and incumbents benefit from fitting in with existing processes and with changes to processes. It is perhaps through alliances that fintech startups and incumbents get the chance to explore a midway between fit-to-process and disruption.

\section{Exchange legitimacy}

Both fintech startups and incumbents supported particular actions of the partner as ones that they would benefit from. This meant that the technology development processes of a fintech startup would benefit an incumbent, while the expertise in complying with regulations would benefit a fintech startup. Each partner expected that the other would share such competencies with them through the partnership. This would be of direct benefit in carrying out business activities.

\section{Consequential legitimacy}

The joint accomplishments from partnering provided a consequential legitimacy for both actors in the eyes of private and corporate customers, investors, shareholders, regulators, and employees, as well as other fintech startups and incumbents. By receiving assistance from an incumbent in complying with regulations, the fintech startup gained social legitimacy from government agencies and regulators. For a fintech startup, building a track record of successful partnerships was a key factor connected to organizational legitimacy that was of interest to potential partners. This helped meet a relational legitimacy need. As one interviewee said:

"This actor has been faster in their decisions, compared to our first partner. We were surprised that they were so much faster. We have our first alliance to thank for that - the new partner considered that alliance an assurance." (Fintech Startup O)

For incumbents, adding a new service that helped with customer retention and customer acquisition was of benefit in the eyes of shareholders and employees. It both met a social and an investment need for legitimacy. As one interviewee said:

"We also have responsibility with our investments to help employees feel that we are moving forward, that we're more agile, and that we're working more closely with startups." (Investor C)

\section{Trustworthiness Signals by Fintech Startups}

Despite the needs for organizational legitimacy of both incumbents and fintech startups, interviewees from fintech startups spoke of the considerable challenges they had faced in navigating the financial ecosystem. In the accounts during the interviews, the interviewees drew on the perceived advantages of fintech startups speed, technical know-how, streamlined decision-making, produce development processes - to frame what they had to offer as new actors in the financial ecosystem. The interviewees talked about the steps they took to signal trustworthiness to potential partners, such as hiring sales and marketing executives as part of estab- 


\section{Alliances in Financial Ecosystems: A Source of Organizational Legitimacy for Fintech Startups and Incumbents Christopher Svensson, Jakob Udesen, and Jane Webb}

lishing a local office in potential markets, partnering with consultancy firms when approaching banks in a new market, appointing board members with a strong network, and the importance of emphasizing a track record.

Time and again, interviewees emphasized the speed under which fintech startups are used to working. The CEO at a payments fintech startup referred to the advantage that fintech startups have over other actors in the financial ecosystem:

"We need to move as fast as possible, because that is the only advantage that we have. The big companies have much more money than us, but we can make faster decisions." (Fintech Startup I)

The same interviewee went on to say this about banks:

"They have a different perspective on what a fast process is. For the incumbents one year is fast. No exaggeration. But, in our case, one year is a whole capital cycle. It's a matter of survival. We have to maintain the intensity in the relationship and be persistent." (Fintech Startup I)

The different pace of the banks presented a way for the fintech startups to distinguish themselves. For the CEO of a startup developing a service that enables authentication through a smartphone, the speed of delivering their installation to a bank appeared to be a badge of honour:

"The bank had never heard of an integration that was so fast. A proof of concept was installed and done in seven weeks - that was a record." (Fintech Startup F)

In terms of how they had strengthened the organizational profile, a co-founder from a startup with an invoicing service, talked about how, when targeting companies using enterprise resource planning (ERP) systems as potential customers, the number of employees was an important signal:

"When we launched our service, many potential customers asked us why they should choose us instead of our competitors. No one knew who we were. We had to establish trust in the service and in the company. Now we're over 200 employees so potential customers see that there is some power behind the company. That signals trustworthiness to a certain extent. If our customers are going to use our service, they need to trust us. It is vital for us and trust takes time to establish." (Fintech Startup G)

Another interviewee emphasized that hiring sales executives familiar with particular local markets was a way to be taken more seriously:

"I believe that, if you are a bank, you ask yourself why you should work with our company. We don't even have a local sales representative. But if they say: ' $S * * t$, they've hired [Name]. They're really going for it - this is serious.' It sends a signal." (Fintech Startup C)

Others signaled experience in the finance industry and gained influence by appointing particular board members:

"I would recommend to other fintech startups that they find experienced board members. This is not the first company I have built. Not everyone has access to the kind of network that we have." (Fintech Startup E)

\section{Implications for Fintech Startups}

We argue that, to achieve clarity about how and why to act in particular ways, an actor must assess the legitimacy needs of other actors in a transforming ecosystem and evaluate the strength of their own organization's organizational legitimacy. This helps an actor position themselves as an attractive partner for possible strategic alliances that can help actors gain, maintain, or repair organizational legitimacy. Thus, there are ongoing simultaneous quests for legitimacy, given legitimation is a social process where all actors within the financial ecosystem are assessing each other and being assessed by other stakeholders. For fintech startups, organizational legitimacy and legitimacy for a particular product go hand in hand. The accomplishments valued by a range of stakeholders mean that an alliance helps gain legitimacy for both the organization and the product. For a startup, building legitimacy is a part of the necessary identity formation that creates competitive advantage (Lounsbury \& Glynn, 2001).

Although, in 1995, Suchman described banks as belonging to an archetype of permanent, structurally legitimate organizations of good character, in 2019, a changing financial ecosystem means that banks are no longer perceived the same way. However, even though the status of banks was changing, fintech startups retained 


\section{Alliances in Financial Ecosystems: A Source of Organizational Legitimacy for Fintech Startups and Incumbents Christopher Svensson, Jakob Udesen, and Jane Webb}

their hopes that they could piggyback on the established status of incumbents. Given that tackling the "liability of newness" (Stinchcombe, 1965) is about mobilizing affirmative commitments, fintech startups must prove that they have "value". Fintech startups accentuated their perceived advantages in order to be attractive to incumbents. It is unclear from the interviews who dictates the terms in the financial ecosystem in Sweden - is it more a case of fintech startups gaining legitimacy by conforming to the environment controlled by incumbents or is it more a case of fintech startups manipulating the environment? This could be a crucial question for each fintech startup in order to be seen as a vital actor within the financial ecosystem. There may be a midway between confirming and manipulating, between fit-to-process and disruption, that is mutually beneficial to both fintech startups and incumbents.

Along with putting effort into emphasizing that a fintech startup is falling in line with compliance requirements, each fintech startup needs to shift the conversation, too, about just what is different about their organization and services. This could mean engaging in creating a shared vision of future changes in technology with other fintech startups and setting an agenda on this, as Bailetti (2012) suggests. This helps build legitimacy for a new way of relating between actors within the transforming financial ecosystem. However, a manager of a fintech startup no doubt also gains legitimacy for their organization by demonstrating awareness of socially accepted procedures and structures. We suggest that playing up the legitimate distinctiveness of a fintech startup and how this distinctiveness complements the legitimacy of another actor is crucial to responding to the intertwined quests for organizational legitimacy within financial ecosystems.

\section{Conclusion}

From interviews with representatives from fintech startups and VCs, we have explored the intertwined quests of fintech startups and incumbents related to their needs to gain, maintain, and repair organizational legitimacy. We have argued that, by partnering with each other, fintech startups and incumbents can meet organizational legitimacy needs and further enhance organizational legitimacy through the joint accomplishments arising from alliances. The legitimating functions of strategic alliances are considered as building competitive advantage for fintech startups and incumbents in a transforming financial ecosystem. Alliances primarily help establish or maintain rights to operate in a specific market with governments or customers; but, they can also legitimate business activities in the eyes of corporate executives, boards, VCs, and shareholders. While meeting these legitimacy needs, an alliance may also help legitimate the alliance form as a part of strategy for future cooperation with other actors in the financial ecosystem.

This article brings to the fore the necessity - for both fintech startups and incumbents - of managing organizational legitimacy and considering it as a vital part of strategy. Considering the interplay of legitimacy needs across actors in a financial ecosystem makes clearer what managers of a fintech startup can emphasize when seeking to position themselves as attractive partners. To meet the expectations of incumbents, managers from fintech startups emphasize innovative services with sound business models that add value to an incumbent's platform. They are prepared to comply with the incumbent's policies and procedures. In turn, the managers of fintech startups seek out incumbents who are trusted by customers, who are investing in new technology, and who are willing to support the fintech startup in navigating regulatory frameworks. Together, an incumbent and a fintech startup may achieve a midway approach that harnesses each other's expertise to achieve competitive advantage in the financial ecosystem transforming around new technology.

This article provides but a snapshot of the current moment from the perspective of Swedish fintech startups with regards to relationships between fintech startups and incumbents. It offers a starting point for research on intertwined quests for legitimacy in financial ecosystems. A follow-up to this explorative article would be to systematically map the legitimacy needs of all organizational actors in a financial ecosystem and how this impacts technology commercialization, performance, and strategy. Investigating the perceptions of both corporate and private customers about the legitimacy of financial actors could reveal pressing legitimacy challenges that make necessary strategic alliances. This article also opens up opportunities for exploring intertwined quests for legitimacy in other ecosystems transforming due to technology entrepreneurship. In addition, researchers could study how organizational legitimacy needs interact with other business needs to influence strategies adopted by technology startups and by incumbents, especially in relation to when to choose acquisition and when to choose alliance. 


\section{Alliances in Financial Ecosystems: A Source of Organizational Legitimacy for Fintech Startups and Incumbents Christopher Svensson, Jakob Udesen, and Jane Webb}

\section{Acknowledgements}

This article draws on a research project carried out from January to May 2018 to conclude Master of Science programs at Chalmers University of Technology, Sweden. The report Actions to Gain Legitimacy in the Swedish Financial Sector: A Study of Swedish Fintech Startups by Christopher Svensson and Jakob Udesen is available at: tinyurl.com/ya8zhzrv

\section{About the Authors}

Christopher Svensson is a Business Developer and fintech enthusiast working at Minna Technologies, a fintech startup in Sweden. He has a Master's degree in Mechanical Engineering, with a focus on Quality and Operations Management, from Chalmers University of Technology, Sweden. He has also studied Economics at the Gothenburg School of Business, Economics and Law, Sweden. His multidisciplinary background within Technology Management and Economics has shaped Christopher's particular interest in how technology startups transform and disrupt industries.

Jakob Udesen is an Associate Business Developer working at Tetra Pak. He holds a Master's degree in Industrial Engineering, with a focus on the Management and Economics of Innovation, from Chalmers University of Technology, Sweden. A part of his Master's level studies was carried out at the Lisbon School of Economics and Management, Portugal. Jakob has a strong interest in how to manage innovation processes to ensure the best financial outcomes, and he has a deep understanding of agile processes as well as classic management approaches.

Jane Webb is a $\mathrm{PhD}$ candidate in Innovation Management and Organizational Behavior at Chalmers University of Technology, Sweden. Her doctoral research draws on a two-year ethnographic study of a partnership of 15 organizations testing and demonstrating electric vehicles and related services "live" in a city. Her interest is in how participants in collaborative innovation successfully nurture a web of goals to keep joint work alive. Jane has previous experience in policy, project, and operations management in the public sector, as well as in design research.

\section{References}

Aarikka-Stenroos, L., \& Sandberg, B. 2012. From New-Product Development to Commercialization through Networks. Journal of Business Research, 65(2): 198-206.

https://doi.org/110.1016/j.jbusres.2011.1005.1023

Adner, R. 2017. Ecosystem as Structure: An Actionable Construct for Strategy. Journal of Management, 43(1): 39-58.

https://doi.org/10.1177/0149206316678451

Adner, R., \& Kapoor, R. 2010. Value Creation in Innovation Ecosystems: How the Structure of Technological Interdependence Affects Firm Performance in New Technology Generations. Strategic Management Journal, 31(3): 306-333. https://doi.org/310.1002/smj.1821

Arner, D. W., Barberis, J., \& Buckley, R. P. 2016. 150 Years of Fintech: An Evolutionary Analysis. Jassa, 2016(3): 22-29.

Bailetti, T. 2012. Technology Entrepreneurship: Overview, Definition, and Distinctive Aspects. Technology Innovation Management Review, 2(2): 5-12.

http://doi.org/10.22215/timreview/520

Bitektine, A., \& Haack, P. 2015. The "Macro" and the "Micro" of Legitimacy: Toward a Multilevel Theory of the Legitimacy Process. Academy of Management Review, 40(1): 49-75.

https://doi.org/10.5465/amr.2013.0318

Björn, M. 2018. The Adoption of Online Banking in Sweden. In R. Teigland, S. Siri, A. Larsson, A. Moreno Puertas, \& C. Ingram Bogusz (Eds.), The Rise and Development of FinTech: Accounts of Disruption from Sweden and Beyond. New York: Routledge.

Carbone, P. 2011. Acquisition Integration Models: How Large Companies Successfully Integrate Startups. Technology Innovation Management Review, 1(1): 26-31.

http://doi.org/10.22215/timreview/490

CB Insights. 2018. Fintech Trends to Watch in 2018. New York: CB Insights.

https://www.cbinsights.com/research/report/fintech-trends2018/

Dacin, M. T., Oliver, C., \& Roy, J. P. 2007. The Legitimacy of Strategic Alliances: An Institutional Perspective. Strategic Management Journal, 28(2): 169-187.

https://doi.org/110.1002/smj.1577

Dorfleitner, G., Hornuf, L., Schmitt, M., \& Weber, M. 2017. FinTech in Germany. Cham, Switzerland: Springer.

https://doi.org/10.1007/978-3-319-54666-7

Dougherty, D. 2017. Organizing for Innovation in Complex Innovation Systems. Innovation: Organization \& Management, 19(1): 11-15.

https://doi.org/10.1080/14479338.14472016.11245109

Dutta, D. K., \& Hora, M. 2017. From Invention Success to Commercialization Success: Technology Ventures and the Benefits of Upstream and Downstream Supply-Chain Alliances. Journal of Small Business Management, 55(2): 216-235. https://doi.org/210.1111/jsbm.12334

Dyer, J. H., \& Singh, H. 1998. The Relational View: Cooperative Strategy and Sources of Interorganizational Competitive Advantage. Academy of Management Review, 23(4): 660-679. https://doi.org/610.2307/259056 


\section{Alliances in Financial Ecosystems: A Source of Organizational Legitimacy for Fintech Startups and Incumbents Christopher Svensson, Jakob Udesen, and Jane Webb}

Felländer, A., Siri, S., \& Teigland, R. 2018. The Three Phases of FinTech. In R. Teigland, S. Siri, A. Larsson, A. Moreno Puertas, \& C. Ingram Bogusz (Eds.), The Rise and Development of FinTech: Accounts of Disruption from Sweden and Beyond. New York: Routledge.

Giones, F., \& Brem, A. 2017. From Toys to Tools: The Co-Evolution of Technological and Entrepreneurial Developments in the Drone Industry. Business Horizons, 60(6): 875-884. https://doi.org/810.1016/j.bushor.2017.1008.1001

Gomber, P., Kauffman, R. J., Parker, C., \& Weber, B. W. 2018. On the Fintech Revolution: Interpreting the Forces of Innovation, Disruption, and Transformation in Financial Services. Journal of Management Information Systems, 35(1): 220-265. https://doi.org/210.1080/07421222.07422018.01440766

Gromek, M. 2018. Clarifying the Blurry Lines of FinTech: Opening the Pandora's Box of FinTech Categorization. In R. Teigland, S. Siri, A. Larsson, A. Moreno Puertas, \& C. Ingram Bogusz (Eds.), The Rise and Development of FinTech: Accounts of Disruption from Sweden and Beyond. New York: Routledge.

Iansiti, M., \& Levien, R. 2004. The Keystone Advantage: What the New Dynamics of Business Ecosystems Mean for Strategy, Innovation, and Sustainability. Boston: Harvard Business Press.

Ingram Bogusz, C., Teigland, R., \& Vaast, E. 2018. Designed Entrepreneurial Legitimacy: The Case of a Swedish Crowdfunding Platform. European Journal of Information Systems. https://doi.org/10.1080/0960085X.2018.1534039

Jonsdottir, F., Toivonen, O., Jaatinen, V., Utti, A., \& Lindqvist, R. 2017. FinTech in the Nordics: A Deloitte Review. Deloitte, January 24, 2017. Accessed July 24, 2018. https://www2.deloitte.com/content/dam/Deloitte/se/Documents /financial-services/FinTech_Publikation_A4_WEB_FINAL.PDF

Kumaraswamy, A., Garud, R., \& Ansari, S. S. 2018. Perspectives of Disruptive Innovation. Journal of Management Studies, 55(7): 1025-1042.

https://doi.org/1010.1111/joms.12399

Lee, I., \& Shin, Y. J. 2018. Fintech: Ecosystem, Business Models, Investment Decisions, and Challenges. Business Horizons, 61(1): $35-46$.

https://doi.org/10.1016/j.bushor.2017.1009.1003

Lounsbury, M., \& Glynn, M. A. 2001. Cultural Entrepreneurship: Stories, Legitimacy, and the Acquisition of Resources. Strategic Management Journal, 22(6-7): 545-564. https://doi.org/510.1002/smj.1188
Navis, C., \& Glynn, M. A. 2011. Legitimate Distinctiveness and the Entrepreneurial Identity: Influence on Investor Judgments of New Venture Plausibility. Academy of Management Review, 36(3): 479-499.

https://doi.org/410.5465/amr.2008.0361

Nordic Tech List. 2018. Nordic Tech List. Stockholm: Dagens Industri. Accessed January 18, 2018: http://www.nordictechlist.com

Payette, J. 2014. Resolving Legitimacy Deficits in Technology Startups through Professional Services Practices. Technology Innovation Management Review, 4(6): 22-27. http://doi.org/10.22215/timreview/801

Rao, R. S., Chandy, R. K., \& Prabhu, J. C. 2008. The Fruits of Legitimacy: Why Some New Ventures Gain More from Innovation than Others. Journal of Marketing, 72(4): 58-75. https://doi.org/10.1509/jmkg.1572.1504.1558

Sandström, C., Berglund, H., \& Magnusson, M. 2014. Symmetric Assumptions in the Theory of Disruptive Innovation: Theoretical and Managerial Implications. Creativity and Innovation Management, 23(4): 472-483.

https://doi.org/410.1111/caim.12092

Stinchcombe, A. 1965. Social Structure and Organizations. In J. G. March (Ed.), Handbook of Organizations. Chicago: Rand McNally.

Suchman, M. C. 1995. Managing Legitimacy: Strategic and Institutional Approaches. Academy of Management Review, 20(3): 571-610. https://doi.org/510.2307/258788

Citation: Svensson, C., Udesen, J., \& Webb, J. 2019. Alliances in Financial Ecosystems: A Source of (cc) BY Organizational Legitimacy for Fintech Startups and Incumbents. Technology Innovation Management Review, 9(1): 20-32.

http://doi.org/10.22215/timreview/1209

Keywords: fintech startups, organizational legitimacy, financial ecosystems, strategic alliances, relational perspective 


\title{
Are High-Tech Companies More Competitive Than Others? An Empirical Study of Innovative and Exporting French SMEs
}

\author{
Manon Enjolras, Mauricio Camargo, and Christophe Schmitt
}

\author{
(6 Technology is changing so fast that knowledge") \\ about specifics can quickly become obsolete. \\ That's why so much of what technicians learn \\ is on the job.
}

\author{
Robert B. Reich \\ Professor of Public Policy \\ and former US Secretary of Labor
}

\begin{abstract}
The main objective of this research work is to question the relationship between the technological intensity of SMEs (defined by the share of R\&D expenditure in turnover, according to the OECD) and their growth potential (defined by their innovation and export capabilities). Through a multiple case study conducted with a panel of nine French SMEs, and through an analysis combining a qualitative approach (illustrative cases study) and a quantitative one (multidimensional statistical methods), several hypotheses were tested. Finally, this study points out that technological intensity, as defined by the OECD, is not directly correlated with the growth potential of SMEs. On the other hand, a company's technological intensity would have an impact on the way it manages its innovation and internationalization process, and thus the way it manages its internal practices.
\end{abstract}

\section{Introduction}

For several years, the global ranking of the most innovative companies has been clearly dominated by the largest multinationals in the high-tech sector (Google, Apple, etc.) (Ringel et al., 2018). These companies seem to have particular abilities to launch innovations on a regular basis. But what about small structures? It is commonly accepted that small and medium-sized enterprises (SMEs) face more difficulties than large enterprises in activities such as innovation or internationalization (Dhanaraj \& Beamish, 2003; Okręglicka et al., 2015; Paul et al., 2017). However, startups and high-growth firms are seen as particularly fertile ground for innovation (Demir et al., 2017). They are agile and dynamic, and their flexibility allows them to be particularly competitive in their markets. Moreover, they are generally inherently international (e.g., born-global firms), which considerably fuels their growth potential (Cannone \& Ughetto, 2014).

In view of this context, this article aims to question the technological intensity of a company as a determining factor of its potential growth. Is technological intensity a real facilitator for business competitiveness? Can traditional and low-tech companies compete with these intrinsically innovative and dynamic high-tech firms? Through an analysis of nine business cases in France, we will focus on the particular context of SMEs and study the impact of the technological intensity of these companies on their innovation and export capabilities.

Our analysis is therefore based on empirical experience. Nine innovative and exporting SMEs were evaluated on the basis of a joint diagnosis of the companies' innovation and export capabilities: the Potential Export and Innovation Index (PE2I) (Enjolras, 2016). The results of these evaluations make it possible to establish the degree of maturity of the evaluated companies concerning nine innovation and export best practices: Strategy, Intellectual Property, Corporate Culture, Customer Relationship Management, Technological and Commercial Intelligence, Networking, Knowledge Management, Project Management, and Human Resources Management. 


\section{Are High-Tech Companies More Competitive Than Others? An Empirical Study of Innovative and Exporting French SMEs M. Enjolras, M. Camargo, and C. Schmitt}

These companies were then ranked according to their technological intensity. For that purpose, the industries' classification proposed by the OECD was used (Hatzichronoglou, 1997). This classification assigns to each activity sector a technological intensity according to the following graduated scale: Low technology, Medium/Low technology, Medium/High technology, High technology. Thus, a degree of technological intensity was assigned to each company and was related to its profile in terms of innovation and export practices.

This multiple-case study was conducted in a qualitative way. Moreover, several multivariate data analysis methods have been used to explore potential trends enriching the cases. Our objective was to describe how the relationship between technological intensity and innovation and export capabilities could be qualified into the sample of French SMEs. Does a high technological intensity imply a high innovation and export performance? Does it imply a particular profile in terms of internal processes?

\section{Literature Review}

\section{The dominant paradigm: Technological intensity defined by $R \& D$ expenditure}

Technological intensity has become an integral part of the discussion of economic policy in recent decades (Kirner et al., 2009). The notions "high-tech" and "lowtech" derive from the OECD definition of the share of R\&D expenditure in an industry's turnover. According to this definition, firms with more than $5 \%$ of annual turnover invested into $R \& D$ are classified as "hightech" and those with less than $5 \%$ of annual turnover invested into $\mathrm{R} \& \mathrm{D}$ as "low-tech" (Hirsch-Kreinsen et al., 2008). This classification is based on the assumption that a high level of $R \& D$ expenditure is directly linked to significant growth. High-tech industries, through their high level of R\&D investment, are therefore strategic industries with high growth potential (Guillou, 2006).

Innovation and export were identified as the main drivers of economic growth (Love \& Roper, 2015; PlaBarber \& Alegre, 2007). Yet, prior studies suggest R\&D expenditure as a key factor in determining a firm's innovation capability (van Beers \& Zand, 2014; Shefer \& Frenkel, 2005). So, a positive relationship between industry-level dynamism and firm-level innovation is put forward by the literature. In the dynamic high-tech manufacturing sector, the percentage of firms introducing new products was more than double that of the low-tech sector (Thornhill, 2006). Moreover, high-tech companies are generally positioned in international markets. Indeed, several empirical studies favour the level of $R \& D$ investment or other technological variables to explain export performance (Carlin et al., 2001; Fagerberg, 1994; Landesmann \& Pfaffermayr, 1997). According to the OECD (Hatzichronoglou, 1997), firms that are more technologically intensive innovate more, gain new markets, use available resources more productively, and generally offer higher remuneration to their employees. High-tech industries are the fastest growing industries in international trade, and their dynamics contribute to improving the performance of other sectors. In the same way, Colombo and co-authors (2016) note that high-tech entrepreneurial ventures have responded to the economic crisis through investments in product innovation and expansion into international markets. On the other hand, low-tech industries faced additional difficulties because they require greater internal organizational capabilities to adapt themselves to their external environments.

In the context of SMEs, several findings put forward the hypothesis that SMEs with a high technological intensity (and therefore a high level of R\&D investment) would be more competitive than others through their innovation performance, on one hand, and their international activities on the other. From the point of view of Heidenreich (2009) and Kirner and colleagues (2009), most low-tech SMEs are less likely to engage themselves in formal $R \& D$ so they are less technologically innovative and are less export intensive than high-tech SMEs. They therefore have lower growth potential.

This previous research could therefore be related to the resource-based theory. According to this theory, companies can be considered as a set of resources that are distributed heterogeneously within companies (Teece et al., 1997). Some of these so-called strategic resources are considered to be the foundations of competitive advantage in the domestic and international market (Barney, 1991). Thus, by considering that a company's technological intensity (i.e., its degree of investment in $R \& D)$ represents a strategic resource for its growth dynamic, a high-tech company is then better able to regularly propose innovations on its domestic market but also internationally. So, based on this dominant paradigm, a first theoretical hypothesis is proposed:

H1: The innovation and export capabilities of an SME are influenced by its technological intensity (i.e., its R\&D investment). 


\section{Are High-Tech Companies More Competitive Than Others? An Empirical Study of Innovative and Exporting French SMEs M. Enjolras, M. Camargo, and C. Schmitt}

\section{An R\&D-oriented point of view challenged by the Schumpeterian vision of innovation \\ Many research studies challenge the OECD approach (focused on the degree of R\&D investment) by high- lighting two factors that appear to play a role in influen- cing these issues: the nature of the innovation and the way of managing it (Aydalot \& Keeble, 2018).}

Indeed, innovation has often been correlated only to R\&D activities and to new product development. However, the OECD's Oslo Manual (Mortensen, 2005) defines four types of innovation: product innovation, process innovation, marketing innovation, and organizational innovation. Most of the attention has been given to product innovation, in particular technological product innovation. Some research works therefore propose to move away from the technological vision of innovation, linked to pure R\&D investment, in order to move towards a more Schumpeterian understanding where innovation is a means to an end, the end being economic success, increased competitiveness, or growth (Schumpeter, 1934).

For example, this was highlighted by (Raymond \& StPierre, 2010) who stated that "the link between R\&D activities and innovation in SMEs still requires clarification and further understanding". According to them, high-tech manufacturers seem to gain more benefits from $R \& D$ investment in product development, while low-tech firms seem to gain benefits from investment on process innovations. In the same way (Lindman et al., 2008), studied SMEs in the creative industries sectors, which demonstrated high levels of innovation despite having non-technological innovations.

Reboud and colleagues (2014) formulated a hypothesis that the level of innovative activity among SMEs with low $R \& D$ intensity will be lower than that of SMEs with high R\&D intensity. Through a comparative study of French and Australian SMEs using a discriminant analysis procedure, this hypothesis has been refuted in favour of a second hypothesis that emphasizes that firms with high $R \& D$ intensity will focus more on product innovations than other types of innovation.

In a more general manner (Mazzarol \& Reboud, 2011) suggest that the difference between the low-tech firms and their high-tech counterparts relies on the number and type of innovations generated and how such firms manage the process of commercialization.

So, this Schumpeterian vision puts forward that the $\mathrm{R} \& \mathrm{D}$-intensive firms are considered as been highly in- novative because of the large number of product innovations they implement. But low-tech firms, with their lower $\mathrm{R} \& \mathrm{D}$ intensity, are also able to show a high level of innovation, albeit with greater orientation toward process innovations. Taking into account this vision, a second hypothesis is proposed:

H2: Low-tech firms develop more process innovations than high-tech firms, which are more product-oriented.

\section{An $R \& D$ perspective challenged by the contingency theory (Mintzberg, 1979)}

The R\&D expenditure vision of technological intensity is also challenged by several authors (Hirsch-Kreinsen et al., 2008; von Tunzelmann \& Acha, 2006), who consider that this vision necessarily implies a sectorial and aggregative view of $R \& D$ intensity and does not apply in detail to the level of the single firm (Kirner et al., 2009). In order to take into account the level of the firm, we rely on Mintzberg's contingency theory. Based on this theoretical paradigm, it is possible to consider that there is no good organization "in itself". Mintzberg states that the structure of an organization depends both on its own characteristics and on the nature of its environment. There is therefore no universal structure that can be adapted to all situations. A "good" structure must be adapted to its environment, and an environment shapes the organizations that make it up.

So, the internal routines of a company must be as varied as the environment with which it must deal. To remove the constraints linked to its environment, the company must adjust its behaviour by taking strategic decisions (Uzunidis, 2016) to set up a coherent and specific internal functioning that will allow it to improve its performance and to have an impact on the structure of its own market (Tirole, 1988). So, in a growth dynamic, firms can follow different innovation and exportation paths.

Previous works in this field support this theoretical vision, showing, for example, that low-tech sectors do not lack opportunities for innovation, but these opportunities often take a different form than those in the hightech sectors (Haudeville \& Bas, 2016). Moreover, highand low-tech industries require different types of innovation resources (Zouaghi et al., 2018). Besides developing new products, manufacturing firms can also develop new product-related services, introduce innovative manufacturing technologies, or implement innovative organizational concepts. Each of these innovation types can be a source of competitive advantage in itself 


\section{Are High-Tech Companies More Competitive Than Others? An Empirical Study of Innovative and Exporting French SMEs M. Enjolras, M. Camargo, and C. Schmitt}

(Kirner et al., 2009). Research by Reichert and colleagues (2016) highlights that innovation occurs and is important not only for industries active at the technological frontier, but also for low-technology industries. The innovative capability of low-tech firms does not necessarily derive from R\&D investment. Instead, high innovation capacity can result from the profitable deployment of resources to create capabilities that do not involve R\&D.

So, it seems that companies can implement different internal practices to manage their growth process. There are thus various contingency factors that directly affect the structuring of companies. They concern both the specific characteristics of the organization, but also the nature of its environment (Mintzberg, 1979). Based on this theoretical background, we propose to test if technological intensity can also be considered as a contingency factor impacting the structure and practices of innovative and exporting SMEs. We therefore propose a third hypothesis:

H3: The way a company manages its innovation and export activities depends on its technological intensity. Specific profiles can be identified according to the internal practices in place within the companies.

Figure 1 illustrates the relationship between the three hypotheses built from the literature.

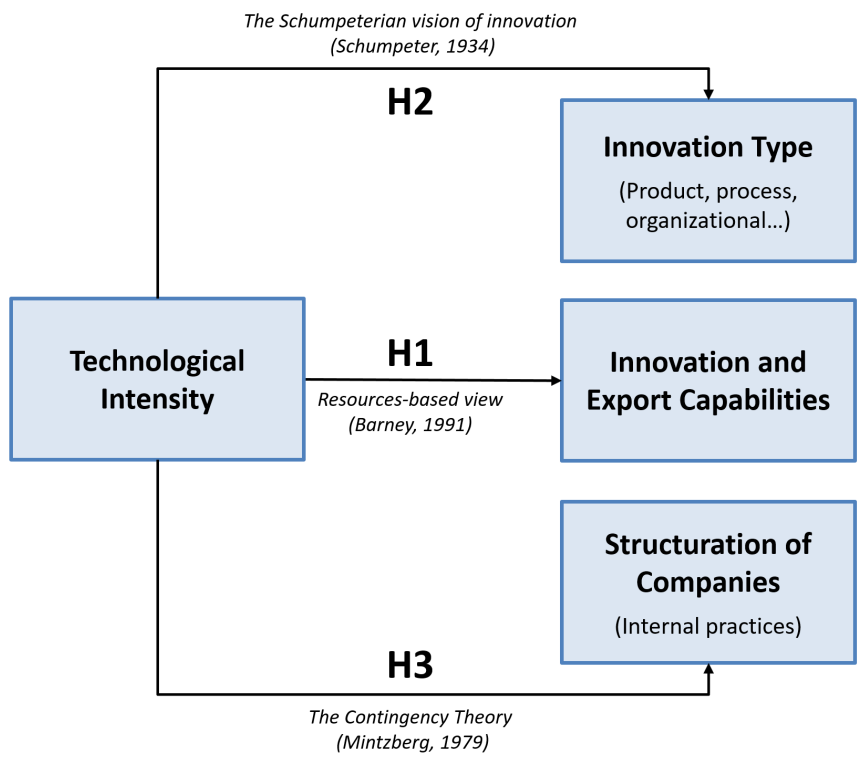

Figure 1. The framework underlying the research hypotheses tested in this study

\section{Methodology}

\section{Theoretical background}

This research focuses on the relationship between technological intensity and the potential growth of firms that has been defined as their innovation and export capabilities. For that purpose, different theoretical foundations have been mobilized.

First, we chose to use the OECD's classification of technological intensity (Hatzichronoglou, 1997) in order to assess the firms in the panel. This classification is based on a grouping by industrial sector within which the notion of technological intensity has been translated into the ratio of $R \& D$ expenditure to value added. Four categories were thus identified: low-tech, medium-low, medium-high, and high-tech. Although this classification has been criticized by many authors in the scientific literature (Hirsch-Kreinsen et al., 2008; von Tunzelmann \& Acha, 2006), it has the main advantage of providing a simple and consistent instrument for international comparisons. Furthermore, based on the Standard International Trade Classification (SITC) revision 2, it combines both a sectoral approach (industry classification) and a product approach (list of manufactured products according to categories) (Hatzichronoglou, 1997).

The second theoretical basis concerns the evaluation of the innovation and export capabilities of SMEs. Given that the objective is to evaluate the potential correlations between technological intensity and innovation and export capabilities, it is essential to propose an evaluation of the companies on a standard basis in order to be able to make comparisons. It was therefore decided to use a mixed innovation/export diagnostic tool in order to put into practice a joint vision of these two activities within SMEs. So, the innovation/export relationship in SMEs, traditionally thought of in a causal way, was envisaged through the prism of the complementarity (Enjolras et al., 2016). By improving one of these activities, companies activate a single lever that simultaneously improves innovation and export capabilities. In the context of SMEs, for whom the lack of resources is a major difficulty, it makes perfect sense. This diagnostic tool, called the potential exportation and innovation index (PE2I), relies on a joint evaluation methodology of the innovation and exportation capabilities of SMEs (Enjolras, 2016). Thus, the main specificity of this tool is that it concentrates on the activities/resources/skills that an SME has to mobilize first and foremost to simultaneously improve its innovation and export performance while reducing the effort 


\section{Are High-Tech Companies More Competitive Than Others? An Empirical Study of Innovative and Exporting French SMEs M. Enjolras, M. Camargo, and C. Schmitt}

associated with its performance improvement. This index measures the firm's maturity in the joint activities of innovation and export (Figure 2). It makes it possible to propose a diagnosis of the situation of a company by identifying its strengths and its weaknesses, and it gives an indication of its potential domain of preference (innovation or export). Another advantage of this diagnostic tool is that it does not evaluate innovation or export based on performance indicators (export turnover, number of patents, etc.).This tool measures a degree of maturity regarding internal practices or routines in place within the company. It makes therefore possible to identify the profile of the companies evaluated in terms of innovation management and international activities. These findings may highlight significant differences in terms of the internal functioning of companies.

\begin{abstract}
Methodological approach
Based on a sample of nine innovative and exporting French SMEs, this study was conducted by combining a qualitative multiple-case study approach and a quantitative approach through multivariate statistical methods.
\end{abstract}

The case study is a qualitative research method. According to Yin (2013), it is a research strategy using empirical investigation in real context. It seeks to understand a contemporary phenomenon and mobilizes many sources of information. It is traditionally used in an exploratory way, but according to Hlady Rispal (2016), its contributions can be much more numerous. For this research work, the case study approach is used in a qualitative deductive logic. This means comparing a "theoretical" model (research hypotheses) with the reality on the ground (SMEs context).

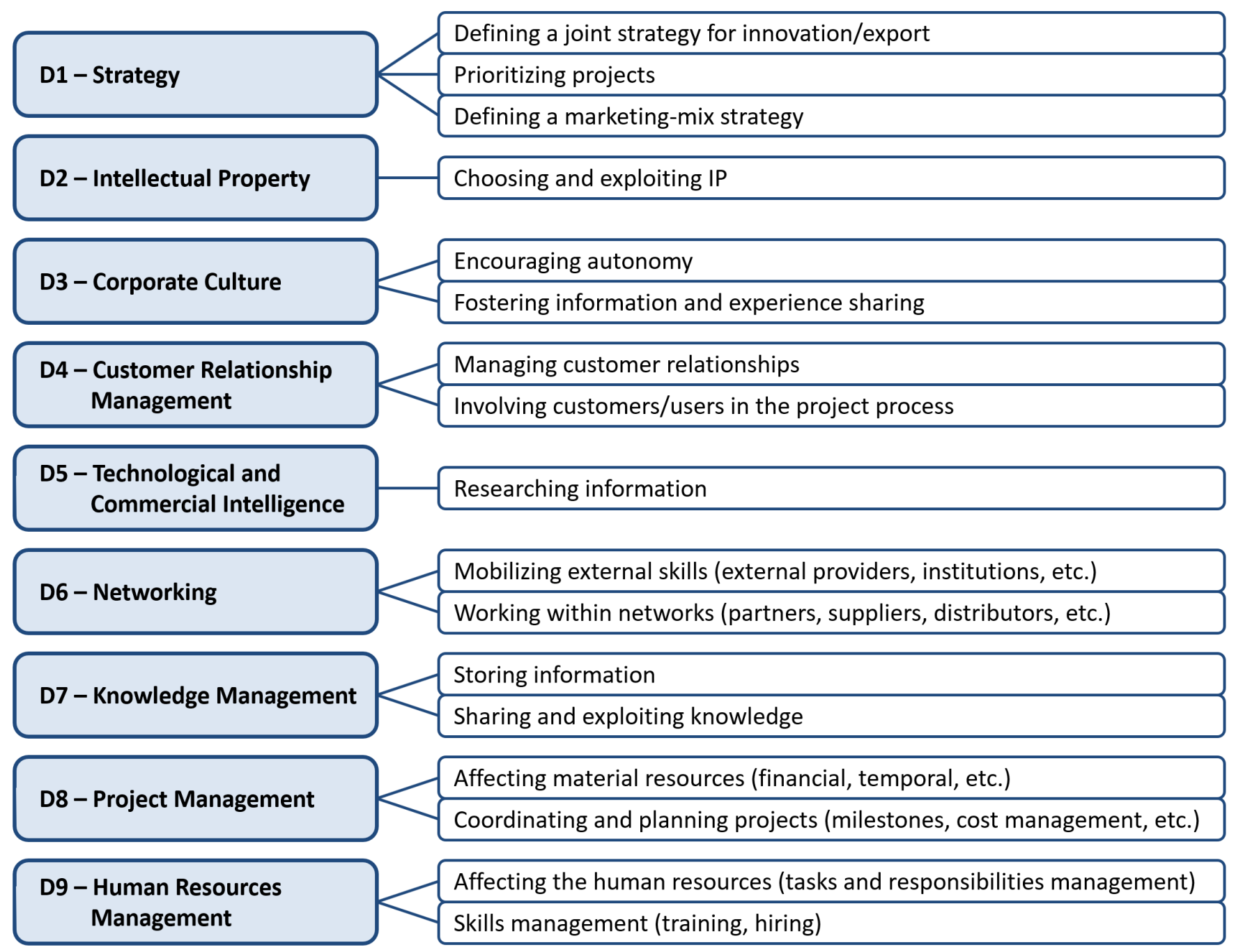

Figure 2. Joint innovation/export practices of the PE2I tool 


\section{Are High-Tech Companies More Competitive Than Others? An Empirical Study of Innovative and Exporting French SMEs M. Enjolras, M. Camargo, and C. Schmitt}

\section{Step 1: Case selection}

We selected nine French companies to form our panel (Table 1). The selection criteria were as follows:

- The company had to be an SME, as defined by the European Commission (2003): it must therefore meet several criteria in terms of number of employees $(<250$ employees) and annual turnover $(<€ 50 \mathrm{M} ; \sim \$ 75 \mathrm{M}$ CAD).

- The company had to be involved in an innovation process (i.e., product or process innovation as defined in the Oslo Manual).

- It had to achieve an export turnover, even if it represented a very small proportion.

- It had to be in a process of development and growth. This selection criterion, relating to the company's strategy and its manager intention, makes it possible to focus this study on growing companies, without considering that this is the case for all SMEs.

Particular attention was paid to the fact that the panel should bring together companies from different business sectors and offer diversity in terms of technological intensity as defined by the OECD.

\section{Step 2: Interviews}

The nine companies in the panel were studied through semi-directive interviews with four stages: context analysis, PE2I evaluation (diagnosis of their innovation and export capabilities), discussion of results, and recommendations. Each interview lasted between 1 and 2 hours. The first part of the interview was dedicated to the company's context analysis. What is its main activity? Who are its customers? How does it work on a daily basis? Then, based on this information, the PE2I evaluation was conducted. The discussion with the business manager allows for the evaluation of the maturity level of the company concerning the joint activities innovation/export of the PE2I. Then, the information gathered during these interviews was then processed in order to build a database.

\section{Step 3: Identification of illustrative cases}

Finally, a global report of each interview was written to put forward the specificities of the case. The objective of these reports was to record the information obtained during the interviews, to contextualize it, and to put it in perspective with the notion of technological intensity. The use of these reports, combined with an analysis of the database (step 2), made it possible to identify illustrative cases highlighting observations of interest for this research work.

Table 1. Profile of the nine companies in the sample

\begin{tabular}{|c|c|c|c|c|c|}
\hline & Sector & $\begin{array}{c}\text { Size } \\
\text { (Workforce) }\end{array}$ & $\begin{array}{c}\text { Technological } \\
\text { Intensity (OECD) }\end{array}$ & $\begin{array}{c}\text { Export } \\
\text { Turnover (\%) }\end{array}$ & $\begin{array}{l}\text { Innovation Type } \\
\text { (Oslo Manual) }\end{array}$ \\
\hline C1 & Scientific Instruments & 9 & Medium-High & 53 & Product innovation \\
\hline C2 & Food Industry & 10 & Low Technology & 4 & Process Innovation \\
\hline C3 & Agricultural Machinery & 200 & Medium-High & 6 & Product Innovation \\
\hline C4 & $\begin{array}{l}\text { Thermoplastic } \\
\text { Materials }\end{array}$ & 30 & Medium-Low & 15 & Process Innovation \\
\hline C5 & Scientific Instruments & 20 & Medium-High & 90 & Product Innovation \\
\hline C6 & Biotechnology & 5 & Medium-High & 5 & Process Innovation \\
\hline $\mathrm{C7}$ & Biotechnology & 3 & Medium-High & 1 & Process Innovation \\
\hline C8 & Food Industry & 100 & Low & 5 & Process Innovation \\
\hline C9 & $\begin{array}{l}\text { Electronics, } \\
\text { Automation }\end{array}$ & 16 & High & 1 & Product Innovation \\
\hline
\end{tabular}




\section{Are High-Tech Companies More Competitive Than Others? An Empirical Study of Innovative and Exporting French SMEs M. Enjolras, M. Camargo, and C. Schmitt}

In order to support the identification of illustrative cases, multivariate statistical tools were used to analyze the database. Due to the small number of companies in the panel, the statistical analysis was considered as a quantitative supporting tool and did not aim to reach statistically significant conclusions. However, the objective of using a quantitative tool to support our qualitative approach was to highlight trends within the database. These trends could then be potentially used to identify specific illustrative cases put into context. These statistical tools make it possible to orient the reflections carried out and to exploit the data as well as possible in order to transform them into value-added information. Based on this value-added information, it was possible to apply our three research hypotheses to our multiple-case study.

The statistical method used as a supporting quantitative tool was the principal component analysis (PCA). This method delivers graphical representations of a sample according to two principal axes defined in regard to different variables (Syms, 2008). In this research work, the PCA was used to identify the correlations between the variables of the database. Each variable is represented by a vector represented in a three-dimensional space and then brought back to a two-dimensional plane constructed by two main axes: the principal components. The graphical representation of this methodology results in a loading plot: a plane where the variables are represented by vectors and where their position determines their level of correlation between them. If two variables are represented in the same direction, they are positively correlated. If they are represented in opposite directions, they are negatively correlated. Finally, if the vectors of two variables are orthogonal, there is no correlation between them. In addition, a variable is well represented in the plan of the main components when the vector approaches the limit of this plan (i.e., a circle containing the majority of the data in the sample) (Lever et al., 2017).

This method was used because it is a well-known technique enabling researchers, through an unsupervised linear dimensionality reduction algorithm, to find a more meaningful basis or coordinate system for a set of data. It works based on covariance matrix and is used mainly to find the more relevant features and, by doing

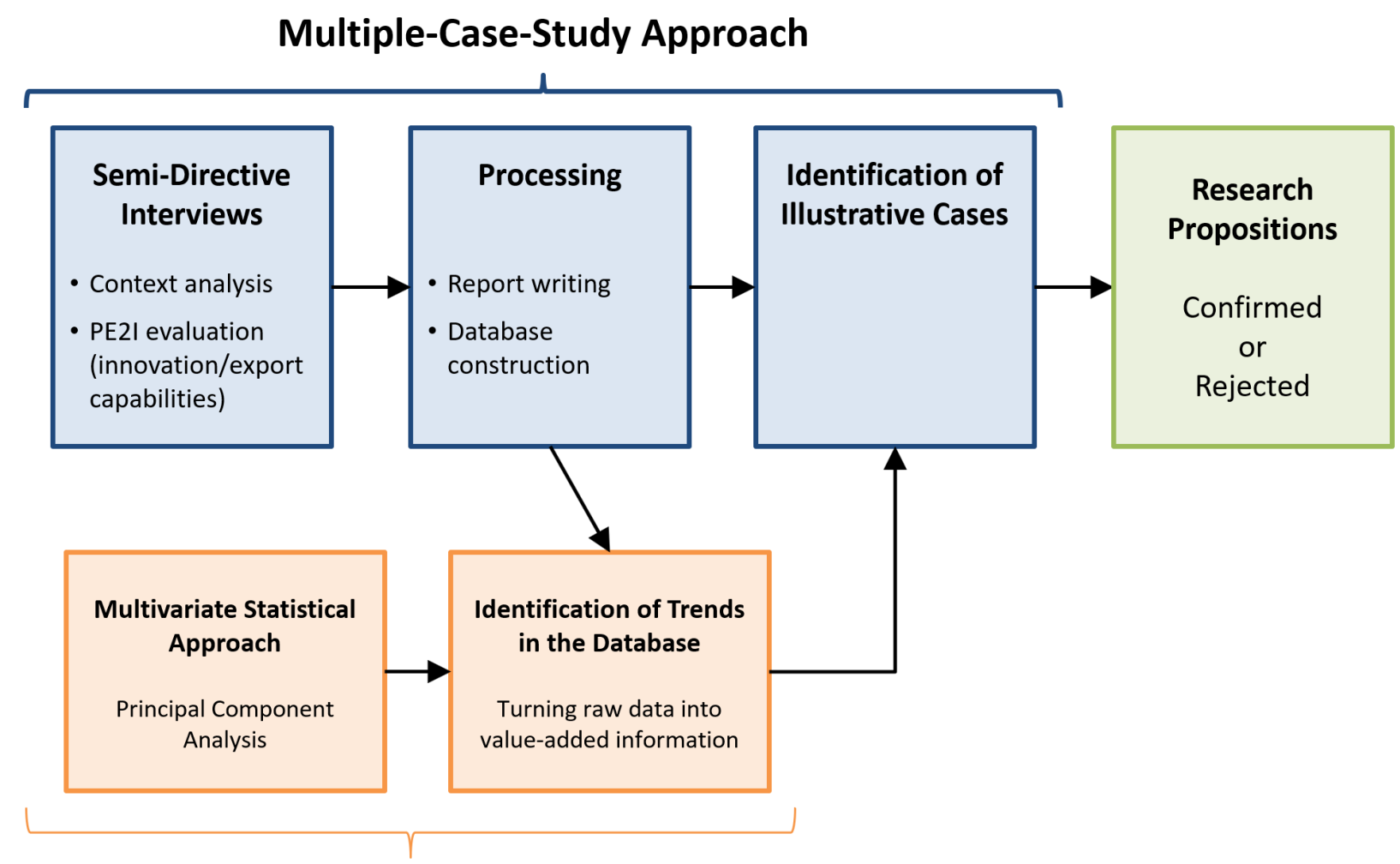

Supporting Quantitative Tools

Figure 3. Methodological approach 


\section{Are High-Tech Companies More Competitive Than Others? An Empirical Study of Innovative and Exporting French SMEs M. Enjolras, M. Camargo, and C. Schmitt}

so, to reduce the number of redundant features. In this exploratory case, it was used in order to have a better perspective on the patterns from the gathered data from the set of case studies.

\section{Results and Discussions}

In this section, we present the results of testing each of the three hypotheses and discuss their implications. We will first focus on the outputs produced by companies, testing the relationship between innovation type and technological intensity (Hypothesis H2). Then, we will extend our investigation to a more global vision of the company, by testing the $\mathrm{H} 1$ and $\mathrm{H} 3$ hypotheses, in order to approach the internal organization of companies allowing them to produce these outputs.

\section{H2: Low-tech firms develop more process innovations} than high-tech firms, which are more product-oriented. Our second hypothesis (H2) was used to identify if the technological intensity is correlated with the type of innovation proposed by companies. Relying on the database, two variables were compared: Technological Intensity and Innovation type. Another contextual variable was added to this analysis: Industrial Sector.

The results of this analysis are presented in Table 2 below. Note that, in our panel, Technological Intensity is not systematically correlated with Innovation Type. The variable Technological Intensity seems to be slightly positively correlated with the product innovation variable: the medium-high and high-tech firms are mainly concerned with product innovation and the lowand medium-low-tech firms focus on process innovation. But this observation is not true for firms C6 and $\mathrm{C} 7$, which are considered as medium-high-tech firms and focus on process innovations.

So, according to this analysis, the second hypothesis is not supported by our sample of SMEs. But, considering the sample in a more detailed way, the specific case of the companies C6 and C7 could be explained by the particularity of their industrial sector: biotechnology. This analysis put forward two specific illustrative cases rejecting our second hypothesis (H2). It seems that the biotechnology industry shows its own specificities in terms of innovation type.

\section{H1: The innovation and export capabilities of an SME are influenced by its technological intensity (i.e., its $R \& D$ investment)}

The results of the PCA conducted to identify the potential correlation between the level of technological intensity of the firms and their innovation and export capabilities are shown in Figure 4. It indicates a strong correlation between the innovation capability (represented by the IIP vector) and the export capability (represented by the IEP vector). This finding was expected because the PE2I diagnosis has been designed on the hypothesis that innovation and export capabilities are

Table 2. Comparison of the Technological Intensity and Innovation Type variables

\begin{tabular}{|c|c|c|c|c|}
\hline Company & Sector & Technological Intensity & Innovation Type & Category \\
\hline C9 & Electronics, Automation & High & Product & \multirow{6}{*}{ High-Tech SMEs } \\
\hline $\mathrm{C} 1$ & Scientific instruments & Medium-High & Product & \\
\hline C3 & Agricultural machinery & Medium-High & Product & \\
\hline C5 & Scientific instruments & Medium-High & Product & \\
\hline C6 & Biotechnology & Medium-High & Process & \\
\hline$C 7$ & Biotechnology & Medium-High & Process & \\
\hline $\mathrm{C} 4$ & Thermoplastic materials & Medium-Low & Process & \multirow{3}{*}{ Low-Tech SMEs } \\
\hline $\mathrm{C} 2$ & Food industry & Low & Process & \\
\hline C8 & Food industry & Low & Process & \\
\hline
\end{tabular}




\section{Are High-Tech Companies More Competitive Than Others? An Empirical Study of Innovative and Exporting French SMEs M. Enjolras, M. Camargo, and C. Schmitt}

strongly correlated. However, another interesting result appears in the loading plot. Because the Technological Intensity variable is almost orthogonal to the IIP and IEP variables, it seems that, in our sample of French SMEs, the technological intensity is not correlated with the innovation and export capabilities. This result challenges our first hypothesis (H1) based on an R\&D-oriented vision of the technological intensity and a technological view of innovation. Based on this observation coming from the PCA analysis, and looking at the panel in a more detailed way, it is possible to identify two illustrative cases showing that a low-tech company is able to have a high innovation and export capability and vice versa. These 2 illustrative cases were analyzed to identify their specificities. Their own profiles in terms of innovation and export internal practices were described based on their PE2I evaluations.

The first illustrative case is company C9. It belongs to the high-tech category in terms of technological intensity. Its main activity is the production of electronic boards dedicated to the control of programmable logic controllers (PLCs) installed in difficult climatic conditions. Its innovation and export capability is medium, with three strong points: networking, knowledge management, and human resources management (Figure 5). This company is a young exporter and works mainly

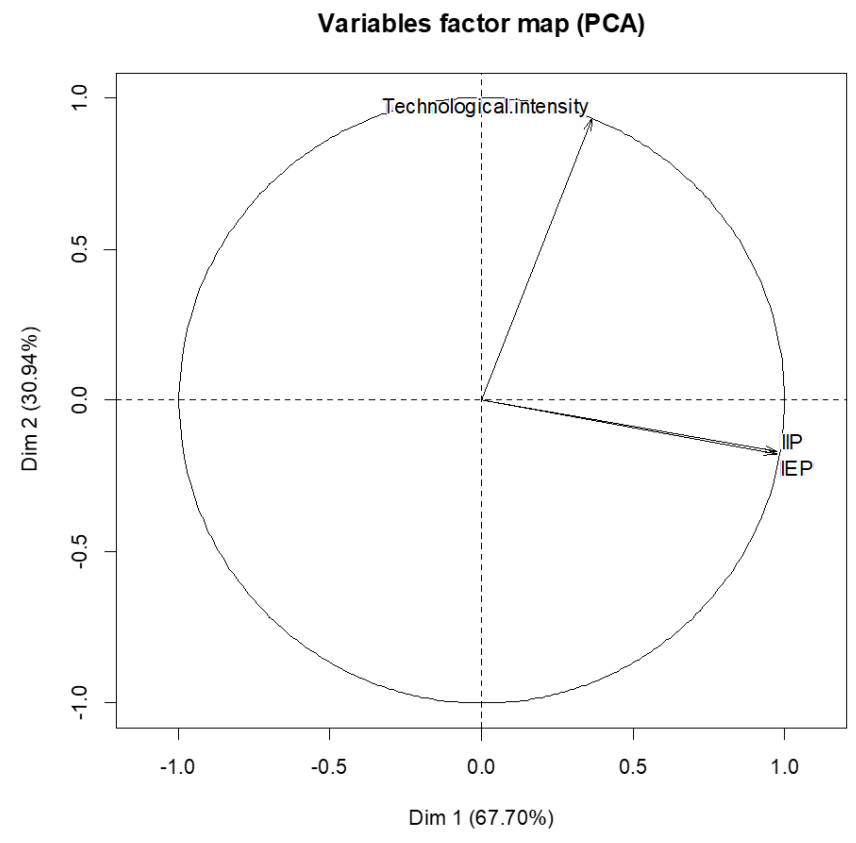

Figure 4. PCA loading plot of Technological Intensity / Innovation Performance (IIP) and Export Performance (IEP) under make-to-order strategy and on design specifications. It does not therefore work in product design in the strict sense. Each order is a new project to be managed, which leaves less room for creativity because of an established set of specifications. This operating mode is a brake on identifying and penetrating new markets because the prospective approach of anticipating customer needs when they are not formulated in the form of specifications is not at the heart of the company's practices. On the other hand, the company relies on highly qualified personnel to suggest ways of development and improvement to its customers during the various projects.

This case therefore highlights the importance of the qualification of human resources for high-tech sectors to be able to make proposals. This does not necessarily imply a strong innovation and export capability, but it reflects an ability to react to customer demand, which is essential in this field. This requires, among other things, a strong capitalization of integrated knowledge within the company. In this case, a shared and collaborative platform has been set up, which is unusual in this type of small company. Company C9 is, therefore, not an extremely proactive company but its mode of operation and its sector of activity urges it to be reactive to its customers' needs and to know how to adapt to them.

As a counter example, company $\mathrm{C} 2$ is a low-tech company in the food industry. It sells processed products with low added value. It has the particularity of selling its products in several countries throughout the world and is able to adapt its products and therefore its manufacturing process for each of its target countries. Its assessment in terms of innovation and export is therefore very good, despite the fact that it shows very limited technological intensity. This is clearly reflected in its very balanced profile of innovation and export practices, with a weak point on project management (Figure 6).

More precisely, this company adapts its product range according to the standards of every country, according to the local consumption and packaging habits, but the company does not drastically modify its own products. Company C2's innovation activity results from its ability to adapt and develop its manufacturing process to best meet the needs of its customers and to stand out from the competition, but their products remain traditional and "Made in France" realizations. The company shows a proactive approach through its clear and long-term strategic positioning and its desire to constantly renew its product range. In general, demand plays a crucial role in these industries, and product differentiation is a 


\section{Are High-Tech Companies More Competitive Than Others? An Empirical Study of Innovative and Exporting French SMEs M. Enjolras, M. Camargo, and C. Schmitt}

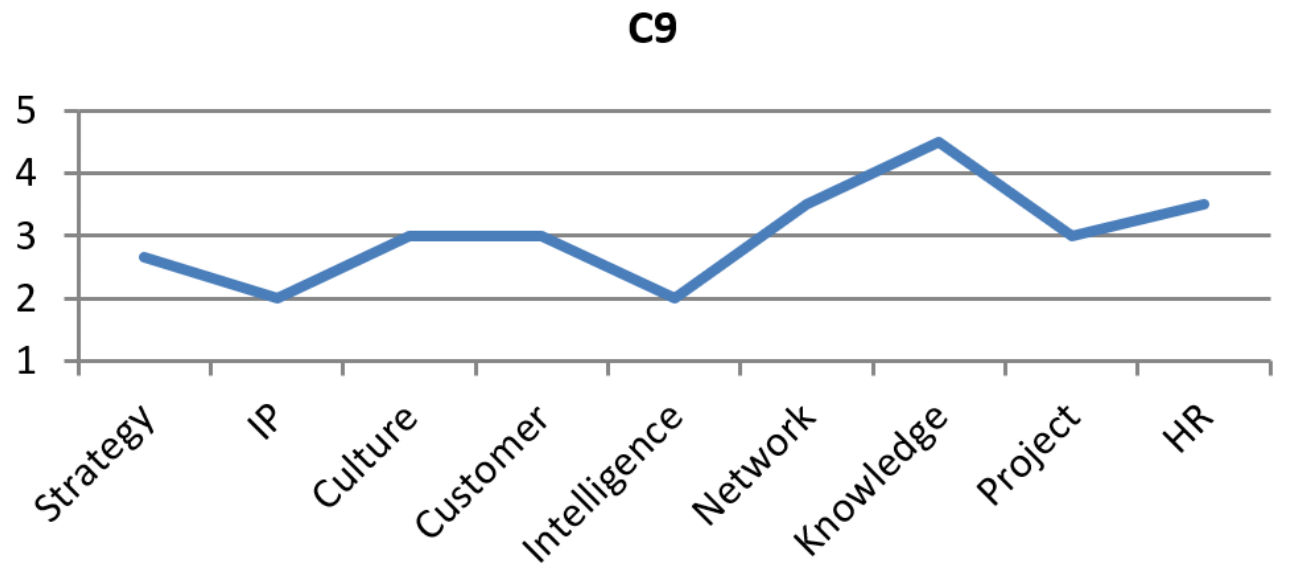

Figure 5. Practice profile of company C9

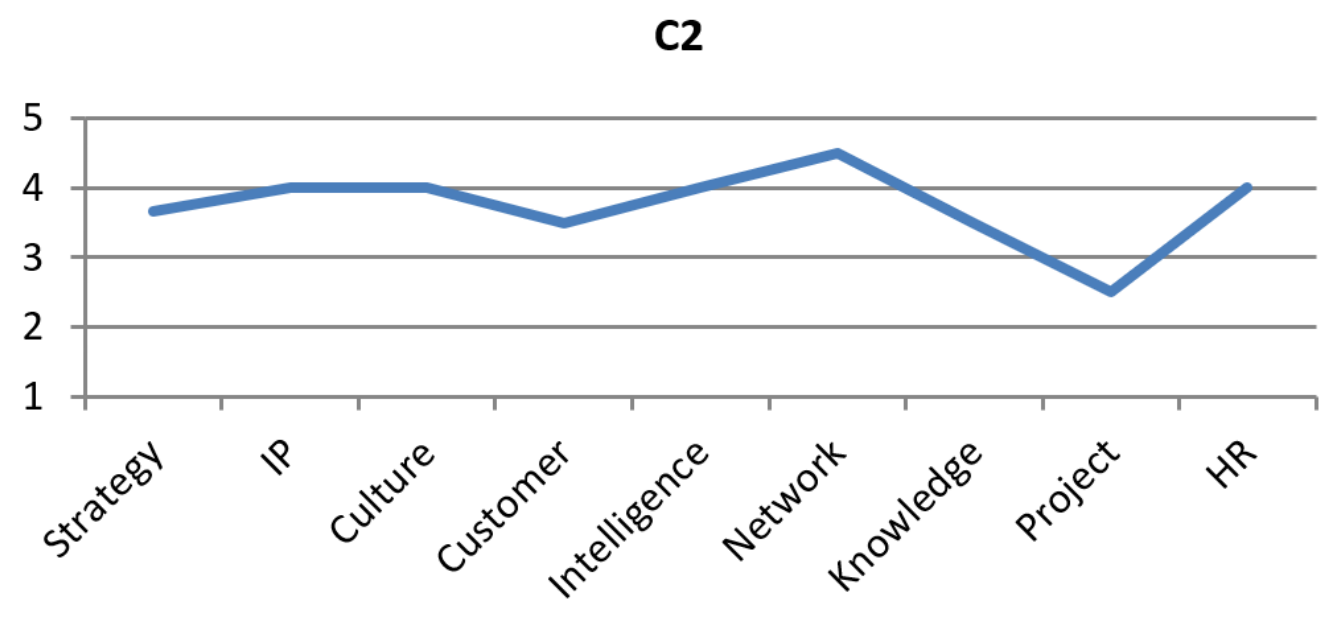

Figure 6. Practice profile of company C2

powerful driver of innovation (von Tunzelmann \& Acha, 2006). So, its low technological intensity is therefore not a brake on its innovation and export capability. On the contrary, it is a factor influencing the manner how it manages the evolution of its processes and its international activities. This company does not make purely product innovation; it makes also process innovation.

This result highlights an interesting issue concerning the influence of technological intensity on the innovation and export capability of companies. This analysis shows that, in this specific sample of French SMEs, a high technological intensity does not imply a high innovation and export capability. So, our first hypothesis (H1) is not validated in this specific context. Moreover, it seems to confirm that low-tech firms and high-tech firms show different behaviour and profiles in terms of internal practices, as mentioned in our third hypothesis (H3), as discussed in the next section.

H3: The way a company manages its innovation and export activities depends on its technological intensity. Specific profiles can be identified according to the internal practices in place within the companies.

In order to more precisely explore the observation from the previous illustrative cases, a second PCA was conducted with the goal of identifying some potential correlations between the technological intensity and the maturity of firms related to the innovation and export practices (Figure 7).

In order to conserve a good representativeness of the variables, this analysis was divided into two loading plots. The first one shows the correlations between the 


\section{Are High-Tech Companies More Competitive Than Others? An Empirical Study of Innovative and Exporting French SMEs M. Enjolras, M. Camargo, and C. Schmitt}

Technological Intensity and the practices of "Networking", "Knowledge Management", "Project Management", and "Human Resources Management". The second loading plot shows the correlations between the Technological Intensity and the practices "Strategy", "Intellectual Property", "Culture", "Customer Relationship Management", and "Technical and Commercial Intelligence".

The main finding of this analysis concerns the positive correlation between Technological Intensity and the Knowledge Management practice (the loading plot on the left side of Figure 7). These two variables are oriented in the same direction. However, the global representativeness of the variables for the first loading plot is not high (66\% of the data are represented on this plot). Indeed, the variable Technological Intensity is not so close to the circle. So, the results of this PCA analysis have to be balanced. Nevertheless, the data analysis put forward a potential trend linking the technological intensity of firms with their maturity in terms of knowledge management. In order to confirm this trend, the average profiles of the companies belonging to each technological category have been calculated (Figure 8).

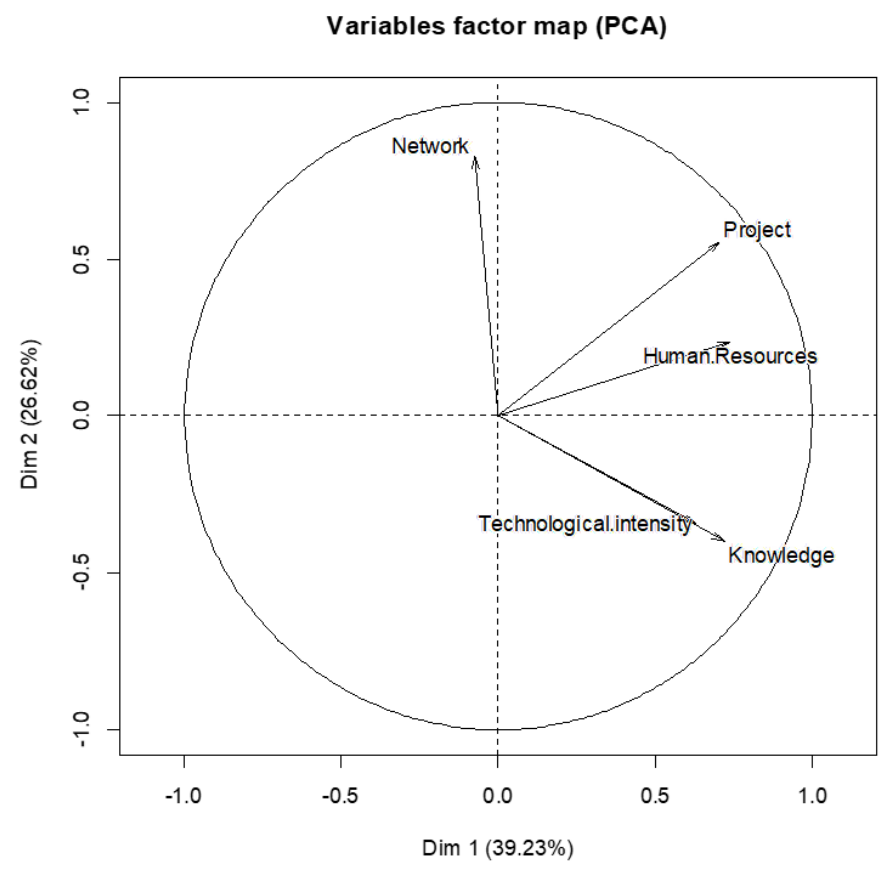

Note that the four profiles in Figure 8 are quite different, but these differences are not necessarily related to technological intensity. The most mature companies in terms of internal practices are not always those that are categorized as high-tech firms. It strengthens the previous observation according to which our panel rejects the first hypothesis (H1).

More precisely, Figure 8 highlights that, unlike other practices, the Knowledge Management practice shows a maturity level strictly in accordance with the level of technological intensity. The most mature companies are those in the high-tech category and vice versa. It confirms the trend identified through the PCA analysis (Figure 7).

This correlation can be illustrated with several cases in our panel. For example, the high-tech firm C9 put in place a collaborative and integrative platform in order to capitalize and share its knowledge within all the company. This kind of practice is rather unusual within small businesses. The medium-high-tech firm $\mathrm{Cl}$ experienced a global process of knowledge formalization and capitalization through a standard procedure. This firm

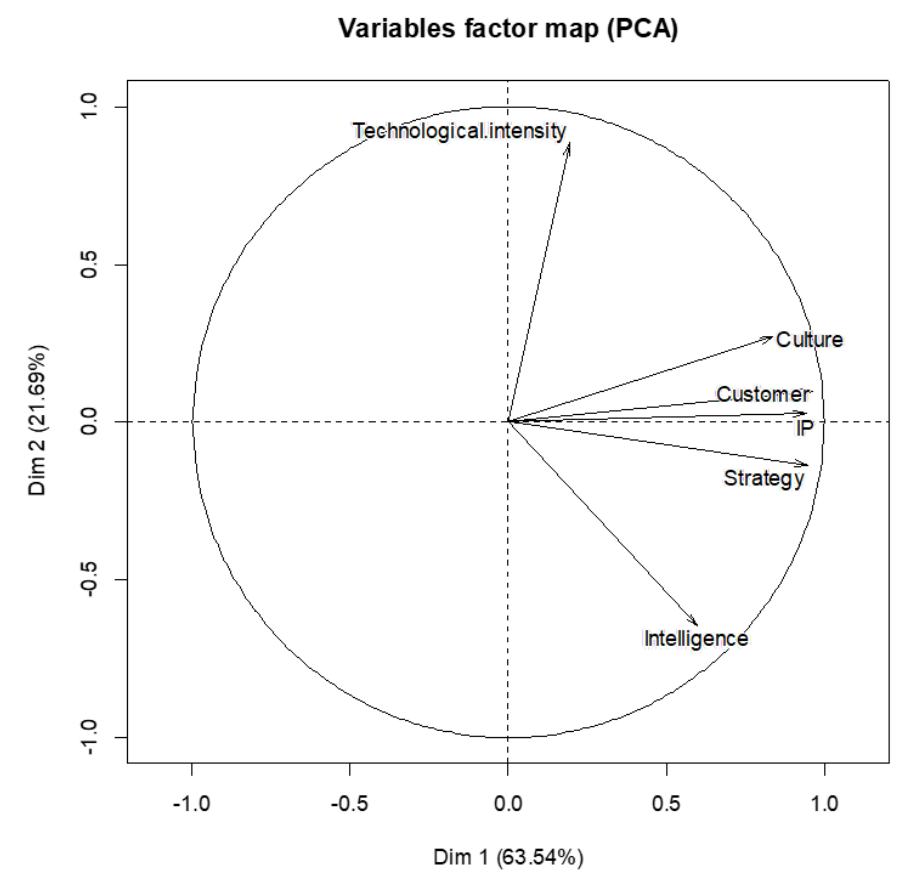

Figure 7. PCA loading plots of Technological Intensity / Practices 


\section{Are High-Tech Companies More Competitive Than Others? An Empirical Study of Innovative and Exporting French SMEs M. Enjolras, M. Camargo, and C. Schmitt}

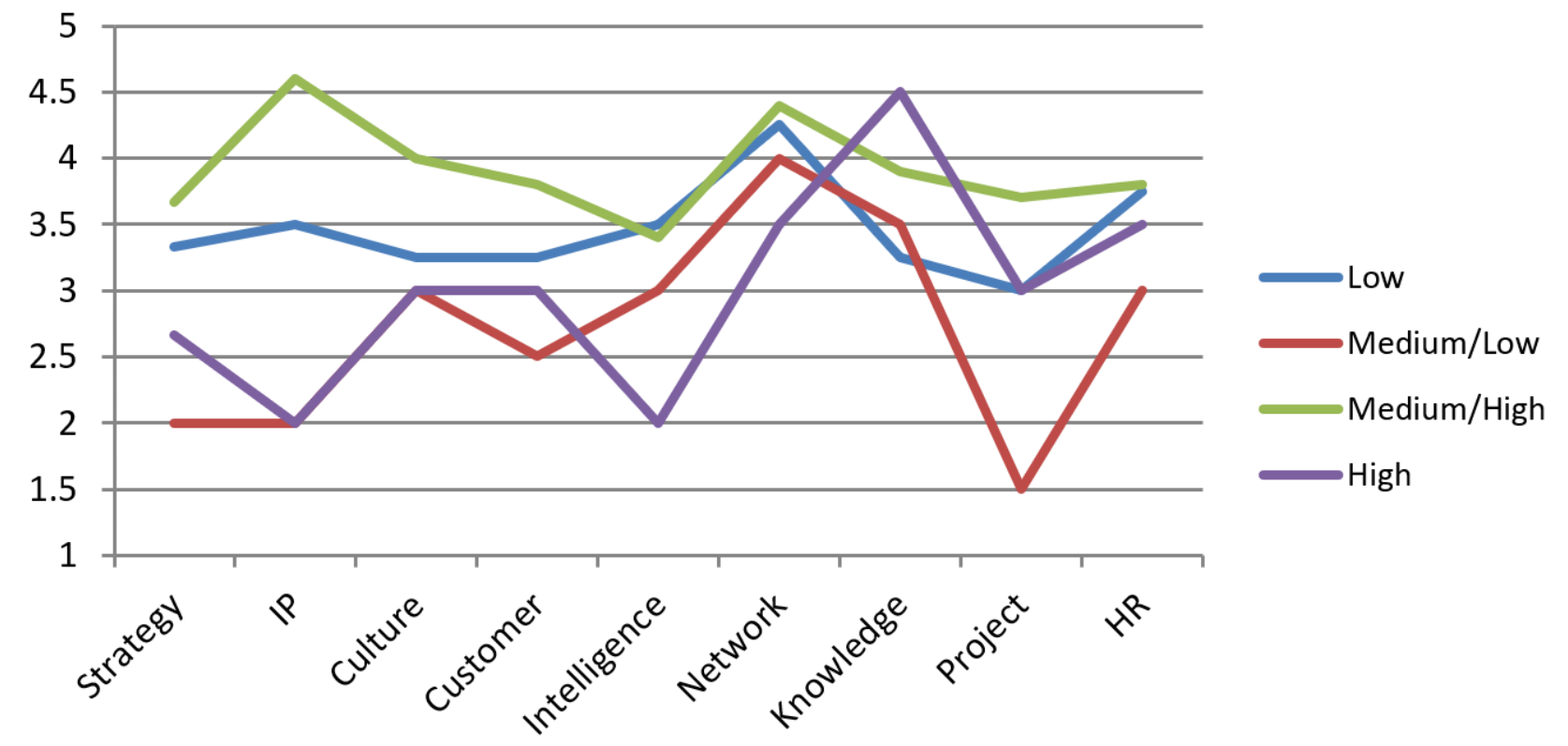

Figure 8. Average company profiles across the four categories of technological intensity

is not considered as a small business because of its important workforce. However, knowledge capitalization is a crucial point of its global strategy. Finally, firm C6 shows a medium-high technological intensity and put in place a sharing process of its knowledge because of its international multi-site configuration. Working in the biotechnology sector and being "born global", this very small company uses a collaborative platform to make its knowledge accessible simultaneously in several places in the world and over several time zones.

This observation could be explained by several arguments. First, innovative new products had the greatest impact on revenue growth of high-tech firms when knowledge assets were high. This is consistent with the resource-based view considering that knowledge is a competitive resource within the firm. So, for high-tech companies, this knowledge management is essential because it conditions the success and continuity of innovations as well as a high level of exports (Sandu \& Ciocanel, 2014). On the other hand, low-tech industries appear to be less exposed to changes, and when they appear, the changes are less extreme and less pronounced. So, for them, knowledge management is less critical, especially with regard to the adaptability of human resources (Thornhill, 2006). Whereas high-tech companies have a large number of "non-productive" employees who hold and yet produce the majority of the necessary knowledge, low-tech companies have a larger number of "productive" employees who produce and transfer their own knowledge, which is closer to "know-how" and therefore more difficult to capitalize on a formal way (Aydalot \& Keeble, 2018).

Knowledge management therefore appears to be a critical point for high-tech companies because it conditions their functioning and growth. In particular, it is a critical point to be able to adapt to the changing context of their environment. For low-tech companies, the capitalization of knowledge potentially takes a different form, closer to human resources management or even companionship in order to maintain know-how within the company.

\section{Conclusions}

Generally speaking, innovation, international development, and growth are associated with companies from high-tech sectors. However, many examples show that growth is not just reserved for large digital multinationals. Born globals, high-growth firms, and small structures are also strong players in the global economy, and companies in traditional or low-tech sectors are not left out. Thus, the ambition of this article was to conduct a multiple case study with French innovative and exporting SMEs to study the relationship between technological intensity and innovation and export capability. A qualitative approach was used, supported by statistical 


\section{Are High-Tech Companies More Competitive Than Others? An Empirical Study of Innovative and Exporting French SMEs M. Enjolras, M. Camargo, and C. Schmitt}

multivariate tools in order to build a set of illustrative cases to support or refute trends into our SMEs panel. Based our findings, we offer several conclusions.

First of all, it would seem that, contrary to what is traditionally accepted, the technological intensity of an SME would not be directly linked to the type of innovation it proposes. Indeed, within our panel, high-tech SMEs were more product-oriented, whereas low-tech companies implemented process innovations. However, this is not true for biotechnology companies. The type of innovation would therefore be related more to the business sector than to the technological intensity.

On the other hand, the panel studied refutes the hypothesis that the most innovative and exporting companies are those from high-tech industries. Indeed, low technology companies show very good performance in terms of innovation and international activities. However, the differentiating element between highand low-tech seems to be the way companies manage their innovation process and their international activities. Indeed, high- and low-tech SMEs show different profiles in terms of innovation and export management practices. The routines in place within companies are different, and this is particularly evident in the case of knowledge management. Despite their small size, hightech SMEs have implemented very successful knowledge management practices, whereas low-tech companies are not as mature on these particular issues.

This study therefore highlights various questions in our current understanding of technological intensity. First, the definition of technological intensity in the form of R\&D expenditure proposed by the OECD can be questioned because, even if the return on investment on such expenditure may be limited in the case of low-tech firms in view of the less significant competitive pressure they suffer (Hansen \& Winther, 2014), these investments nevertheless remain important for setting up a long-term innovation approach (Kafouros et al., 2008). $R \& D$ expenditure is therefore not necessarily representative of a technological intensity, but rather of a proactive vision of companies. Second, the technological vision of innovation should also be questioned because this study shows that innovations in terms of process, organization, or marketing are also vectors of growth for companies, whatever their size and technological intensity. Finally, the maturity of a company in terms of innovation and international activity must be put into perspective according to these specific characteristics, namely in the context of this study its business sector and its technological intensity. Different typical innovation and export profiles could thus be built in order to highlight the specificities of contingent factors such as these ones (business sector, size, technological intensity, export turnover, etc.).

Finally, we acknowledge the limitations of this study and the need for further research. Our objective was to use quantitative tools in support of a qualitative approach to highlight trends within the database. This article represents an initial, exploratory approach before a larger campaign of data gathering, and we encourage others to contribute further studies to enhance our understanding of the relationship between the technological intensity of SMEs and their growth potential.

\section{Acknowledgements}

This work was supported partly by the French PIA project “Lorraine Université d'Excellence" (Reference ANR15-IDEX-04-LUE). 


\section{Are High-Tech Companies More Competitive Than Others? An Empirical Study of Innovative and Exporting French SMEs M. Enjolras, M. Camargo, and C. Schmitt}

\section{About the Authors}

Manon Enjolras is a Researcher in Industrial System Engineering at the Université de Lorraine in Nancy, France, where she is working on the innovation and internationalization capabilities of small and medium-sized enterprises (SMEs). She also holds a $\mathrm{PhD}$ from the Université de Lorraine in addition to an Engineering degree in Project Management and Innovation Management and a Master's degree in Innovation Management, both from the Université de Lorraine's Ecole Nationale Supérieure en Génie des Systèmes et Innovation (ENSGSI). Her main research interests are related to multicriteria decisionmaking and multivariate data analysis methodologies applied to SMEs, especially the capability evaluation metrics for innovation, internationalization, and the protection of industrial property.

Mauricio Camargo is a Professor at the Ecole Nationale en Génie des Systèmes Industriels (ENSGSI) at the Université de Lorraine in Nancy, France. He holds a Bachelor's degree in Chemical Engineering from the Universidad Nacional de Colombia and a $\mathrm{PhD}$ on Automatics of Industrial and Human Systems at the Université de Valenciennes et de Hainaut Cambresis in France. Professor Camargo's main research interests are new product development, design-to-cost, and design and interdisciplinarity. His recent research concerns the application of multi-objective evolutionary techniques to evaluate product performance and innovativeness.

Christophe Schmitt is a Professor in Entrepreneurship at the Université de Lorraine (IAE de Metz and CEREFIGE), he holds the research Chair "Entreprendre", and he is responsible for PeeL (the Lorraine Student Entrepreneurship Pole). He is also an Associate Professor at the Louvain School of Management in Belgium and at the "Haute Ecole de Gestion" of Fribourg in Switzerland. His articles and books mostly concern the notion of value design and knowledge building for action as well as the development of entrepreneurial practices.

\section{References}

Aydalot, P., \& Keeble, D. (Eds.) 2018. High Technology Industry and Innovative Environments: The European Experience. Abingdon, UK: Routledge.

https://doi.org/10.4324/9781315149769

Barney, J. 1991. Firm Resources and Sustained Competitive Advantage. Journal of Management, 17(1): 99-120.

https://doi.org/10.1177/014920639101700108

van Beers, C., \& Zand, F. 2014. R\&D Cooperation, Partner Diversity, and Innovation Performance: An Empirical Analysis. Journal of Product Innovation Management, 31(2): 292-312.

https://doi.org/10.1111/jpim.12096

Cannone, G., \& Ughetto, E. 2014. Born Globals: A Cross-Country Survey on High-Tech Start-Ups. International Business Review, 23(1): 272-283.

https://doi.org/10.1016/j.ibusrev.2013.05.003

Carlin, W., Glyn, A., \& van Reenen, J. 2001. Export Market Performance of OECD Countries: An Empirical Examination of the Role of Cost Competitiveness. The Economic Journal, 111(468): 128-62.

https://doi.org/10.1111/1468-0297.00592

Cassiman, B., Golovko, E., \& Martínez-Ros, E. 2010. Innovation, Exports and Productivity. International Journal of Industrial Organization, 28(4): 372-376.

https://doi.org/10.1016/j.ijindorg.2010.03.005

Colombo, M. G., Rossi-Lamastra, C., \& Matassini, B. 2016. The Organizational Design of High-Tech Entrepreneurial Ventures. Foundations and Trends in Entrepreneurship, 11(6): 427-523. https://doi.org/10.1561/0300000053

Demir, R., Wennberg, K., \& McKelvie, A. 2017. The Strategic Management of High-Growth Firms: A Review and Theoretical Conceptualization. Long Range Planning, 50(4): 431-456. https://doi.org/10.1016/j.lrp.2016.09.004

Dhanaraj, C., \& Beamish, P. W. 2003. A Resource-Based Approach to the Study of Export Performance. Journal of Small Business Management, 41(3): 242-261.

https://doi.org/10.1111/1540-627X.00080

Enjolras, M. 2016. Méthodologie d'analyse de la capacité à innover et à exporter des PME manufacturières et de procédés: Identification et caractérisation d'un espace commun en vue de l'élaboration d'un outil multicritères d'aide à la décision. Doctoral Thesis. Nancy, France: Université de Lorraine.

Enjolras, M., Camargo, M., \& Schmitt, C. 2016. SMEs' Innovation and Export Capabilities: Identification and Characterization of a Common Space Using Data Spatialization. Journal of Technology Management \& Innovation, 11(2): 56-69. https://doi.org/10.4067/S0718-27242016000200006

Fagerberg, J. 1994. Technology and International Differences in Growth Rates. Journal of Economic Literature, 32(3): 1147-1175. https://www.jstor.org/stable/2728605

Filipescu, D. A., Prashantham, S., Rialp, A., \& Rialp, J. 2013. Technological Innovation and Exports: Unpacking Their Reciprocal Causality. Journal of International Marketing, 21(1): 23-38.

https://doi.org/10.1509/jim.12.0099 


\section{Are High-Tech Companies More Competitive Than Others? An Empirical Study of Innovative and Exporting French SMEs M. Enjolras, M. Camargo, and C. Schmitt}

Golovko, E., \& Valentini, G. 2011. Exploring the Complementarity between Innovation and Export for SMEs Growth. Journal of International Business Studies, 42(3): 362-380.

https://doi.org/10.1057/jibs.2011.2

Guillou, S. 2006. Les industries de haute technologie de la zone euro et des États-Unis. Revue de l'OFCE, 98(3): 37-76. https://doi.org/10.3917/reof.098.76

Hansen, T., \& Winther, L. 2014. Competitive Low-Tech Manufacturing and Challenges for Regional Policy in the European Context-Lessons from the Danish Experience. Cambridge Journal of Regions, Economy and Society, 7(3): 449-470. https://doi.org/10.1093/cjres/rsu015

Hatzichronoglou, T. 1997. Révision des classifications des secteurs et produits de haute technologie. Paris: OECD.

Haudeville, B., \& Bas, C. L. 2016. L'innovation frugale: une nouvelle opportunité pour les économies en développement? Mondes en développement, 173(1): 11-28.

https://doi.org/10.3917/med.173.0011

Heidenreich, M. 2009. Innovation Patterns and Location of European Low- and Medium-Technology Industries. Research Policy, 38(3): 483-494.

https://doi.org/10.1016/j.respol.2008.10.005

Hirsch-Kreinsen, H., Hahn, K., \& Jacobson, D. 2008. The Low-Tech Issue. In H. Hirsch-Kreinsen \& D. Jacobson (Eds.), Innovation in Low-Tech Firms and Industries: 3-25. Cheltenham, UK: Edward Elgar Publishing.

https://doi.org/10.4337/9781848445055.00008

Hlady Rispal, M. 2016. Une stratégie de recherche en gestion. Revue française de gestion, 253(8): 251-266. https://doi.org/10.3166/RFG.253.251-266

Kafouros, M. I., Buckley, P. J., Sharp, J. A., \& Wang, C. 2008. The Role of Internationalization in Explaining Innovation Performance. Technovation, 28(1-2): 63-74. https://doi.org/10.1016/j.technovation.2007.07.009

Kirner, E., Kinkel, S., \& Jaeger, A. 2009. Innovation Paths and the Innovation Performance of Low-Technology firms-An Empirical Analysis of German Industry. Research Policy, 38(3): 447-458. https://doi.org/10.1016/j.respol.2008.10.011

Landesmann, M., \& Pfaffermayr, M. 1997. Technological Competition and Trade Performance. Applied Economics, 29(2): 179-196. https://doi.org/10.1080/000368497327254

Lever, J., Krzywinski, M., \& Altman, N. 2017. Points of Significance: Principal Component Analysis. Nature Methods, 14: 621-642. https://doi.org/10.1038/nmeth.4346

Lindman, M., Otero-Neira, C., \& Scozzi, B. 2008. Low-Tech, Smalland Medium-Sized Enterprises and the Practice of New Product Development: An International Comparison. European Business Review, 20(1): 51-72. https://doi.org/10.1108/09555340810843690

Love, J. H., \& Roper, S. 2015. SME Innovation, Exporting and Growth: A Review of Existing Evidence. International Small Business Journal, 33(1): 28-48. https://doi.org/10.1177/0266242614550190

Mazzarol, T., \& Reboud, S. 2011. Innovation Management and Commercialisation: A Study of Low and High R\&D Intensity Firms from Australia and France. Paper presented at the 56th Annual ICSB World Conference, June 15-18, 2011, Stockholm, Sweden.
Mintzberg, H. 1979. The Structuring of Organizations. Englewood Cliffs, NJ: Pearson.

Mortensen, P. S. 2005. Oslo Manual: Guidelines for Collecting and Interpreting Innovation Data (3rd ed). Paris: OECD.

Okręglicka, M., Gorzeń-Mitka, I., \& Ogrean, C. 2015. Management Challenges in the Context of a Complex View - SMEs Perspective. Procedia Economics and Finance, 34: 445-452. https://doi.org/10.1016/S2212-5671(15)01653-6

Paul, J., Parthasarathy, S., \& Gupta, P. 2017. Exporting Challenges of SMEs: A Review and Future Research Agenda. Journal of World Business, 52(3): 327-342. https://doi.org/10.1016/j.jwb.2017.01.003

Pla-Barber, J., \& Alegre, J. 2007. Analysing the Link between Export Intensity, Innovation and Firm Size in a Science-Based Industry. International Business Review, 16(3): 275-293. https://doi.org/10.1016/j.ibusrev.2007.02.005

PME. 2011. PME 2011: Rapport sur l'évolution des PME. MaisonsAlfort, France: BPIFrance.

Raymond, L., \& St-Pierre, J. 2010. R\&D as a Determinant of Innovation in Manufacturing SMEs: An Attempt at Empirical Clarification. Technovation, 30(1): 48-56. https://doi.org/10.1016/j.technovation.2009.05.005

Reboud, S., Mazzarol, T., \& Soutar, G. 2014. Low-Tech vs High-Tech Entrepreneurship: A Study in France and Australia. Journal of Innovation Economics \& Management, 14(2): 121-141. https://doi.org/10.3917/jie.014.0121

Reichert, F. M., Torugsa, N., Zawislak, P. A., \& Arundel, A. 2016. Exploring Innovation Success Recipes in Low-Technology Firms Using Fuzzy-Set QCA. Journal of Business Research, 69(11): 5437-5441.

https://doi.org/10.1016/j.jbusres.2016.04.151

Sandu, S., \& Ciocanel, B. 2014. Impact of R\&D and Innovation on High-tech Export. Procedia Economics and Finance, 15: 80-90. https://doi.org/10.1016/S2212-5671(14)00450-X

Schumpeter, J. A. 1934. The Theory of Economic Development: An Inquiry into Profits, Capital, Credit, Interest, and the Business Cycle. Piscataway, NJ: Transaction Publishers.

Shefer, D., \& Frenkel, A. 2005. R\&D, Firm Size and Innovation: An Empirical Analysis. Technovation: 25(1): 25-32. https://doi.org/10.1016/S0166-4972(03)00152-4

Syms, C. 2008. Principal Components Analysis. In S. E. Jørgensen \& B. D. Fath (Eds.). Encyclopedia of Ecology: 2940-2949. Oxford: Academic Press.

Teece, D. J., Pisano, G., \& Shuen, A. 1997. Dynamic Capabilities and Strategic Management. Strategic Management Journal, 18(7): 509-533.

https://doi.org/10.1002/(SICI)1097-0266(199708)18:7<509::AIDSMJ882>3.0.CO;2-Z

Thornhill, S. 2006. Knowledge, Innovation and Firm Performance in High- and Low-Technology Regimes. Journal of Business Venturing, 21: 687-703.

https://doi.org/10.1016/j.jbusvent.2005.06.001

Tirole, J. 1988. The Theory of Industrial Organization. Cambridge, MA: MIT Press. 


\section{Are High-Tech Companies More Competitive Than Others? An Empirical Study of Innovative and Exporting French SMEs M. Enjolras, M. Camargo, and C. Schmitt}

von Tunzelmann, N., \& Acha, V. 2006. Innovation In “Low-Tech" Industries. In J. Fagerberg \& D. C. Mowery (Eds.), The Oxford Handbook of Innovation. Oxford: Oxford University Press. https://doi.org/10.1093/oxfordhb/9780199286805.003.0015

Uzunidis, D. 2016. Propaedeutics in the Theory of the Industrial Organisation: The SCP (Structure, Conduct, Performance) Model. Journal of Innovation Economics \& Management, 20(2): 197-215. https://doi.org/10.3917/jie.020.0197

Yin, R. K. 2013. Case Study Research: Design and Methods. Thousand Oaks, CA: SAGE Publications.

Zouaghi, F., Sánchez, M., \& Martínez, M. G. 2018. Did the Global Financial Crisis Impact Firms' Innovation Performance? The Role of Internal and External Knowledge Capabilities in High and Low Tech Industries. Technological Forecasting and Social Change, 132: 92-104.

https://doi.org/10.1016/j.techfore.2018.01.011

Citation: Enjolras, M., Camargo, M., \& Schmitt, C. 2019.

Are High-Tech Companies More Competitive Than

(cc) BY

Others? An Empirical Study of Innovative and Exporting

French SMEs. Technology Innovation Management

Review, 9(1): 33-48.

http://doi.org/10.22215/timreview/1210

Keywords: technological intensity, innovation, export, SMEs, multiple-case study 


\title{
The Effect of Digitalization on the Commercialization Process of High-Technology Companies in the Life Sciences Industry
}

\author{
Saheed A. Gbadegeshin
}

\author{
" Digital transformation is a long journey, and the" \\ path for digital transformation can be iterative, \\ evolutionary, revolutionary, or disruptive. \\ Pearl Zhu \\ Author of Digital Maturity
}

\begin{abstract}
This article examines how digitalization influences the commercialization of high technologies in the life sciences industry. It is based on a cross-case study focused on pharmaceutical, medical device, and e-health companies in Finland. Both company representatives and regional stakeholders were interviewed. The findings suggest that "digitalization" needs to be distinguished from "digitization" because both terms seem to be misused or used interchangeably. The findings also show that digitalization led to a concurrent implementation of commercialization processes. Furthermore, the findings revealed that digitalization positively influenced commercialization activities, especially information sourcing and management, various assessments, and official activities, big data creation, and activity routinization. It was also revealed that the creation of new sets of big data and fear of digital attacks are negative influences on digitalization. These findings make a theoretical contribution to the discourses on digitalization and commercialization, but they also provide insights for scientists, engineers, and life science companies.
\end{abstract}

\section{Introduction}

Digitalization is influencing almost every sphere of human activity. Indeed, digitalization has come to stay as the Fourth Industrial Revolution keeps evolving and impacting our lives in countless ways (Parviainen et al., 2017; Tihinen \& Kääriäinen, 2016). It influences communication patterns, working styles, transportation systems, and even manufacturing processes (Schwab, 2015; The Economist, 2012). It fuses many technologies and, thereby, it blurs the lines between different facets of everyday life. For example, physical products, digital services, and biological spheres are now intertwined (Gerlitz, 2015). This situation is changing every sphere of business operations and society's activities as a whole (Degryse, 2016).

However, despite the widespread impact of digitalization, scholarly studies on the subject are not yet common. Many of the writings that do exist are written by practitioners in form of reports, whitepapers, consulting firm service guides, and blogs. These articles centered on digital transformation and they are opinion-based (Parviainen et al., 2017). Few articles coming from academia have only focused on digital technologies, and their business model, business operation, and users' experience (Henriette et al., 2015).

With respect to the limited number of scholarly studies on digitalization, this article aims to reduce the gap and to provide more knowledge about how it affects the commercialization process of high technologies in the life sciences industry. This industry is well known for its strict regulations, its expensive research and development $(\mathrm{R} \& \mathrm{D})$, and its unique and complex development process (Kaitin, 2010; Khilji et al., 2006; Maak \& Wylie, 2016; McKenzie et al., 2006). Within this industry, three sectors were the focus of the current study: the pharmaceutical sector (specifically, new drug development), the medical device sector, and the e-health sector. 


\section{The Effect of Digitalization on the Commercialization Process of High-Technology Companies in the Life Sciences Industry Saheed A. Gbadegeshin}

These sectors were selected because their technologies are complex, highly innovative, $R \& D$ dependent, and resource intensive (Eurostat, 2016; Steenhuis \& de Bruijn, 2006). These features represent characteristics of high technologies (Solberg et al., 2008). Therefore, exploring digitalization and its influences on the commercialization process of the industry would provide in-depth knowledge, which is essential for the development of commercialization skills (Gbadegeshin, 2019). Thus, the following research question was explored:

\section{How does digitalization influence the commercial- ization process of high-technology companies in the life sciences industry?}

To answer this question, the article employed a qualitative research method through a cross-case study analysis. Stakeholders of the industry, which consisted of entrepreneurs, business advisors, government officers, and university technology transfer officers (UTTOs) were interviewed, and the resulting data were analyzed with a thematic method.

The rest of the article is structured as follows: literature overview, methodology, findings and discussion, and conclusion. The literature overview section discusses digitalization and commercialization processes in the life sciences industry. Next, the methodology section describes the interview and data analysis procedures. The findings and discussion section explains the results of the article and their relationship with previous studies. The final section outlines the study's contribution and areas for further research.

\section{Literature Overview}

\section{Digitalization}

"Digitalization" is often interchangeably used with "digitization". Both concepts are related, but they denote different things. Digitalization is an organization of several and diverse social life spheres via digital communication technologies, whereas digitization is a conversion of analogue information into digital forms. Scholarly, digitalization is a structuring of those technologies across: infrastructural, terminal, functional and rhetorical, and market convergence dimensions (Brennen \& Kreiss, 2016), process, organization, business domain (Parviainen et al., 2017), industries (Tihinen \& Kääriäinen, 2016), and the entire economy and society levels (Degryse, 2016; Parviainen et al., 2017). Deductively, in this article, digitalization refers to the use of any digitalization technology on any part of commercialization activities of companies.
Furthermore, digitalization technologies consist of artificial intelligence (AI), robots, automation, Internet of Things, big data, 3D printing, autonomous vehicles, drones, cyber-weapons, surveillance (Brennen \& Kreiss, 2016; Degryse, 2016: 19; Schwab, 2015), nanotechnology, biotechnology, material science, energy storage, and quantum computing (Manyika et al., 2013; The Economist, 2012). Others are: blockchain, smart cities, brain-inspired computing, social computing, cloud computing, smart grids, digital circuits, factory automation, fuzzy logic, expert systems, agents and multi-agent systems, natural language processing, data mining, sentiment analysis, human-computer interaction, image processing, geographic information systems, video analysis, medical diagnosis, segmentation techniques, augmented reality, virtual reality, satellite communication systems, 5G network evolutions, biometrics, electronic data interchange, cryptocurrencies, e-learning, e-business, digital marketing, and virtual organizations (Gbadegeshin, 2019).

The primary motives for the use of digitalization by industries are to reduce cost (Manyika et al., 2013), enhance performance (Markovitch \& Willmott, 2014), promote internal efficiency (Parviainen et al., 2017), improve smart production process (Gerlitz, 2015), add value to a supply chain (Tihinen \& Kääriäinen, 2016), create a new product or service (Degryse, 2016), adapt to new changes (Henriette et al., 2015), manage competition, and stimulate demand (Sabbagh et al., 2012). Parviainen and colleagues (2017) explain that:

"The potential benefits of digitalization for internal efficiency include improved business process efficiency, quality, and consistency via eliminating manual steps and gaining better accuracy. Digitalization can also enable a better real time view on operation and results, by integrating structured and unstructured data, providing better views on organization data, and integrating data from other sources. Furthermore, digitalization can lead to better work satisfaction for employees through automation of routine work, thus freeing time to develop new skills. Digitalization also improves compliance via standardization of records and improves recovery via easier backups and distribution of storage."

Digitalization has been employed in the life sciences industry since the introduction of process analytical technology (which was proposed by the Food and Drug Administration of the United States). The Process analytical technology entails online measurements, 


\section{The Effect of Digitalization on the Commercialization Process of High-Technology Companies in the Life Sciences Industry Saheed A. Gbadegeshin}

real-time control, risk analysis, application of statistical and multivariate analyses, laboratory automation, miniaturization, design of experiments, and use of physical organic chemistry (McKenzie et al., 2006). An example is the use of a high-throughput screening (HTS) tool. This tool plays significant roles in miniaturization, automation, and parallelization of pharmaceutical processes (Bhambure et al., 2011). In fact, Bhambure and colleagues (2011) conclude that: "We are confident that this will occur over the next decade and that the widespread of HTS tools and approaches will dramatically change how we perform the various activities that are required for product and process development and commercialization."

The situation is fast approaching, as it is shown in the pharmaceutical landscape that, by 2025, there will be an intervention treatment instead of current prevention treatment. This need would serve as a driver and it would compel the sector to improve its commercialization (Tierney et al., 2013). Thus, most major players in the sector are changing their present $R \& D$ practices (Kaitin, 2010). Therefore, it is important to understand the application of digitalization on the commercialization activities, for example, through the current study.

\section{The commercialization process in the life sciences} industry

The commercialization process consists of several activities for transforming new innovations into products or services (Fontes, 2005; Meyers, 2009; Speser, 2008). It is a way of bringing new technologies to the market (Pellikka \& Malinen, 2011) so that returns can be made on $\mathrm{R} \& D$ investments (Cornford, 2002) or to make the technologies beneficial for society (Nissen et al., 2015). To achieve these returns and benefits, there must be an efficient channel and a cost-effective means to transfer the innovations from research institutes to commercial-oriented organizations (Nilsson et al., 2006). The efficient channel refers to appropriate commercialization methods (Gbadegeshin, 2017a), which depends on the sector's process. The typical commercialization process in the life sciences industry is complex, long, and unique (Khilji et al., 2006). Thus, scholars have developed different frameworks, for example, a stage-gate model, to facilitate the process (Soenksen \& Yazdi, 2017). Because this study is focused on new drug development, medical devices, and e-health companies, their commercialization processes are briefly explained below.

First, the commercialization process of new drug development is typically grouped into three phases: 1) prelaunch, 2) marketing and sales, and 3) post-exclusivity.
In the phase, pre-launch, $R \& D$, clinical tests, and clinical trials are conducted. In the second phase, marketing and sales, new products are sold. A sale usually involves the transfer of exclusive intellectual property (IP) to a large pharmaceutical company. The last phase, post-exclusivity, occurs when the new product is widely available to the populace and can be copied by competitors (European Commission, 2009). However, this is not the only way to envision the commercialization process in the life sciences industry. The process also can be divided into three phases that correspond to discovery, pre-clinical testing, and post-discovery. Alternatively, these phases can be described as five stages: 1) basic research, 2) innovation and invention, 3) early-stage technology development, 4) product development, and 5) production and marketing (Khilji et al., 2006). Furthermore, Sternitzke (2010) identifies only two phases in the commercialization process: 1) early research and preclinical and 2) clinical. Additionally, Dogra and colleagues (2013) group the process into four phases, but they further break down the process into sub-phases. For example, the sub-phases of discovery are research target, biological evaluation, integrated research, candidacy, drug formation, and patent filing. All these various models show that the commercialization process may be conceptualized with different phases and different names, but there are similarities, especially when it comes to discovery and clinical tests. In Figure 1, the various models described above are combined into a generalized new drug development commercialization process that has six main stages.

Second, consider the commercialization process for medical devices. Despite the diversity of devices, many producers employ a stage-gate model. The process typically consists of five stages: 1) initiation, 2) formulation, 3) design and development, 4) final validation, and 5) product launch and post-launch evaluation (Pietzsch et al., 2009). Similarly, the process can be grouped into discovery, incubation, and acceleration (Holzleitner, 2015), or into discovery and identification of technological opportunity, exploitation of commercial opportunity, and development of the technological product (Abd Rahim et al., 2015). More comprehensively, the process can be broken down into nine steps: 1) basic and applied science, 2) application idea, initial technical, and economic viability, 3) scanning and creation of potential alliances, 4) identification of specific need of target market, 5) customization of R\&D - designing and prototyping, 6) customer testing and experimentation, 7) verification of relating policies, 8) development of a pilot plant, and 9) final customer testing. These steps have three tiers, which include basic research, broad application of basic 


\section{The Effect of Digitalization on the Commercialization Process of High-Technology Companies in the Life Sciences Industry Saheed A. Gbadegeshin}

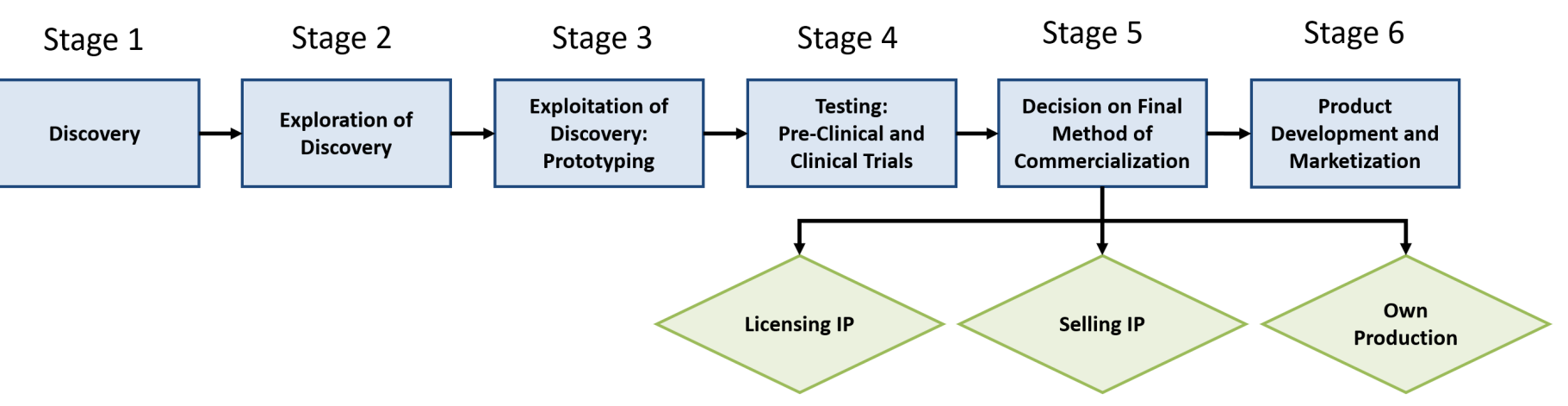

Figure 1. A generalized new drug development (pharmaceutical) commercialization process

research, and identification of specific application (Maine and Garnsey, 2007). Taken together, these various models can be generalized into the process shown in Figure 2.

Third, e-health is described as the use of information and communication technology (ICT) to link and educate healthcare stakeholders (such as governments, healthcare providers, and patients). It is the use of ICT to promote delivery of high-quality services in a healthcare system. It also includes the promotion of efficiency and effectiveness of healthcare system management (World Health Organization, 2003). E-health has an impact on patients' lives, especially those who need intensive healthcare services, such as the elderly or people with disabilities or chronic illnesses (Kumar et al., 2013; Silva et al., 2015). Other terms use synonymously with (or as subcategories of) e-health are mhealth (Kumar et al., 2013; Istepanaian \& Zhang, 2012), telehealth (Cho et al., 2008), telematics (Silva et al., 2015), and telemedicine (Silva et al., 2015). E-health consists of medical applications, wearable sensors, mobile devices, and health records (Silva et al., 2015). Despite the importance of e-health, there are few studies on how e-health innovations move from their origins to sustainable market acceptability. Academic work discussing the migration of an e-health idea to the marketplace is rare (Cho et al., 2008). Moreover, many initiatives and projects on e-health fail due to improper or insufficient analyses of business models (Mettlera \& Eurich, 2012; Cho et al., 2008). To address e-health challenges, Cho and colleagues (2008) present a framework that shows four stages in the commercialization process of e-health: 1) adoption, 2) implementation, 3) commercialization, and 4) diffusion. It is shown in Figure 3.

Considering all the above processes, it can be noted that they imply a stage-gate model. This assertion seems to be common for technology commercialization in which an invention or innovation comes from a research institute (e.g., a university) (Al Natsheh et al., 2013; Bradley et al. 2013). However, following the stages in a strict and orderly fashion may not necessary (Al Natsheh et al., 2014; Gbadegeshin, 2017b), because simultaneous development of product and market is an essential step in the commercialization process nowadays. For example, developing a product and its market simultaneously is common in the commercialization of medical devices such as microfluidic devices (Volpatti \& Yetisen, 2014) and e-health applications (Mettlera \& Eurich, 2012).

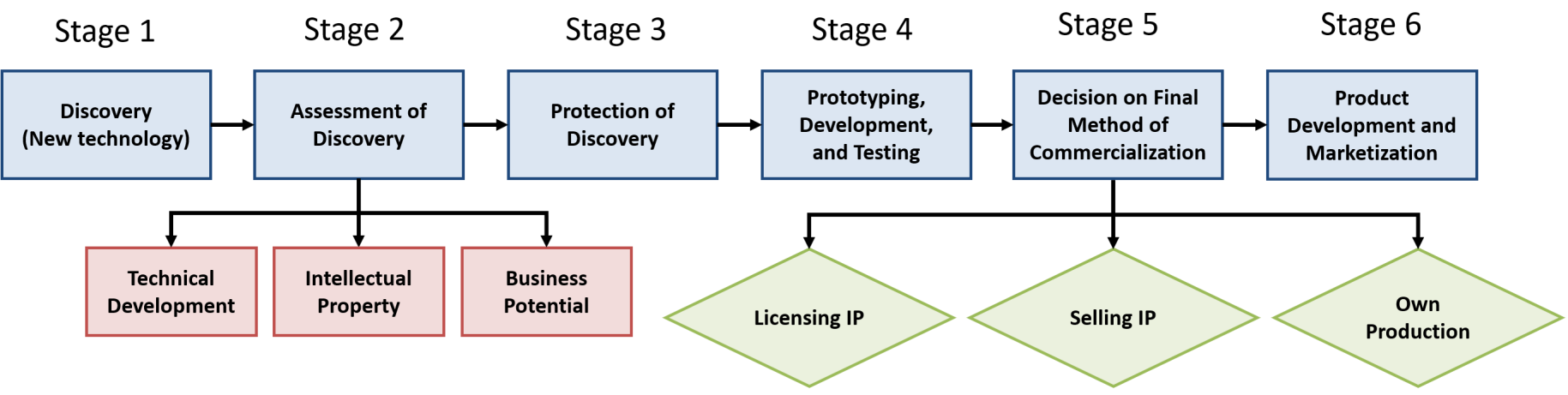

Figure 2. A generalized medical device commercialization process 


\section{The Effect of Digitalization on the Commercialization Process of High-Technology Companies in the Life Sciences Industry Saheed A. Gbadegeshin}

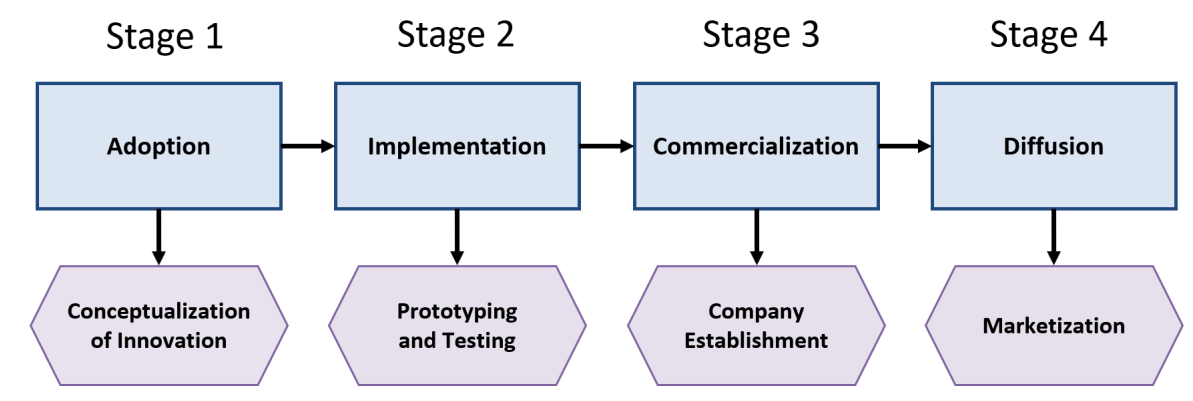

Figure 3. The e-health commercialization process (Adapted from Cho et al., 2008)

\section{Methodology}

A case study method is recommended to be used in order to facilitate mutual understanding of the commercialization process (Gaubinger et al., 2012; Pellika, 2014; Prebble et al., 2008; Siegel et al., 2004; Walsh, 2012) and to provide an in-depth knowledge on a specific phenomenon (Denzin \& Lincoln, 2000; Yin, 2003), especially for business-related empirical studies (Eriksson \& Kovalainen, 2008). A cross-case study sub-method, otherwise known as multiple case analysis, was used to compare and contrast different case studies so that new knowledge can be derived from them (Eisenhardt, 1989; West \& Oldfather, 1995). The details of the methodological process used in this study are presented in the following subsections.

Interview questions, interviewee selection, and procedure Based on the research question of this study, interview questions were developed for each of sectors. The questions had the same structure, which included background, ethical, and research questions. The background questions consisted of academic and professional information, entrepreneurial experience, or company history, and samples of assisted companies. Likewise, the ethical questions were focused on confidentiality and the research questions focused on digitalization and commercialization. All interview questions were open-ended. The selection criteria for interviewees were: 1) an interviewee must be a life sciences stakeholders, 2) they must have more than 10 years' experience in the industry, 3) their present company or institution must be in the industry 4), and their company must operate internationally. The stakeholders, in these criteria, refer to diverse parties who engage in the life sciences industry such as companies, research institutes, and government agents. These criteria were based on recommendations from Prebble and colleagues (2008), Pellika (2014), and Lavoie and colleagues (2017) who suggested that case study participants should represent different stakeholders within the concerned industry. With these criteria, a list of companies was compiled from a region in Finland by contacting pharmaceutical, medical device, and e-health companies, a life sciences park, university technology transfer office (UTTO), and a national organization for innovation funding. Sixteen interviewees participated: four C-level executives (CEOs or CTOs), three business development directors, four top-level staff members of UTTO, four senior business experts, and a director of a funding organization. All these stakeholders were selected because of their roles in the commercialization process and their knowledge about digitalization. The details of these interviewees are presented in Table 1.

The interviews were conducted and recorded at the companies or institutions. The interview sessions to the form of a dialogue because the investigator shared some opinions with the interviewees. Conducting interviews dialogically adds value to collected data (Silverman, 2011).

\section{Data analysis}

A thematic analysis was used because it produces core knowledge of a phenomenon (Braun \& Clarke, 2006; Eriksson \& Kovalainen, 2008). First, three themes were identified according to the research goals and question: 1) digitalization knowledge, 2) commercialization process, and 3) influences of digitalization on the process. Then each theme was analyzed according to the following steps: data familiarization, code generation, theme identification, theme review, themes renaming, and result report (Braun \& Clarke 2006). In following these steps, the recorded interviews were listened to five times and notes were made on each theme according to the interviewees. After that, the interviews were transcribed and were read attentively.

The codes were generated as follows. For theme 1, coding focused on interpretation, level of understanding of digitalization, and examples of digitalization. For theme 


\section{The Effect of Digitalization on the Commercialization Process of High-Technology Companies in the Life Sciences Industry Saheed A. Gbadegeshin}

Table 1. Background information of the interviewees

\begin{tabular}{|c|c|c|c|c|}
\hline & Current Position & Background & Life Sciences Sector & $\begin{array}{l}\text { Type of } \\
\text { Stakeholder }\end{array}$ \\
\hline 1 & $\mathrm{CEO}$ & $\begin{array}{l}\text { A medical doctor and a serial entrepreneur } \\
\text { with more than } 30 \text { years' experience }\end{array}$ & New drug development & Inventor \\
\hline 2 & CEO & A scientist with 20 years' experience & $\begin{array}{l}\text { New drug development } \\
\text { \& Medical device }\end{array}$ & Inventor \\
\hline 3 & CEO & $\begin{array}{l}\text { A scientist and a professional CEO who has } \\
\text { almost } 30 \text { years' experience }\end{array}$ & New drug development & Innovator \\
\hline 4 & CEO & $\begin{array}{l}\text { A physicist and an economist with } 20 \text { years' } \\
\text { experience, mostly as a manager and CEO }\end{array}$ & Medical device & Business developer \\
\hline 5 & $\begin{array}{l}\text { Head of Business } \\
\text { Development }\end{array}$ & $\begin{array}{l}\text { A professional marketer and business } \\
\text { developer who has } 25 \text { years' experience }\end{array}$ & $\begin{array}{l}\text { New drug development } \\
\text { \& Medical device }\end{array}$ & Business developer \\
\hline 6 & $\begin{array}{l}\text { Vice President, } \\
\text { Business Director }\end{array}$ & $\begin{array}{l}\text { A medical doctor and an economist who has } \\
\text { more than } 15 \text { years' experience }\end{array}$ & New drug development & Business developer \\
\hline 7 & $\begin{array}{l}\text { Senior Business } \\
\text { Advisor }\end{array}$ & $\begin{array}{l}\text { A computer scientist who has } 20 \text { years' } \\
\text { experience, mostly working on clinical } \\
\text { instruments and quality assurance for } \\
\text { medical devices }\end{array}$ & E-Health & Business developer \\
\hline 8 & $\begin{array}{l}\text { Senior Business } \\
\text { Advisor }\end{array}$ & $\begin{array}{l}\text { A chemist and an economist with } 40 \text { years' } \\
\text { experience from pharmaceutical and } \\
\text { biotechnology companies }\end{array}$ & All sectors & $\begin{array}{l}\text { Inventor and } \\
\text { Business developer }\end{array}$ \\
\hline 9 & $\begin{array}{l}\text { Senior Business } \\
\text { Advisor }\end{array}$ & $\begin{array}{l}\text { A physicist, a mathematician, and a serial } \\
\text { entrepreneur with } 30 \text { years' experience }\end{array}$ & All sectors & $\begin{array}{l}\text { Innovator and } \\
\text { Business developer }\end{array}$ \\
\hline 10 & $\begin{array}{l}\text { Senior Business } \\
\text { Advisor }\end{array}$ & $\begin{array}{l}\text { A pharmacist and a biochemist with } 30 \\
\text { years' experience }\end{array}$ & $\begin{array}{l}\text { New drug development } \\
\text { \& Medical device }\end{array}$ & Business developer \\
\hline 11 & $\begin{array}{l}\text { Executive Director of } \\
\text { Health and Wellbeing }\end{array}$ & A biotechnologist with 25 years' experience & All sectors & Business developer \\
\hline 12 & $\begin{array}{l}\text { Senior Business } \\
\text { Advisor }\end{array}$ & A biochemist with 40 years' experience & $\begin{array}{l}\text { New drug development } \\
\text { \& Medical device }\end{array}$ & Business developer \\
\hline 13 & $\begin{array}{l}\text { Business Development } \\
\text { Manager }\end{array}$ & $\begin{array}{l}\text { A biochemist and a pharmacologist with } \\
\text { more than } 20 \text { years' experience }\end{array}$ & All sectors & Business developer \\
\hline 14 & Innovation manager & $\begin{array}{l}\text { A chemist and a pharmacologist with more } \\
\text { than } 10 \text { years' experience }\end{array}$ & All sectors & Business developer \\
\hline 15 & Innovation manager & $\begin{array}{l}\text { An economist and a business administrator } \\
\text { with more than } 10 \text { years' experience }\end{array}$ & All sectors & Business developer \\
\hline 16 & Innovation manager & $\begin{array}{l}\text { A biochemist with more than } 10 \text { years' } \\
\text { experience }\end{array}$ & All sectors & Business developer \\
\hline
\end{tabular}




\section{The Effect of Digitalization on the Commercialization Process of High-Technology Companies in the Life Sciences Industry Saheed A. Gbadegeshin}

2, coding focused on stages and activities of the commercialization process of each life sciences sector. And, for theme 3, coding focused on the influences of digitalization on the process for each sector. The generated codes were labelled "indicators" (to avoid confusion with the "themes") and summarized. Then, the indicators were reviewed in relation to the goals and the research question of the article. This review produced "tentative results", which were refined by giving a relevant and intuitive name. An example of the tentative results is presented in Appendix 1. The last step was done by comparing each life sciences sector. Figure 4 details the entire research process.

\section{Findings and Discussion}

\section{Digitization or digitalization?}

It was evident that people interchangeably used "digitization" to mean "digitalization". As Brennen and Kreiss (2016), Degryse (2016), and Parviainen and colleagues (2017) explained, digitalization is the application of information and communication technologies to various spheres of human activity; whereas, digitization is the transformation of analogue pieces of information to digital format. Thus, digitization is a part of digitalization. In the current study, it was found that the participants misused both terms. The examples they offered made it clear that there were using the term digitization to denote digitalization. In fact, their examples revealed that digitalization had penetrated the life sciences industry more than it was previously stated in the work of Bhambure and colleagues (2011). Furthermore, it was noted older CEOs, business experts, university technology transfer officers, and a funding agency director appeared to understand the influences of digitalization on the industry better than younger ones, because they explained differences between before and after the advent of digitalization with clear examples. Their examples include cloud computing, factory automation, expertise management systems, data mining, image processing, video analysis, medical diagnosis, segmentation techniques, biometrics, digital marketing, and virtual organizations.

The above results revealed that there is a need to clarify the difference between the terms, because if the study participants, who are highly educated, could misuse the terms, it might be even more difficult for laypeople to understand the difference between the terms. Therefore, from the examples given by the scholars, the practitioners, and the participants of this study, digitalization is more comprehensive than digitization and it refers to the application of any digital technologies to any human activities, such as personal life, social, economic, and political activities. Meanwhile, digitization is one of the processes of digitalization that converts analogue inputs to digital outputs. Therefore, the difference between the terms is that digitization is a process of the digitalization phenomenon.

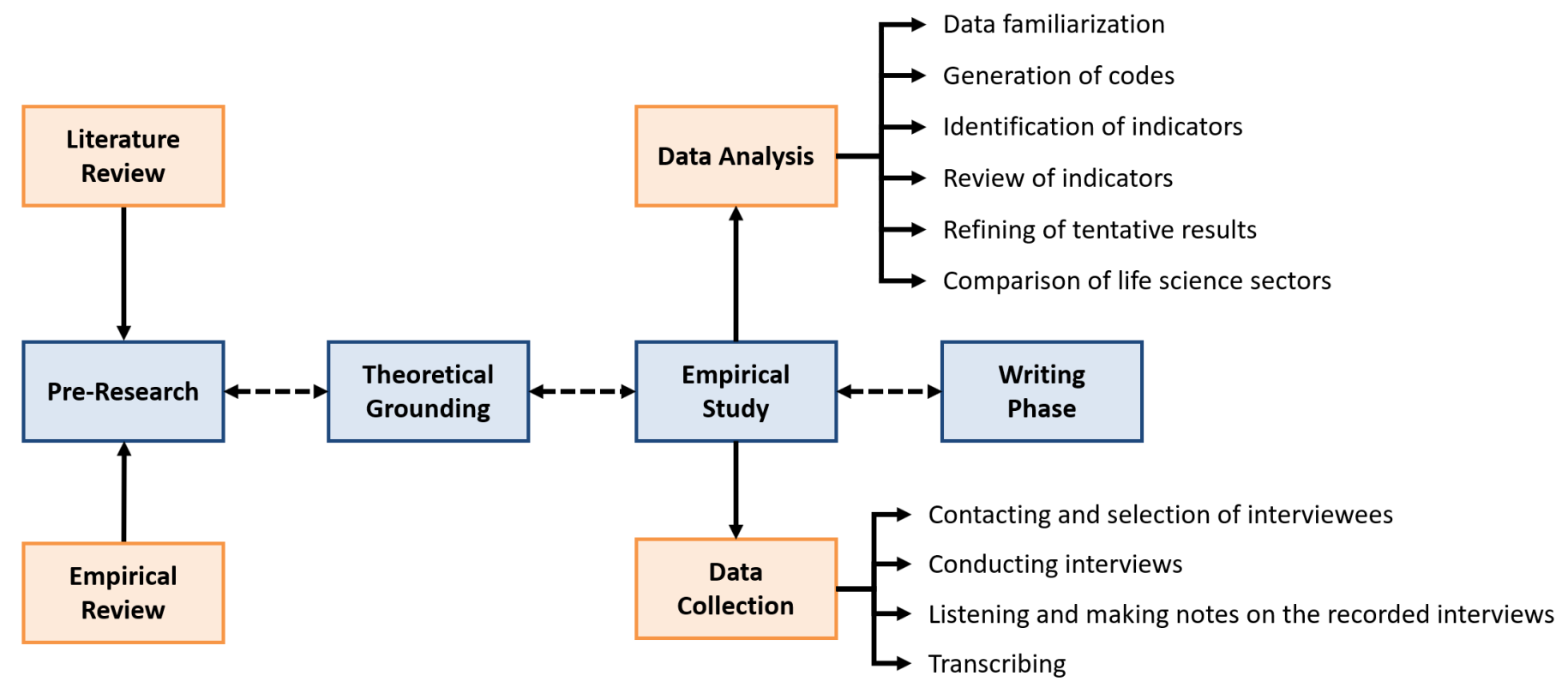

Figure 4. The research process used in this study 


\section{The Effect of Digitalization on the Commercialization Process of High-Technology Companies in the Life Sciences Industry Saheed A. Gbadegeshin}

\section{Digitalization and a new form of commercialization process}

Although pharmaceuticals, medical devices, and ehealth belong to the same industry, they are different in terms of complexity, innovation process, $R \& D$ activities, resource intensity, regulation, and legislation frameworks. Despite their differences, their commercialization processes are changing. All of them seem to have "simultaneous" commercialization process. The traditional stages were there, but the activities of these stages were interconnected. The stages were done in "parallel" or "simultaneously" as observed by Kaitin (2010) and Khilji and co-authors (2006). For example, at the discovery stage, many activities from other phases are undertaken, such as analyses of IP, market, prototyping or production potential, financial, and even, subcontracting. The drivers for a new form of commercialization are cost and timeframe reduction, customer-market orientation, positive entrepreneur attitude, and high need for business. Degryse (2016), Gerlitz (2015), Manyika and colleagues (2013), Markovitch and Willmott (2014), and Parviainen and colleagues (2017) have identified these drivers as motivating factors for adopting digitalization.

The new form of commercialization appears to be different from what the stage-gate theorist, Cooper (2008) explained. The interviewees made it known that, in each stage of commercialization, activities are done according to nature of the discovery. For instance, at the exploration (pharmaceutical) stage, many activities related to discovery and product development and marketization stages are done in addition to the original stage activities. The interviewees also made it known that their parallelization started recently and is enhanced by digitalization, which helps them to execute many commercialization activities simultaneously. This finding corresponds with findings from other researchers (e.g.,
Bhambure et al., 2011; Khilji et al., 2006; McKenzie et al., 2006). Therefore, with digitalization, a new form of commercialization may emerge (Tierney et al. 2013), which focuses on high productivity and quality (McKenzie et al. 2006; Bhambure et al. 2011). This new approach (Kaitin, 2010) does not need to follow the traditional stage-gate model, as shown in Figure 5, which uses the pharmaceutical process as an example.

Figure 5 shows that the commercialization activities are interconnected, and the stages seem to be blurry. Indeed, digitalization clears border lines among different spheres of life, including business operations (Degryse, 2016; Gerlitz, 2015; Parviainen et al., 2017; Schwab, 2015). The figure also shows that commercialization is grouped into three stages: pre-commercialization, actual commercialization, and post-commercialization. This grouping corresponds to the author's earlier works (Gbadegeshin2017b, 2018), which included the observation that "commercialization process does not need to be stage-based or follow the stage-gate process, because simultaneous implementation of commercialization activities seems to facilitate the process as well as manage unexpected problems" (Gbadegeshin (2017b). Although this earlier work focused on a cleantech high technology, it is notable that such a move has also occurred in the more traditional life sciences industry.

Therefore, the arguments stating that commercialization activities should be implemented simultaneously (Al Natsheh et al., 2014; Bradley et al., 2013; Cho et al., 2008; Gbadegeshin, 2017b; Mettlera \& Eurich, 2012; Volpatti \& Yetisen, 2014) seem to be right. The current study affirmed that the simultaneous implementation of commercialization processes is a new form of commercialization process. This new process can be described as a "concurrent commercialization process".

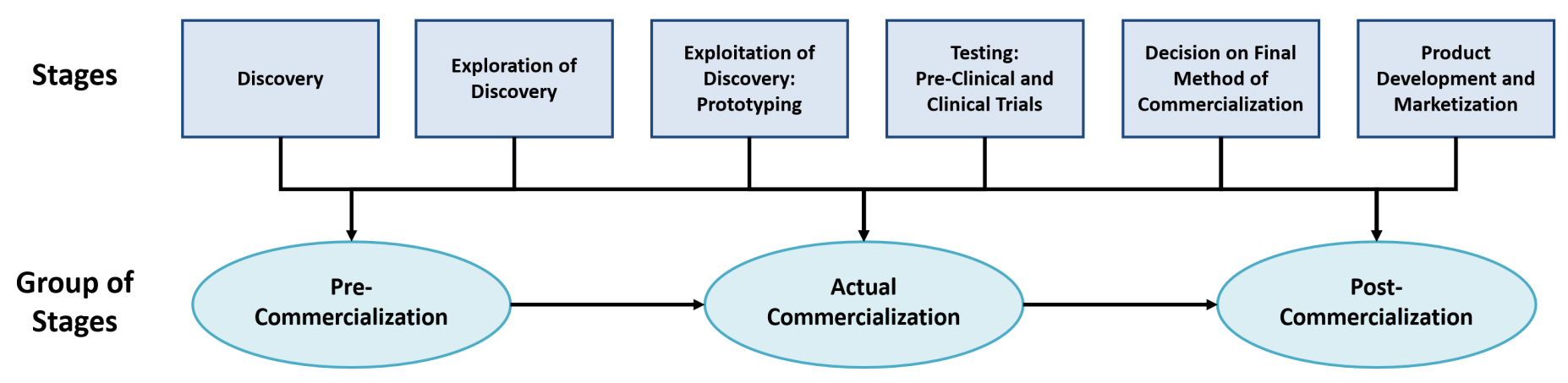

Figure 5. A new commercialization process for pharmaceuticals 


\section{The Effect of Digitalization on the Commercialization Process of High-Technology Companies in the Life Sciences Industry Saheed A. Gbadegeshin}

In addition, this study found that the e-health commercialization framework proposed by Cho and colleagues (2008) needs further improvement. Thus, the current findings suggested that the key stages outlined by these scholars needed to be reframed so that practitioners can understand them. For instance, these scholars proposed "adoption" to mean "conceptualization of innovation"; logically, readers might interpret "adoption" as acceptance of new technology. Similarly, the current findings suggested that the e-health commercialization process is supposed to have five stages, not four: 1) new technology or solution, 2) exploitation of the new technology/solution, 3) decision on commercialization method, 4) protection of the technology/solution, and 5) diffusion and marketization. These new stages could be easily understood by practitioners. In the new stages, commercialization activities are similar to the above medical and pharmaceutical companies, which align them with the life sciences industry. Furthermore, stage 4 (protection of the technology/solution) is the main difference between the previous framework of Cho and colleagues (2008) and the new framework. This stage is essential because there is a need to protect intellectual property due to the effect of digitalization, which makes much more information available and accessible online. In a nutshell, an improved form of ehealth commercialization process is shown in Figure 6.

The interviewees also disclosed that there is much information available online these days on every aspect of commercialization and that digitalization enables them to reach the state-of-the-art of any discovery (technology or solution). It also enables them to monitor, observe, and sometimes predict incoming products and solutions. This accessibility assists them in making market-entry decisions. All these possibilities were nowhere to be found a few decades ago. Hence, digitalization influenced the way commercialization informa- tion is planned, organized, coordinated, and controlled. For instance, a commercialization team may be spread across the globe because of outsourcing, and sensitive information needs careful attention, such information is now stored and shared in secured platforms. Sensitive information now can be checked and coordinated online. The interviewees recalled that previous forms of information management were tedious and cumbersome. Meanwhile, with digitalization, managing information is easier and less expensive, but riskier. This finding adds value to existing studies showing that digitalization influences innovation processes in the life sciences industry (Bhambure et al., 2011; Kaitin, 2010; McKenzie et al., 2006) by showing that digitalization's influence is not only on the innovation process; it also affects the commercialization process.

Furthermore, the interviewees revealed that they employed different types of digitalization tools, such as AI and big data analytics, to evaluate scholarly discussions (via articles), and to derive information on different scientific methods or techniques, possible trends, and sometimes, forthcoming drugs or technologies or solutions. An example was given by one of the interviewees stating that he knows the number of new drugs that will be available in the market from this year (2018) up to 2028. The interviewee claimed that he and his team were able to know this through their science and marketing assessments. He also explained that their predictions have been right since the beginning of 2014. They were able to do this with the help of digitalization. The interviewee recalled that this "intelligence" information could never have been attained 20 years ago without vast financial resources. This result relates to the work of Sabbagh and colleagues (2012) and Quinton and Simkin (2016), who argued that digitalization enables companies to monitor their competition. Meanwhile, this finding is relevant beyond competition management; it

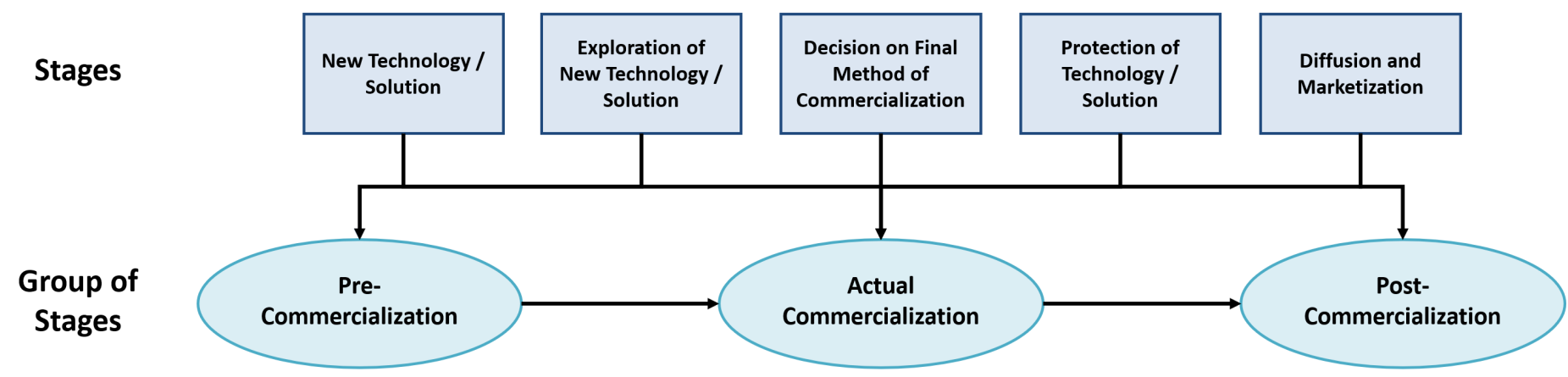

Figure 6. A new commercialization process for e-health 


\section{The Effect of Digitalization on the Commercialization Process of High-Technology Companies in the Life Sciences Industry Saheed A. Gbadegeshin}

shows that digitalization can be used to evaluate different issues in the commercialization process and gain insight for better decision making.

The data also showed that many official processes are now digitized. The paper forms are now available online, bills are paid online, questions are answered online (mostly through email interaction and online feedback), application monitoring is done online, and even, booking for face-to-face meetings is done online. Unlike previous works, which acknowledge that digitization is a part of digitalization transformation (e.g., Degryse, 2016; Parviainen et al., 2017; Tihinen \& Kääriäinen, 2016), this finding affirmed that the transformation is almost completed and is influencing official processes and activities.

The participants also affirmed that their commercialization activities have led to the creation of millions of pieces of information. For instance, they created new big data from information sourcing and management, using AI for big data analysis, prototyping and testing (including clinical trials), conducting marketing intelligence, using robots for mass production, and collaborating. The issue of creating more data from utilizing new data is not yet discussed by scholars in the digitalization field, such as Manyika and colleagues (2013), and Degryse (2016), and Tihinen and Kääriäinen (2016). Therefore, this finding is new and may need further attention by scholars.

One of the advantages of digitalization is efficiency and effectiveness (Manyika et al., 2013; Markovitch \& Willmott, 2014; Parviainen et al., 2017). However, the participants made it known that the application of digitalization tools adds more to their workload as well as makes the new activities become routine. For example, conducting potential partner analyses are now becoming daily activities for a commercialization project team. It is somewhat counterintuitive that digitalization may add to the workload, therefore further investigation about this possible negative influence of digitalization is needed.

Finally, the interviewees explained that digitalization made their commercialization flexible, effective, and efficient, which corresponds with earlier studies (e.g., Bhambure et al., 2011; McKenzie et al., 2006). However, the interviewees noted security issues (e.g., the risk of cyber-attacks), insufficient/incorrect information, exposure to business predators, and limitations on secrecy. The study participants also showed concerns about high dependence on the Internet and digitaliza- tion. Thus, despite the benefits of digitalization, it is also the source of new risks and associated "digital fear".

\section{Conclusion}

Scholars, politicians, and business leaders have all recognized that digitalization affects every aspect of human activities, both positively and negatively (Degryse, 2016; The Economist, 2012; Parviainen et al., 2017; Schwab, 2015; Tihinen \& Kääriäinen, 2016; World Economic Forum, 2018). The current study supports this view by highlighting the impact of digitalization on the commercialization processes of the life sciences industry - an industry where the effects on human activities can be profound.

The effect of digitalization leads to a new form of commercialization process. If this effect continues, it can be argued that the commercialization process will become more iterative, lean, or agile because commercialization activities will be more flexible and intertwined, as Schwab (2015) and Gerlitz (2015) have stated. Additionally, an iterative and lean process will be needed for the discovery and commercialization of new technologies. Thus, an iterative and lean process paves the way for rapid commercialization (Gbadegeshin 2017a, 2018; Gbadegeshin \& Heinonen, 2016) by shortening the duration of the process, which is essential for the current high demand for commercialization of innovations or inventions (Still, 2017). Furthermore, if the influences of digitalization on official processes, big data, workloads, and digital fears continued, as Tihinen and Kääriäinen (2016) and Parviainen and colleagues (2017) noted, these influences would change the business models of the life sciences industry and soften government regulations. Therefore, it can be concluded that digitalization has both positive and negative influences on the commercialization process.

This article makes a theoretical contribution to the study of digitalization by showing how it influences commercialization processes. It also makes a theoretical contribution by revealing a new form of commercialization process, which has not yet been discussed by commercialization scholars and practitioners. Additionally, it contributes to the theoretical discussion of digitalization by revealing that digitalization influenced workload, government procedures, big data, and digital fear, which have not yet been investigated by digitalization scholars and experts. Furthermore, the article contributes to practice by identifying the areas that digitalization has influenced. These contributions are relevant to academics, practitioners, and policy makers 


\section{The Effect of Digitalization on the Commercialization Process of High-Technology Companies in the Life Sciences Industry Saheed A. Gbadegeshin}

and call for more open discussions on the impacts of the digitalization - not only on the commercialization process, but also on the other aspects of human activities.

Besides the contributions, the article has limitations. The first limitation comes from the research methodology the study employed. Normally, the case study method offers limited generalization (Denzin \& Lincoln 2000; Eriksson \& Kovalainen 2008; Yin 2003). Thus, the findings derived from a few sectors of an industry might not be generalized. Similarly, a case study drawn from a single region of a small populated country (Finland) calls for caution in generalizing the results. Another limitation is the focus of the study, which concentrates only on the application of digitalization to the commercialization process.

However, these limitations suggest research opportunities for future studies. For instance, the findings of the article could serve as variables that can be tested quantitatively among the life science sectors in any country or between countries. Additionally, there is a need for further research on the new form of commercialization process and its methodology in the industry and other industries. This kind of research will shed more light on the changes that emerge from different forms of digitalization. There is also a need for studies on the future impact of digitalization on commercialization. Finally, there is a need for research on how digitalization has affected different business activities, such as business model development and the acquisition of new skills (especially, commercialization skills: see Gbadegeshin, 2019). Such research will provide insights on human resource management for universities, governments, and industries.

\section{Acknowledgements}

The author would like to thank the Finnish Cultural Foundation, the Foundation for Economic Education, the Turku University Foundation, TOP-Säätiö, and Turku School of Economics Support Foundation (Matti Koivurinnansäätiö) for their financial support. The author also thanks his supervisors: Professor Jarna Heinonen and Professor Anne Kovalainen, as well as his colleagues, especially Dr Solomon Oyelere, Dr Luqman Awoniyi, Dr Sunday Olaleye, Dr Tunde Jogunola, and Mr Ezak Ofem, for their feedback on the manuscript drafts.

\section{About the Author}

Saheed A. Gbadegeshin is a PhD Candidate at Turku School of Economics, University of Turku, Finland. His research interests include commercialization, high technology, the lean startup methodology, entrepreneurship, business internationalization, and family-run businesses. He holds an MSc degree in Entrepreneurship from the University of Jyväskylä and an MBA in International Business Management from Turku University of Applied Sciences in Finland.

\section{References}

Abd Rahim, N., Mohamed, Z. B., \& Amrin, A. 2015. Commercialization of Emerging Technology: The Role of Academic Entrepreneur. Procedia - Social and Behavioral Sciences, 169: 53-60. http://doi.org/10.1016/j.sbspro.2015.01.285

Al Natsheh, A., Gbadegeshin, S. A., Rimpiläinen, A., \& Mainela, T. 2013. Technology Based Entrepreneurship: Measurement Technology Perspective. Interdisciplinary Journal of Research in Business, 2(9): $26-42$.

Al Natsheh, A., Gbadegeshin, S. A., Rimpiläinen, A., Imamovic-Tokalic, I., \& Zambrano, A. 2014. Building a Sustainable Start-up? Factors to Be Considered During the Technology Commercialization Process. Journal of Advanced Research in Entrepreneurship and New Venture Creation, 1(1): 4-19.

Bhambure, R., Kumar, K., \& Rathore, A. S. 2011. High-Throughput Process Development for Biopharmaceutical Drug Substances. Trends in Biotechnology, 29(3): 127-135. http://doi.org/10.1016/j.tibtech.2010.12.001

Bradley, S. R., Hayter, C. S., \& Link, A. N. 2013. Models and Methods of University Technology Transfer. Foundations and Trends in Entrepreneurship, 9(6): 571-650. http://dx.doi.org/10.1561/0300000048

Braun, V., \& Clarke, V. 2006. Using Thematic Analysis in Psychology. Qualitative Research in Psychology, 3(2): 77-101. https://doi.org/10.1191/1478088706qp063oa

Brennen, S. J., \& Kreiss, D. 2016. Digitalization and Digitization. In K. Bruhn Jensen, R. T. Craig, J. D. Pooley, \& E. W. Rothenbuhler (Eds.), The International Encyclopedia of Communication Theory and Philosophy. Oxford, UK: Wiley-Blackwell. https://doi.org/10.1002/9781118766804.wbiect111

Cho, S., Mathiassen, L., \& Gallivan, M. 2008. Cross the Chasm: From Adoption to Diffusion of a Telehealth Innovation. In G. León, A. Bernardos, J. Casar, K. Kautz, \& J. DeGross, (Eds), International Federation for Information Processing: Open IT-Based Innovation: Moving Towards Cooperative IT Transfer and Knowledge Diffusion: 361-378. Boston, MA: Springer.

https://doi.org/10.1007/978-0-387-87503-3_21

Cooper, R. G. 2008. The Stage-Gate- Idea-to-Launch Process-Update: What's New and NextGen Systems. Journal of Product Innovation Management, 25(3): 213-232.

https://doi.org/10.1111/j.1540-5885.2008.00296.x 


\section{The Effect of Digitalization on the Commercialization Process of High-Technology Companies in the Life Sciences Industry Saheed A. Gbadegeshin}

Degryse, C. 2016. Digitalisation of the Economy and Its Impact on Labour Markets. Working Paper 2016.02. Brussels: European Trade Union Institute (ETUI).

Denzin, N. K., \& Lincoln, Y. S. (Eds). 2000. Handbook of Qualitative Research (2nd ed.). Thousand Oaks, CA: Sage Publication Inc.

Dogra, R., Garg, R., \& Jatav, P. 2013. Technology Transfer in Pharmaceutical Industry: Transfer of Process from Development to Commercialization. International Journal of Pharmaceutical Sciences and Research, 4(5): 1692-1708.

http://dx.doi.org/10.13040/IJPSR.0975-8232.4(5).1692-08

Eriksson, P., \& Kovalainen, A. 2008. Qualitative Methods in Business Research. London: Sage Publications Ltd. http://dx.doi.org/10.4135/9780857028044

Eisenhardt, K. M. 1989. Building Theories from Case Study Research. Academy of Management Review, 14(4): 532-550. http://dx.doi.org/10.2307/258557

European Commission. 2009. Pharmaceutical Sector Inquiry: Final Report. Brussels: European Commission.

http://ec.europa.eu/competition/sectors/pharmaceuticals/inquir y/staff_working_paper_part1.pdf

Eurostat. 2016. High-Technology Versus Low-Technology Manufacturing. Eurostat: Statistics Explained, April 13, 2016. Accessed January 15, 2019:

https://ec.europa.eu/eurostat/statisticsexplained/index.php?title=Archive:High-technology_versus_lowtechnology_manufacturing

Fontes, F. 2005. The Process of Transformation of Scientific and Technological Knowledge into Economic Value Conducted by Biotechnology Spin-offs. Technovation, 25(4): 339-347. https://doi.org/10.1016/j.technovation.2003.08.004

Gaubinger, K., Schweitzer, F., \& Zweimüller, R. 2012. A Commercialization Process Model for Technology Innovations. Paper presented at the 2012 International Society for Professional Innovation Management (ISPIM) Conference, June 17-20, 2012, Barcelona, Spain.

Gbadegeshin, S. A. 2017a. Stating Best Commercialization Method: An Unanswered Question from Scholars and Practitioners. International Journal of Social, Behavioral, Educational, Economic, Business and Industrial Engineering, 11(5): 1088-1094.

Gbadegeshin, S. A. 2017b. Commercialization Process of High Technologies: Case Study of Finnish University Spin-off. Academy of Entrepreneurship Journal, 23(2): 1-22.

Gbadegeshin, S. A. 2018. Lean Commercialization: A Framework for Commercializing High Technologies. Technology Innovation Management Review, 8(9): 50-63.

http://doi.org/10.22215/timreview/1186

Gbadegeshin, S. A. 2019. Commercialization Skills: Necessity for High Technology Entrepreneurs in Digital Era. In K. Arai, R. Bhatia, \& S. Kapoor (Eds), Proceedings of the Future Technologies Conference (FTC) 2018: Advances in Intelligent Systems and Computing: 965-975. Cham, Switzerland: Springer.

https://doi.org/10.1007/978-3-030-02683-7_71

Gbadegeshin, S. A., \& Heinonen, L. 2016. Application of the Lean Start-Up Technique in Commercialisation of Business Ideas and Innovations. International Journal of Business Management and Research, 43(1): 1270-1285.
Gerlitz, L. 2015. Design for Product and Service Innovation in Industry 4.0 in Emerging Smart Society. Journal of Security and Sustainability Issues, 5(2): 181-198.

https://doi.org/10.9770/jssi.2015.5.2(5)

Henriette, E., Feki, M., \& Boughzala, I. 2015. The Shape of Digital Transformation: A Systematic Literature Review. In S. Kokolakis, M. Karyda, E. N. Loukis, \& Y. Charalabidis. (Eds.), Proceedings from Ninth Mediterranean Conference on Information Systems (MCIS), Samos, Greece: 431-443.

Holzleitner, R. 2015. A Comprehensive Framework for Successful Commercialisation of Technology Push Innovations. Paper presented at the 2015 International Society for Professional Innovation Management (ISPIM) Special Workshop, Upper Austria University of Applied Sciences.

http://ffhoarep.fh-ooe.at/bitstream/123456789/430/1/FFH2015IM2-4.pdf

Istepanaian, R. S. H., \& Zhang, Y.-T. 2012. Guest Editorial Introduction to the Special Section: 4G Health: The Long-Term Evolution of m-Health. IEEE Transactions on Information Technology in Biomedicine, 16(1): 1-5. https://doi.org/10.1109/TITB.2012.2183269

Kaitin, K. I. 2010. Deconstructing the Drug Development Process: The New Face of Innovation. Clinical Pharmacology \& Therapeutics, 87(3): 356-361. https://doi.org/10.1038/clpt.2009.293

Khilji, S. E., Mroczkowski, T., \& Bernstein, B. 2006. From Invention to Innovation: Toward Developing an Integrated Innovation Model for Biotech Firms. Journal of Product Innovation Management, 23(6): 528-540. https://doi.org/10.1111/j.1540-5885.2006.00222.x

Kumar, S., Nilsen, W. J., Abernethy, A., Atienza, A., Patrick, K., Pavel, M., Riley, W. T., Shar, A., Spring, B., Spruijt-Metz, D., Hedeker, D., Honavar, V., Kravitz, R., Lefebvre, R. C., Mohr, D. C., Murphy, S. A., Quinn, C., Shusterman, V., \& Swendeman, D. 2013. Mobile Health Technology Evaluation: The mHealth Evidence Workshop. American Journal of Preventive Medicine, 45(2): 228-236. https://doi.org/10.1016/j.amepre.2013.03.017

Lavoie, J. R., Kim, J., \& Daim, T. U. 2017. A Technology Transfer Framework: A Case Study from the Energy Sector. International Journal of Innovation, Management and Technology, 8(4): 249-260. https://doi.org/10.18178/ijimt.2017.8.4.737

Maak, T. G., \& Wylie, J. D. 2016. Medical Device Regulation: A Comparison of the United States and the European Union. Journal of the American Academy of Orthopaedic Surgeons, 24(8): 537-543. https://doi.org/10.5435/JAAOS-D-15-00403

Maine, E., \& Garnsey, E. 2007. The Commercialisation Environment of Advanced Materials Ventures. International Journal of Technology Management, 39(1/2): 49-71. https://doi.org/10.1504/IJTM.2007.013440

Manyika, J., Chui, M., Bughin, J., Dobbs, R., Bisson, P., \& Marrs, A. 2013. Disruptive Technologies: Advances that Will Transform Life, Business, and the Global Economy. Washington, DC: McKinsey Global Institute.

Markovitch, S., \& Willmott, P. 2014. Accelerating the Digitization of Business Processes. Digital McKinsey, May 2014. Accessed January 15, 2019:

http://www.mckinsey.com/business-functions/digitalmckinsey/our-insights/accelerating-the-digitization-of-businessprocesses 


\section{The Effect of Digitalization on the Commercialization Process of High-Technology Companies in the Life Sciences Industry Saheed A. Gbadegeshin}

McKenzie, P., Kiang, S., Tom, J., Rubin, A. E., \& Futran, M. 2006. Can Pharmaceutical Process Development Become High Tech? AIChE Journal, 52(12): 3990-3994.

https://doi.org/10.1002/aic.11022

Mettlera, T., \& Eurich, M. 2012. A “Design-Pattern”-Based Approach for Analyzing E-health Business Models. Health Policy and Technology, 1(2): 77-85.

https://doi.org/10.1016/j.hlpt.2012.04.005

Meyers, A. D. 2009. Book Review: Commercialisation of Innovative Technologies: Bringing Good Ideas to the Marketplace. Journal of Commercial Biotechnology, 15(4): 374-375.

https://doi.org/10.1057/jcb.2009.18

Nilsson, A., Friden, H., \& Serger, S. S. 2006. Commercialisation of Life Sciences Research at Universities in the United States, Japan, and China. Study A2006:006. Östersund, Sweden: Swedish Institute for Growth Policy Studies.

Nissen, H. A., Evald, M. R., \& Clarke, A. H. 2015. Firms' Reshaping of Commercialization Practices to Overcome the 'Not Invented Here' Phenomenon in Public Health Care Organizations. The Innovation Journal: The Public Sector Innovation Journal, 20(3): 1-27.

Parviainen, P., Tihinen, M., Kääriäinen, J., \& Teppola, S. 2017. Tackling the Digitalization Challenge: How to Benefit from Digitalization in Practice. International Journal of Information Systems and Project Management, 5(1): 63-77. https://doi.org/10.12821/ijispm050104

Pellika, J. 2014. The Commercialization Process of Innovation in Small High-Technological Firms - Theoretical View. In F. Thérin (Ed.), Handbook of Research on Techno-Entrepreneurship: How Technology and Entrepreneurship Are Shaping the Development of Industries and Companies (2nd ed.): 91-109. Cheltenham, UK: Edward Elgar Publishing Ltd.

Pellikka, J., \& Malinen, P. 2011. Developing Commercialisation of Innovation in High Technology Industries - Regional Perspective. Paper presented at the 56th International Council for Small Business (ICSB) in Stockholm, Sweden, June 15-18, 2011.

Pietzsch, J. B., Shluzas, L. A., Paté-Cornell, M. E., Yock, P. G., \& Linehan, J. H. 2009. Stage-Gate Process for the Development of Medical Devices. Journal of Medical Devices, 3(2): 021004. https://doi.org/10.1115/1.3148836

Prebble, D. R., De Waal, G. A., \& De Groot, C. 2008. Applying Multiple Perspectives to the Design of a Commercialization process. $R \& D$ Management, 38(3): 311-320.

https://doi.org/10.1111/j.1467-9310.2008.00517.x

Quinton, S., \& Simkin, L. 2016. The Digital Journey: Reflected Learnings and Emerging Challenges. International Journal of Management Reviews, 19(4): 455-472. https://doi.org/10.1111/ijmr.12104

Sabbagh, K., Friedrich, R., El-Darwiche, B., Singh, M., Ganediwalla, S., \& Katz, R. 2012. Maximizing the Impact of Digitization. New York: Booz \& Company.

http://www.strategyand.pwc.com/media/file/Strategyand_Maxim izing-the-Impact-of-Digitization.pdf

Schwab, K. 2015. The Fourth Industrial Revolution: What It Means and How to Respond. Foreign Affairs, December 12, 2015. Accessed January 15, 2019:

https://www.foreignaffairs.com/articles/2015-12-12/fourthindustrial-revolution
Siegel, D. S., Waldman, D. A., Atwater, L. E., \& Link, A. N. 2004. Toward a Model of the Effective Transfer of Scientific Knowledge from Academicians to Practitioners: Qualitative Evidence from the Commercialization of University Technologies. Journal of Engineering and Technology Management, 21(1-2): 115-142. https://doi.org/10.1016/j.jengtecman.2003.12.006

Silverman, D. 2011. Interpreting Qualitative Data: A Guide to the Principles of Qualitative Research (4th ed). London: Sage Publications Ltd.

Speser, P. 2008. What Every Researcher Needs to Know About Commercialisation. Providence, RI: Foresight Science and Technology Inc.

Soenksen, L. R., \& Yazdi, Y. 2017. Stage-Gate Process for Life Sciences and Medical Innovation Investment. Technovation, 62-63: 14-21. https://doi.org/10.1016/j.technovation.2017.03.003

Solberg, C. A., Sundal, T., \& Thoresen, K. 2008. High-Tech and LowTech Born Globals: Are They Any Different? Paper presented at Annual EIBA conference in Tallinn, Estonia, December 2008.

Steenhuis, H. J., \& de Bruijn, E. J. 2006. High Technology Revisited: Definition and Position. In Proceedings of IEEE International Conference on Management of Innovation and Technology: 1080-1084. Singapore, June 21-23, 2006.

https://doi.org/10.1109/ICMIT.2006.262389

Sternitzke, C. 2010. Knowledge Sources, Patent Protection, and Commercialization of Pharmaceutical Innovations. Research Policy, 39(6): 810-821. https://doi.org/10.1016/j.respol.2010.03.001

Still, K. 2017. Accelerating Research Innovation by Adopting the Lean Startup Paradigm. Technology Innovation Management Review, 7(5): 32-43. http://doi.org/10.22215/timreview/1075

The Economist. 2012. The Third Industrial Revolution: The Digitisation of Manufacturing Will Transform the Way Goods Are Made and Change the Politics of Jobs Too. The Economist, April 21, 2012. Accessed January 15, 2019:

http://www.economist.com/node/21553017

Tierney, R., Hermin, W., \& Walsh, S. 2013. The Pharmaceutical Technology Landscape: A New Form of Technology Road Mapping. Technological Forecasting \& Social Change, 80(2): 194-211.

https://doi.org/10.1016/j.techfore.2012.05.002

Tihinen, M., \& Kääriäinen, J. (Eds.) 2016. The Industrial Internet in Finland: on Route to Success? Espoo, Finland: VTT Technology. http://www.vtt.fi/inf/pdf/technology/2016/T278.pdf

Volpatti, L. R., \& Yetisen, A. K. 2014. Commercialisation of Microfluidic Devices. Trends in Biotechnology, 32(7): 347-350. https://doi.org/10.1016/j.tibtech.2014.04.010

Walsh, P. R. 2012. Innovation Nirvana or Innovation Wasteland? Identifying Commercialization Strategies for Small and Medium Renewable Energy Enterprises. Technovation, 32(1): 32-42. https://doi.org/10.1016/j.technovation.2011.09.002

West, J., \& Oldfather, P. 1995. Pooled Case Comparison: An Innovation for Cross-Case Study. Qualitative Inquiry, 1(4): $452-464$.

https://doi.org/10.1177/107780049500100405 


\section{The Effect of Digitalization on the Commercialization Process of High-Technology Companies in the Life Sciences Industry Saheed A. Gbadegeshin}

World Economic Forum. 2018. Jack Ma on the IQ of Love and Other Top Quotes from his Davos Interview. World Economic Forum, January 24, 2018. Accessed January 15, 2019:

https://www.weforum.org/agenda/2018/01/jack-ma-davos-topquotes/
World Health Organization. 2003. eHealth. Geneva, Switzerland: World Health Organization.

http://www.emro.who.int/ehealth/

Yin, R. K. 2003. Case Study Research: Design and Methods (2nd ed). New York: Sage Publications Inc.

Appendix 1. Tentative results on the influences of digitalization on the commercialization process

\begin{tabular}{|c|c|c|}
\hline Pharmaceutical Sector & Medical Device Sector & E-Health Sector \\
\hline $\begin{array}{l}\text { Discovery } \\
\text { - Accessing scholarly articles (easily) } \\
\text { - Monitoring science focus (easily) } \\
\text { - Evaluating novelty } \\
\text { - Accessing new method/technique } \\
\text { - Deducing new } \\
\text { molecule/knowledge/novelty } \\
\text { - Identifying new problem or trend in } \\
\text { existing problem } \\
\text { - Defining market needs }\end{array}$ & $\begin{array}{l}\text { Discovery (New technology) } \\
\text { - Accessing scholarly articles (easily) } \\
\text { - Deducing new technology/knowledge } \\
\text { - Identifying new problem or trend in } \\
\text { existing problem } \\
\text { - Defining market needs }\end{array}$ & $\begin{array}{l}\text { Discovery (New application or solution) } \\
\text { - Accessing all available solutions and their } \\
\text { weaknesses } \\
\text { - Defining novelty (uniqueness) } \\
\text { - Planning for development of the } \\
\text { application or solution } \\
\text { - Accessing solution delivery mode } \\
\text { - Evaluating market needs } \\
\text { - Evaluating possible legal constraints } \\
\text { - Monitoring problem trends or market } \\
\text { - Arend } \\
\text { - Evsessing technical possibilities }\end{array}$ \\
\hline $\begin{array}{l}\text { Exploration of discovery } \\
\text { - Assessing technical possibilities } \\
\text { - Evaluating IP situations } \\
\text { - Screening molecules before starting any } \\
\text { large investment } \\
\text { - Developing alternative molecules } \\
\text { - Detecting similar and previous failures } \\
\text { - Analyzing business potential } \\
\text { - Compiling knowledge on forthcoming } \\
\text { - (similar) drugs } \\
\text { - Analyzing potential competitors } \\
\text { - Enabling own company profiling } \\
\text { - Developing qualitative business case } \\
\text { - Evaluating potential collaborators and } \\
\text { - Recruiting personnel, partners, and } \\
\text { collaborators } \\
\text { - Digitization (changing paper documents } \\
\text { to digital form) }\end{array}$ & $\begin{array}{l}\text { Assessment of discovery } \\
\text { - Evaluating novelty } \\
\text { - Analyzing IP } \\
\text { - Assessing technical development } \\
\text { possibilities } \\
\text { - Assessing business potential (mostly } \\
\quad \text { conducting market analysis) }\end{array}$ & $\begin{array}{l}\text { Exploitation of new application/solution } \\
\text { - Prototyping } \\
\text { - Normal testing } \\
\text { - Clinical testing }\end{array}$ \\
\hline $\begin{array}{l}\text { Exploitation of discovery } \\
\text { - Assessing and contacting potential } \\
\text { financiers, partners, and collaborators } \\
\text { (communication purpose) } \\
\text { - Managing drug process (e.g., outsourcing, } \\
\text { maintaining information sharing } \\
\text { platform, enabling iteration process) } \\
\text { - Enabling use of modern technologies } \\
\text { (e.g., use of silicon material) }\end{array}$ & $\begin{array}{l}\text { Protection of discovery } \\
\text { - Facilitating patent filing (digitization) } \\
\text { - Facilitating of "CE" certificate registration }\end{array}$ & $\begin{array}{l}\text { Decision on final method of } \\
\text { commercialization } \\
\text { - Analyzing market information } \\
\text { - Assessing new solution market value } \\
\text { - Assessing different methods and their } \\
\text { potential outcomes }\end{array}$ \\
\hline
\end{tabular}




\section{The Effect of Digitalization on the Commercialization Process of High-Technology Companies in the Life Sciences Industry Saheed A. Gbadegeshin}

\section{Appendix 1 (continued). Tentative results on the influences of digitalization on the commercialization process}

\begin{tabular}{|c|c|c|}
\hline Pharmaceutical Sector & Medical Device Sector & E-Health Sector \\
\hline $\begin{array}{l}\text { Testing: pre-clinical and clinical trials } \\
\text { - Maintaining relationship with the } \\
\text { financiers, partners, and collaborators } \\
\text { (communication purpose) } \\
\text { - Managing the drug process } \\
\text { - Collecting information on previous trials } \\
\text { - Producing prototype (easily) (selecting } \\
\text { promising candidates) } \\
\text { - Recruiting of patients } \\
\text { - Easy trial data collection and analysis } \\
\text { - Easy trial monitoring and management } \\
\text { - Reducing cost (more than before arrival } \\
\text { of digitalization) }\end{array}$ & $\begin{array}{l}\text { Prototyping, development, and testing } \\
\text { - Assessing and contacting potential } \\
\text { partners and collaborators } \\
\text { - Analyzing potential competitors } \\
\text { - Easy production of prototype (e.g., with } \\
\text { 3D printer and outsourcing) } \\
\text { - Recruiting personnel, partners, and } \\
\text { collaborators } \\
\text { - Easy conduction of preclinical and } \\
\text { clinical tests }\end{array}$ & $\begin{array}{l}\text { Protection of new application/solution } \\
\text { - Facilitating patent filing (digitization) }\end{array}$ \\
\hline $\begin{array}{l}\text { Decision on final method of } \\
\text { commercialization } \\
\text { - Analyzing market information } \\
\text { - Assessing new drug market value } \\
\text { - Assessing different methods and their } \\
\text { potential outcomes } \\
\text { - Evaluating potential licensees or IP } \\
\text { buyers }\end{array}$ & $\begin{array}{l}\text { Decision on final method of } \\
\text { commercialization } \\
\text { - Analyzing market information } \\
\text { - Assessing new device market value } \\
\text { - Assessing different methods and their } \\
\text { potential outcomes } \\
\text { - Evaluating potential licensees or IP } \\
\text { buyers } \\
\text { - Evaluating own production process }\end{array}$ & $\begin{array}{l}\text { Diffusion and marketization } \\
\text { - Reviewing production process } \\
\text { - Using of many marketing tools with lesser } \\
\text { cost } \\
\text { - Easy management of post-sales activities } \\
\text { (e.g., feedback) } \\
\text { - Creation of new big data }\end{array}$ \\
\hline
\end{tabular}

\section{Product development and marketization}

- Reviewing new drug production process

- Evaluating subcontractors

- Planning manufacturing process

- Using of robots, virtual reality, and augmented reality (for production process and management purposes)

- Promoting personalized medicine (different use of dosage)

- Changing workforce composition

- Using various marketing tools at lower cost

- Easy management of post-sales activities (e.g., feedback)

- Creation of new big data

\section{Product development and marketization}

- Reviewing production process

- Evaluating subcontractors

- Planning manufacturing process (e.g., using robots)

- Changing workforce composition

- Using of many marketing tools with lesser cost

- Easy management of post-sales activities (e.g., feedback)

- Creation of new big data 


\title{
E-Leadership in Small and Medium-Sized Enterprises in the Developing World Maksim Belitski and Bain Liversage
}

\author{
"For Europe to compete, grow and generate jobs, we must ensure" \\ that we have the people who can lead the digital innovation \\ and transformation of our industries. ... E-leadership is a key \\ component of the Digital Single Market Strategy's drive to foster \\ digital skills needed for the modern European industry.
}

\author{
Lowri Evans \\ European Commission Director General \\ Internal Market, Industry, Entrepreneurship and SMEs
}

\begin{abstract}
Small- and medium-sized enterprises (SMEs) play an important role in the economies of many developing countries. A critical challenge faced by SME leaders, as digitization continues, is how to adopt digital technologies to create value and enable faster product commercialization. There is a paucity of empirical research examining how e-leadership in SMEs drives technology and new product commercialization processes in the developing world. In this study, we have broadened the notion of what constitutes e-leadership, from the perspective of how advanced information technologies affect the leadership dynamic and the appropriation of advanced information technologies. Although there have been several studies on leading technologies in developed countries, we focus on developing an e-leadership framework for SMEs in developing economies. Using this framework and five selection criteria, we conducted 11 interviews with a sample of successful SMEs selected from a pool of 2,240 firms in the city of Johannesburg, South Africa. We conclude by highlighting the five key findings of this study, which explain how SMEs can develop effective e-leadership to foster commercialization and improve firm performance.
\end{abstract}

\section{Introduction}

Information and communication technology (ICT) has a major impact on businesses and society, however, the adoption of ICT has not been well incorporated into leadership theory (Van Wart et al., 2017). In particular, there is a paucity of research on e-leadership in developing countries (Hüsing et al., 2015; Rogerson, 2000) and the factors that direct leadership behaviour towards commercialization. The creation of new products to exploit existing technologies in a firm is a good example of a situation where knowledge that is codified within a firm requires the setup of a system of stable interactions between sets of skills relating to management, strategy, and ICT. These interactions and their implementation as managed by an e-leader will enable faster development and commercialization of new products and services.
However, simply having skills in management, operations, strategy, and ICT is not enough to effectively commercialize new products and new knowledge. It is also important to generate congruence between them, which is known as e-leadership (Coltman et al., 2015). E-leadership in SMEs will thus rely on the leader's capacity to learn, change, and apply ICT to the existing firm's dynamic capabilities (Cohen \& Levinthal, 1989; Zahra \& George, 2002) in a fast-moving environment. The importance of using e-leadership in facilitating new product commercialization and, in particular, for SMEs has been emphasized recently (Li et al., 2016).

The lack of empirical evidence and theory on e-leadership does not allow policy makers and firm leaders to understand how competitive advantage could be created using ICT (Walumbwa et al., 2011). Along with facilitating e-leadership, firms must also to keep up with 


\section{E-Leadership in Small and Medium-Sized Enterprises in the Developing World}

\section{Maksim Belitski and Bain Liversage}

technological developments, which naturally affects how leadership is viewed (Avolio et al., 2014).

Although e-leadership is an emerging phenomenon in the developed world (Avolio et al., 2014; Li et al., 2016), it has received little attention in developing countries. In many instances, e-leadership is viewed as the adoption of ICT by SMEs (Gono et al., 2016), which is a limited view. The concept of e-leadership is broader than simply focusing on how leaders use advanced information technologies. Our view is "zooming out" in an examination of leadership and advanced information technologies by considering how advanced information technologies and leadership - in the broadest sense are interrelated. We argue that e-leadership is a fundamental building block for organizations operations and strategy to comply with the alignment of information systems strategic business and IT. Consequently, to the extent that examination of e-leadership is broader than simply focusing on how leaders use technologies, it is about decision making engaging with inter-disciplinary staff, suppliers, and customers, and interacting in a digital space. Specifically, in our examination of e-leadership is a dynamic process of interaction with technologies and people within an organization and beyond, by bringing together organizational culture, knowledge of technology, and interconnectivity.

In this study, we focus on the development of an e-leadership framework in SMEs and ask the following research question: what are the building blocks of e-leadership as a strategic, management, and operational component of an organization, and how do they interact to create a better value for an organization? To answer this question, we use a mixed-methods approach: 11 face-to-face interviews with fast-growing SMEs in Johannesburg, South Africa, and data-mining using interview data. Johannesburg is an interesting case in the developing world because the city is dominated by young people and $82 \%$ of its business and community services already use digital technology (City of Johannesburg, 2018). Moreover, the local government has recognized the economic value of digital skills in SMEs and has begun to facilitate programs to support ICT skill development in Johannesburg.

Using the Johannesburg context, our study theoretically examines and empirically tests e-leadership skills in the developing world as a commercialization tool for new knowledge and products within this novel area of research on innovation commercialization and information systems. In addition to knowing about the adoption of digital technologies in the developing world
(Nkomo \& Kriek, 2011), managers in SMEs need to know to what extent e-leadership can be exploited as a conduit to new market knowledge, creativity, and firm performance (Audretsch \& Belitski, 2017; Belitski \& Desai, 2016). Indeed, in South Africa, e-leadership supports SMEs in the adoption and management of technologies and in commercializing them in the market (Audretsch \& Keilbach, 2007).

The remainder of the article is structured as follows. Next, we briefly describe the current state of e-leadership in South Africa, where SMEs struggle with ICT skills shortages and ineffective commercialization of new products. Then, we develop the theoretical framework of e-leadership. This is followed by descriptions of the methodology and results. Finally, we discuss the findings of the study and their managerial and policy implications.

\section{E-Leadership in South Africa}

Ever since the end of the apartheid era and the implementation of a new South African constitution in 1994, the government has placed significant emphasis on innovation and entrepreneurship. Almost 95\% of businesses in South Africa are small firms, which are the main job creators in the institutional context of corruption, high poverty, and inequality. South Africa's SMEs contribute around $34 \%$ of the country's gross domestic product (GDP) and employ approximately $60 \%$ of the labour force (Naicker \& Peters, 2013). These statistics are similar to other emerging economies in Africa. Government support to SMEs in South Africa is provided through the Small Enterprise Development Agency (SEDA), the Industrial Development Corporation (IDC), and the National Empowerment Fund (NEF), which were initiated by the National Development Plan (NDP) to enable their neo-liberal policy to drive economic development. The success of these agencies has unfortunately been negligible mostly due to the lack of awareness by SMEs of how to combine skills and in what technologies to invest in a digital age (Cant \& Wiid, 2013; Naicker \& Peters, 2013).

There is no shortage of entrepreneurs in African countries, however, few of them survive because they are unable to effectively commercialize the products and services that they produce (Rogerson, 2000). In developing African countries, SMEs face tremendous challenges in establishing and adopting new technologies. The limitations are associated with limited access to finance, low skill levels, ineffective leadership, and slow adoption of digital technologies (Matzler et al., 2008). In 


\section{E-Leadership in Small and Medium-Sized Enterprises in the Developing World}

\section{Maksim Belitski and Bain Liversage}

these circumstances, an alignment of businesses and ICT operations and strategies (De Haes \& Van Grembergen, 2009) does not happen effectively and the commercialization of new products can be delayed up to the point when they become obsolete by the time they reach the market.

\section{Theoretical Framework}

Building on the work of Avolio and colleagues (2014) and $\mathrm{Li}$ and colleagues (2016) in conceptualizing e-leadership, we found that the concept is based on successful alignment between business strategy and digital technology fostering longevity and firm growth. Li and colleagues (2016) conducted 42 interviews exploring the construct of e-leadership and how successful SMEs achieve an effective strategic alignment through e-leadership. For SMEs in developing economies, e-leadership could be viewed as a commercialization tool that enables e-leaders to better leverage business and digital skills to exploit the potential of digital technologies in selling the products to market. In doing so, SMEs in developing economies will aim to improve IT adoption and diffusion to facilitate firm performance and sales (Bruque-Camara et al., 2004; Ramamurthy \& Premkumar, 1995).

We therefore distinguish three groups of factors that affect e-leaders in SMEs in developing economies more than those in developed economies. First, are the individual characteristics and personality traits influencing the ability of an e-leader. Second, is the organizational environment in which technologies are adopted (Bruque-Camara et al., 2004). Third, is the entrepreneurship ecosystem: how competitive it is, its culture, its institutions, and regulations about new technologies and how firms can exercise and adopt them (Audretsch \& Belitski, 2017). Linking these three strands of antecedents, we argue that the e-leadership is embedded into individual skills at organizational and ecosystem levels. In adopting and developing e-leadership, an SME is required to translate its existing, traditional leadership (Vargas, 2015) into e-leadership by making the organization acquire such dynamic competences as strategic leadership, ICT readiness, and business readiness, which correspond to strategic, digital, and business savviness (Hüsing et al., 2013; Korte et al., 2015). In the digital age, these three characteristics emerge as important dynamic capabilities in an organization (Zahra and George, 2002), which empower its leaders (Seltzer \& Bass, 1990; LEAD, 2014; Li et al., 2016).
A process that enables transformational leadership (Vargas 2015) into e-leadership is crucial to enable learning new ways of commercializing new ideas and knowledge. Leadership requires transformation to enable better responses to changes in the business environment and entrepreneurship ecosystem (Audretsch and Belitski, 2017) and to commercialize new products. E-leadership is viewed in this instance as the ability to open up to new ways of making products and services using both market knowledge and digital tools to be highly innovative. This transformational process from traditional leadership mainly focuses on individuallevel factors (Matzler et al., 2008), but it also embraces the adoption of digital technologies (Li et al., 2016). Eleadership, therefore, builds on the importance of changing behaviours using market knowledge and networks only, rather than learning new ICT skills, to be able to effectively manage and sell technology (Avolio et al., 2001). By learning and integrating a variety of strategic, business, and ICT capabilities, SMEs in developing countries will not aim for stronger alignment of business and IT strategy and operations; rather, SME leaders will transform their firms' commercialization practices by exploiting digital technologies (Li et al., 2016) to market, position, and deliver the product to customers. This is when e-leadership is not only required to change the skill-set but also to integrate new knowledge into organizational routines and practices (Li et al., 2016). New e-leaders will themselves adopt and exploit technology for potential performance gains as well as being able to view other departments by integrating their ICT skills and market knowledge. These changes require e-leaders to appoint digital tools and learn new skills to sell (Avolio et al., 2001) to align business and ICT, as many large firms and SMEs in developed countries do already (Korte et al., 2015; Li et al., 2016). Based on this view, we have developed a model of e-leadership formation and adoption in SMEs (Figure 1).

An important question to answer here is: How does eleadership work as a tool to facilitate product commercialization? E-leaders provide the guiding vision for SMEs, set the business standards, and set out how to use new technologies. These links appear when the eleader understands customer needs and develops solutions to meet these needs. Furthermore, digital savviness is important (Hüsing et al., 2013; Korte et al., 2015). When digital technology is available in an organization, e-leadership is a way to encourage risk taking and problem solving. Thus, it is important to develop an understanding of what technology - whether it is 


\section{E-Leadership in Small and Medium-Sized Enterprises in the Developing World}

\section{Maksim Belitski and Bain Liversage}

\section{Transformational Leadership Factors E-Leadership Factors}

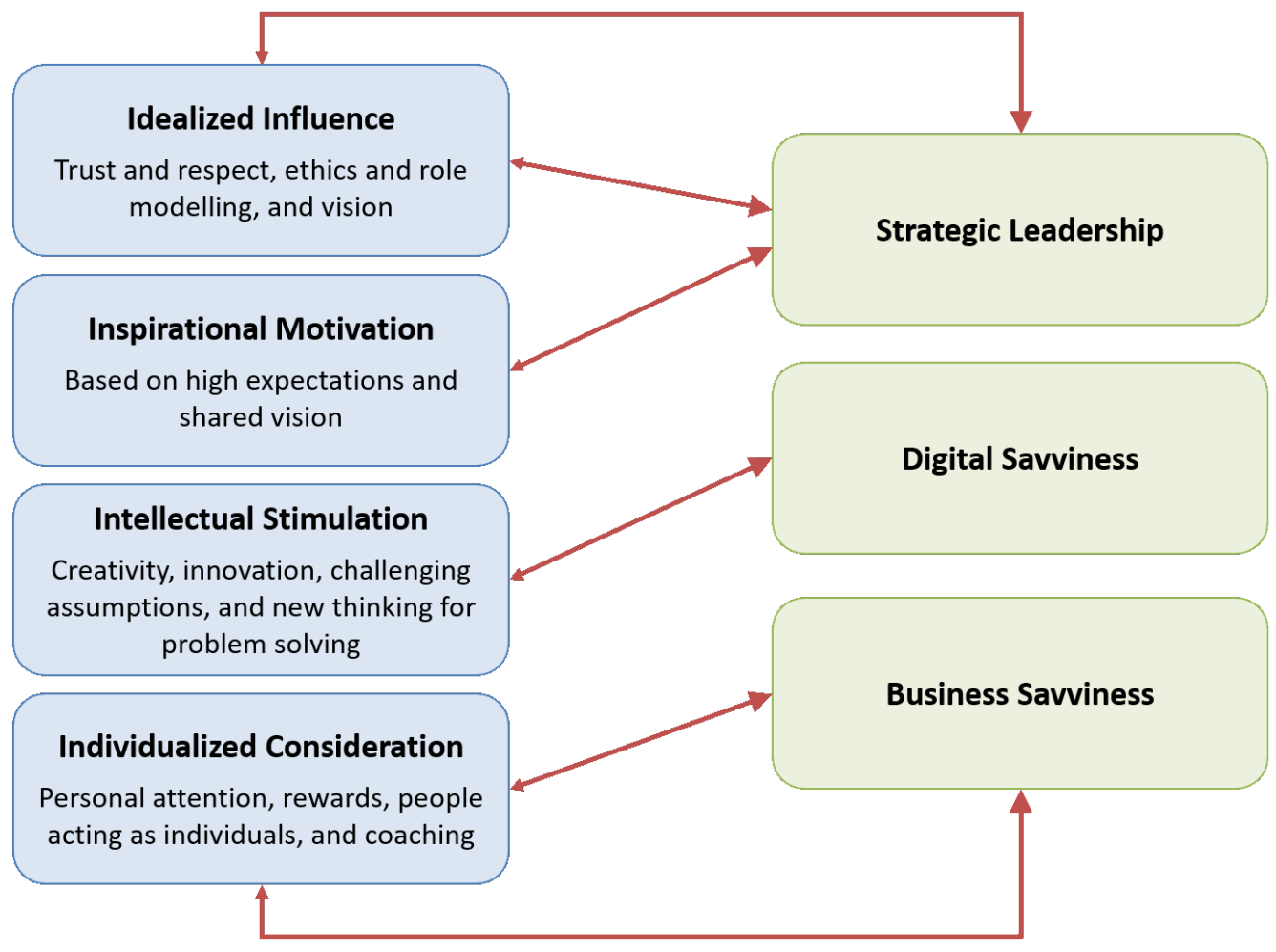

Figure 1. Adopting e-leadership in SMEs

mobile apps, the Internet of Things, social media, or some other technology - can or cannot do to exploit business ideas, collect feedback, or market a product. Eleadership recognizes the need to further develop and update digital technologies along with individual competences on how those technologies could be used (Hüsing et al., 2015). Thus, digital savviness complements business expertise in one area, while business savviness may complement another employee's knowledge on how to use technology. Business and ICT savviness in addition to strategic management of resources (Li et al., 2016) will enable complementarities and the development of a system for understanding customers and using technology to position the firm's product accordingly.

At the same time, we identify two major challenges that may be faced by e-leaders in SMEs in developing countries when adopting and understanding digital technologies. First, in ensuring that technology is embedded in managerial and strategic practices in organizations (e.g., that it is used both during the negotiations and during marketing and product development). Second, digital technologies should be supporting business strategy, and this is only possible if employees are trained (Avolio \& Kahai, 2003). E-leadership is also different because of changes in access to information and media. There is now greater workforce interconnectedness, so it is easier to reach others and communication is more permanent. Thus, faster commercialization of products and targeting more distant markets has become possible.

One of the main challenges faced by SME leaders in developing countries, as compared to those in developed countries, is how to optimally integrate business and information technology to deliver the best experience to external stakeholders and, in particular, to customers. The integration of business and information technology aims to achieve greater customer satisfaction while also making them more digitally savvy in the ways they engage with a company, such as by posting and sharing information about their experiences on Instagram, Facebook, and other digital means (Ferneley \& Bell, 2006). Not surprisingly, SME leaders capable of effectively introducing new products to market by developing both business and digital strategies are more likely to succeed (Sun et al., 2014). However, to the best of our 


\section{E-Leadership in Small and Medium-Sized Enterprises in the Developing World}

\section{Maksim Belitski and Bain Liversage}

knowledge, there is little research examining how eleadership within SMEs drives successful alignment between business needs and technology innovation for customer needs, even though alignment thinking is dominant in the literature (Avolio et al., 2001, 2014).

\section{Method}

To answer our research question, we use a mixed-method analysis (Lieberman, 2005) including qualitative semi-structured interviews and data mining. This approach is based on existing e-leadership research (Avolio et al., 2014; Bansal \& Singh, 2017; Hüsing et al., 2015; Li et al., 2016; Purvanova \& Bono, 2009) and the digital adoption literature (Gono et al., 2016; Van Wart et al., 2017). The semi-structured interview approach enabled us to gain a better understanding of the experiences, attitudes, values, and processes regarding the adoption of e-leadership in SMEs (Lieberman, 2005).

The qualitative data collected were coded and transcribed, and the data were then analyzed through wordprocessing software to ascertain commonalities and anomalies from which conclusions could be drawn. For the quantitative analysis, we used basic descriptive statistics of mean standard deviation, maximum and minimum values.

\section{Sampling}

We started our sampling by following $\mathrm{Li}$ and colleagues (2016) to develop our selection criteria. Out of a population of all SMEs in Johannesburg, we preselected those who have websites or Instagram accounts, or who trade their products digitally (e-commerce). Second, out of pool of 2,240 firms, we selected those who complied with the following criteria: 1) employ between 10 and 250 people; 2) operate in the greater Johannesburg area (but may have national representation), 3) have been in operation for three or more years; 4) show turnover growth of approximately $20 \%$ annually over past the three consecutive years (gazelles); and 5) be considered successful in the ICT sector, as acknowledged by a third party (e.g., a national newspaper publication or national award). These criteria yielded an initial sample of 177 SMEs, to which an introductory email containing the permission and information documentation was sent to the leaders of the selected SMEs (Li et al., 2016).

The responses resulted in a final sample of 11 SMEs. Care was taken in selecting the appropriate level or seniority of leadership; to be invited, interviewees must perform a strategic or directional role in their organization. Thus, we interviewed 4 Chief Executive Officers (CEO),
2 Managing Directors (MD), 1 Partner, 1 Chief Information Officer (CIO), 2 Sales Directors, and 1 Marketing Director (Table 1). The semi-structured questions allowed for easy adaptation and rephrasing to ensure a proper understanding of the responses. They also provided flexibility, depth, and anonymity. Conditions and boundaries were established when developing the open and closed-ended questions using categorization. The interview protocol is provided in Appendix 1.

To make further sense of the data, we used NVivo software to reduce and code the data into themes. Each question was designated as a node from which the essence of the answers was identified. Through this method, the data were quality tested to meet the criteria discussed earlier. The data analysis presented patterns of the views and experiences of the interviewees, thereby forming identifiable links to the literature and the transformational and e-leadership continuum to answer the research question.

\section{Results}

Our analysis yielded five key findings about e-leadership development and its role in the commercialization of new knowledge in developing countries.

\section{Adoption of digital technology is higher in ICT-related businesses}

In our sample, as expected, the adoption rate was higher in ICT-related businesses because they were already advanced in these technologies, due to the nature of their businesses. The higher level of adoption of digital technologies in ICT firms was true only for these four SMEs. The other seven SME leaders commented they are challenged to adopt technology, particularly those limited and more expensive technologies such those supporting the Internet of Things. All interviewees agreed that digital technology is important in commercializing new products. When asked if the digital technology adoption and its support in commercialization is higher in their SMEs than in other firms two CEOs responded, "I wouldn't say so as we all use it for commercialization of what we do" (Interviewee 1) and "No, it needs more focus on the commercialization side" (Interviewee 11). Another described the role of e-leadership in commercialization as, "I see that e-leadership, or as we call it here, "IT leadership", is required to intellectually stimulate and challenge leaders, making all employees digital leaders in their field and making them digitally savvy. Digitization and savviness are not only about the Chief Technical Officer, but everyone, such as a secretary who is able to a use computer, use 


\section{E-Leadership in Small and Medium-Sized Enterprises in the Developing World}

\section{Maksim Belitski and Bain Liversage}

Table 1. The sample of SME leaders interviewed for this study

\begin{tabular}{ccclll} 
Company & $\begin{array}{c}\text { Industry } \\
\text { Sector }\end{array}$ & $\begin{array}{c}\text { Founding } \\
\text { Year }\end{array}$ & Product Type & Leader Interviewed & $\begin{array}{l}\text { Location in } \\
\text { Johannesburg }\end{array}$ \\
\hline SC & ICT & 2006 & Cellular VAR & CIO & MD \\
\hline RA & ICT & 1983 & Automation RF & Partner & Bedfordview \\
\hline IU & ICT & 1983 & SAP consultancy & MD & Sandton \\
\hline PC & ICT & 2004 & Medical technology tracking & Bryanston \\
\hline WA & ICT & 1998 & ISP & Sales Director & Sandton \\
\hline TR & ICT & 2011 & Mobility billing solutions & CEO & Illovo \\
\hline SCS & ICT & 2007 & WASP & CEO & Rosebank \\
\hline BC & ICT & 2006 & ISP & Sales Director & Bryanston \\
\hline ZN & ICT & 2010 & ISP & CEO & Fourways \\
\hline AM & ICT & 2005 & Mobility solutions \& applications & CEO & Bryanston \\
\hline SK & ICT & 2007 & Cellular contract sales & Marketing Director & Craighall Park
\end{tabular}

software to make a presentation, promote a company online, design a promotion video, or unite people with other skills to enhance online presence of a company" (Interviewee 5).

\section{Digital technologies improve sales}

All SMEs leaders interviewed view their uncompromising focus on commercialization as vital to their business and IT strategy. Therefore, the role of e-leadership is seen as a skill itself to transform traditional leadership model and come up with a more agile one as a combination of management and ICT. This seems mainly due to the size of the organizations and their respective context and competitive environment. When asked to describe the role of e-leadership in commercialization, three out of eleven CEOs referred to the importance of "hands-on" experience with newly adopted technologies in their organizations. They mentioned that this is crucial to support sales.

One Chief Technical Officer posited that "The place of digital leadership and technology needs to be given better attention. This also includes recognizing the power of social media. Moreover, business strategy needs to move forward from the sale concept to the more embra- cing market concept.” (Interviewee 2). A Chief Information Officer argued that "Digital leadership is strategic management with business and technological acumen with the purpose of adapting in line with innovations in order to ultimately gain competitive advantage and sell. Adoption of digital techs is done by implementing technologies that improve the effectiveness and efficiency of sales first." (Interviewee 9) They added that "Digital leaders are important because they have a wide understanding of how digital technologies can be used to market the products at different lifecycles. This changes sales. Introducing products using digital techs is important for our new customers. Digital techs help to keep up with trending technologies, thinking strategically, to increase sales and gain competitive advantage" (Interviewee 9).

Our word-mining techniques were able to determine that the most-repeated words when the interviewees were asked about e-leadership as sales skills, and the results were "sales and business performance", "commercialization through technology", "sales", and "making product visible". As one leader put it, "If I do not use social media, I am powerless to make myself visible to customers, so my sales don't take off" (Interviewee 10). 


\section{E-Leadership in Small and Medium-Sized Enterprises in the Developing World}

\section{Maksim Belitski and Bain Liversage}

\section{Digital technologies act as a feedback tool}

Firms must effectively gather and internalize customer feedback to improve their products. As one leader said, “That's interesting, I hadn't given much thought to the idea of 'in-house' apps, or apps for a smaller community that works together. A company can communicate more efficiently and effectively if they are sharing a bespoke app on a project or a new initiative. These apps will need daily monitoring, reporting feedback, and collecting data and responses. This will all need to be managed and presented, and it will become more effective as the learning process evolves." (Interviewee 4). Another IT director added that "These digital technologies now have the power to enable businesses to talk to themselves and exchange feedback, but also businessto-business interaction is important. With the app that we created, we connect to our colleagues within the enterprise group and use Microsoft Yammer to provide feedback on sales or any issues." (Interviewee 8). His colleague also explained the role of technology in feedback: "From mere observations of technology adopted and used in some organizations or businesses, I see the challenges that face the digital leader and their team. First, by making sure that the technology adopted is dynamic enough to embrace any foreseen changes and respond quickly to customer and supplier feedback. It is very important for technology to process information and to relate that to everyone on board from bottom to top. Second, it is vital that the company implements training on simplifying the use of that technology and is open to the feedback gathered while implementing the technology within a company." (Interviewee 6). An IT Director in one of the IT sector SMEs further suggested that "the most challenging one, and after digesting all that, here comes the point of presenting/introducing the technology to the end user in a friendly and simple way. It cannot be done without collecting daily feedback on who adopts and uses the technology, and clients should ensure that everything is presented to them." (Interviewee 1). He further posits "Only a skillful e-leader with a team, of course, can blend all these pieces of information and feedback into a friendly, acceptable, and productive interface of the organization."

Another added that, without e-leadership, there would be no mobility solutions and "our networks will be flat" (Interviewee 5). Another stated the following: "My firm relies a lot on repackaging, and providing novel services is of great importance to customers who are often larger organizations lacking the flexibility of SMEs, where our digital technology allows to track products all the way to customers and see how happy they are" (Interviewee 10). Our interviews demonstrated that e- leadership is also about engagement with customers throughout commercialization of a product and customer management. It is important to ensure that SMEs in developing economies adapt to environmental pressures (Audretsch \& Belitski, 2017) so that suppliers and customer are connected through technology.

\section{Digital technologies facilitate information exchange with customers}

Leaders from all 11 SMEs found information exchange between their firms and customers to be critical to their business performance and sales. Answering the question "How is information strategically collected and used to enhance sales?", one leader posited that "it's by exchange of information that we develop credibility and know how marketing should be arranged" (Interviewee 10). Another added, "Digital technologies would allow for an interactive chat, which is very helpful to understand your customers" (Interviewee 3). Another lamented that "Without digital chat and online connection with my customers, commercialization would take ages and never directly reach customers, but I will be asking a middle man to be this channel" (Interviewee 5).

\section{E-leadership facilitates human resources management}

People and business success are linked, and factors that affect business competences will also affect ICT skills. One leader commented that "Human resource management acumen is of great importance and technology enables to easier monitoring and motivating employees" (Interviewee 8). Another added that "We need digital leaders to see whom to employ and effectively fastscreen and pre-select candidates so we only pick up those who quickly create value" (Interviewee 11). It was also stated that "Firms often have flat organizational structures making decision making easier, transparency is heightened, and people are clear about what is needed and how technology is to be used (Interviewee 1). One leader explained that "We need a hands-on approach to day-to-day operations, and digital skills of managers are important to see what works at different levels of management (Interviewee 6). Another added that "Being overly operational is bad; when managing people, you need to be both operational and strategic" (Interviewee 10). Finally, one leader noticed that "Technology can improve business operations and increase automation to free-up e-leaders to focus on the future, but it is e-leaders who arrange it altogether, looking at human resource requirements and what digital skills new recruits need to have. If the e-leader does not know what digital technologies and skills are there, how can they hire new people and make them sell?" (Interviewee 2). 


\section{E-Leadership in Small and Medium-Sized Enterprises in the Developing World}

Maksim Belitski and Bain Liversage

\section{Discussion and Conclusion}

This study demonstrated that e-leadership is seen as a tool for new knowledge and new product commercialization. By combining technology, business, and management skills, e-leaders of SMEs in the city of Johannesburg, South Africa, were able to better connect with their customers (sell), recruit employees with relevant skills (manage people), receive feedback from customers and better engage in new product development (manage customers), and transfer information with their suppliers and customers throughout product creation and delivery (exchange information).

Through this work, we make several contributions. Building on the innovation and information systems literature (e.g., De Haes \& Van Grembergen, 2009; Leidner \& Preston, 2011; Lyytinen et al., 2016), our first contribution comes from applying an e-leadership perspective to new product commercialization as a combination of management, strategic, and ICT skills for improving a firm's market position and performance. Thus, our goal was to inform academics, policy makers, and firm managers about the role of e-leadership in the commercialization of knowledge and new products by managing people, information, sales, and firm performance through the use of digital technology.

Our second contribution is in demonstrating the role of alignment between the management, strategic, and ICT operational component (Leidner \& Preston, 2011) of eleadership and the role than ICT capabilities play in decision making and new product commercialization.

Our most interesting finding is that e-leadership provides a tool for commercialization and it enables digital technologies to be used to create new value for businesses. Unlike e-leadership in developed countries (Avolio, 2014; LEAD, 2014), in a developing country such as South Africa, e-leadership emerges as a skill of commercialization rather than a skill of business-IT alignment in a firm (De Haes \& Van Grembergen, 2009). This is a major and important difference, which switches the focus of academics and policy makers on e-leadership as a tool for the exploitation of knowledge rather than locking it within the congruence of operations and the strategic component in digital business models.

The study yielded five findings that demonstrate how a theoretical perspective on e-leadership in SMEs is real- ized through engagement with the market using data from 11 fast-growing SMEs in the city of Johannesburg. The e-leadership perspective on commercialization in developing economies is different from the one applied in developed economies, where e-leadership affects firm performance through strategic alignment of business and IT operations and strategies (Avolio et al., 2001, 2014; Avolio \& Kahai, 2003; Li et al., 2016).

Although a transformation process may take time (Avolio et al., 2014), it has become clear that the application of e-leadership as a skill in SMEs in South Africa is critical to winning customers in today's market. Government agencies and policy makers must, therefore, consider programs that communicate and promote the learning of e-leadership as a skill. In so doing, they should facilitate the development of practices that give SMEs easier access to technology-based training. Access to cheaper or subsidized technology should become a more focused proposition, where policy makers apply price pressure to data and technology suppliers, to form a lower price of entry. Innovative costing and payment structures should be devised to facilitate access to technology. Initiatives such as those proposed by the Department of Trade and Industry (DTI) that aim to encourage and develop innovation and commercialization in SMEs must continue. E-leaders in SMEs should engage in support tools available through online education such as those offered by online open courses. This can be accomplished through partnerships that link government support initiatives to SMEs and universities on their way to commercialization. For example, SMEs could join networks of local universities.

Larger corporations can contribute to training and development activities, and in so doing support the economic improvements needed in developing countries. Established SMEs, such as those that formed part of our research, should formalize their digital strategies. Crucially, in the final stage of e-leadership development, eleaders will need to align their digital strategy to their overarching business strategy.

This study examined a limited sample of SMEs in South Africa. Future research will expand the sample and include the role of regional culture and institutions in eleadership. There are differences of opinion on how culture affects hiring decisions, but the overall sense is there must be a combination of skills and cultural fit for effective e-leadership to take root. 


\section{E-Leadership in Small and Medium-Sized Enterprises in the Developing World}

\section{Maksim Belitski and Bain Liversage}

\section{Acknowledgements}

This study was developed within the project "E-Leadership Skills for Small and Medium Sized Enterprises" project sponsored by the European Commission, Directorate-General for Enterprise and Industry and as an MBA final project at Henley Business School in Johannesburg, South Africa supervised by Dr. Maksim Belitski.

We very much appreciate the constructive comments received through blind review and from the Editor-inChief, Chris McPhee, which enabled us to significantly improve the quality and focus of the final manuscript.

\section{About the Authors}

Maksim Belitski is an Associate Professor in the Henley Business School at the University of Reading, United Kingdom. He holds a $\mathrm{PhD}$ in Applied Economics from the University of Leicester, UK, and a $\mathrm{PhD}$ in Economics from the University of Milan, Italy. He is a Trusted Researcher of the Secure Data Service, UK Data Archive and Virtual Micro-data Lab, Office of National Statistics, UK. His research interests lie in the area of entrepreneurship, innovation, and regional economics, with a focus on entrepreneurship as a spillover of knowledge and creativity. He is an editor of the Small Business Economics Journal.

Bain Liversage is the CEO at Smartcom in Johannesburg, South Africa. His research focuses on businesses and the people in business, in particular, what makes people make choices, grow, and fail. Bain has over 10 years of experience as an executive manager and CEO in the ICT sector as well as in strategy, finance, operations, human resources, and networking. He manages a variety of sales teams and individuals, including a broad range of executive decision-making activities related to technology adoption. He gained his MBA from Henley Business School in Johannesburg, South Africa.

\section{References}

Audretsch, D. B., \& Belitski, M. 2017. Entrepreneurial Ecosystems in Cities: Establishing the Framework Conditions. The Journal of Technology Transfer, 42(5): 1030-1051.

https://doi.org/10.1007/s10961-016-9473-8

Audretsch, D. B., \& Belitski, M. 2013. The Missing Pillar: The Creativity Theory of Knowledge Spillover Entrepreneurship. Small Business Economics, 41(4): 819-836. https://doi.org/10.1007/s11187-013-9508-6

Audretsch, D. B., \& Keilbach, M. 2007. The Theory of Knowledge Spillover Entrepreneurship. Journal of Management Studies, 44(7): 1242-1254.

https://doi.org/10.1111/j.1467-6486.2007.00722.x

Avolio, B. J., \& Kahai, S. S. 2003. Adding the 'E' to E-Leadership: How It May Impact Your Leadership. Organizational Dynamics, 31(4): 352-338.

http://dx.doi.org/10.1016/S0090-2616(02)00133-X

Avolio, B. J., Kahai, S. S., \& Dodge, G. E. 2001. E-Leadership: Implications for Theory, Research, and Practice. The Leadership Quarterly, 11(4): 615-668.

https://doi.org/10.1016/S1048-9843(00)00062-X

Avolio, B. J., Sosik, J. J., Kahai, S. S., \& Baker, B. 2014. E-Leadership: ReExamining Transformations in Leadership Source and Transmission. The Leadership Quarterly, 25(1): 105-131. https://doi.org/10.1016/j.leaqua.2013.11.003

Bansal, M., \& Singh, K. 2017. From Leadership to E-Leadership: A Paradigm Shift. The Indian Journal of Industrial Relations, 40(3): 394-409.

https://www.jstor.org/stable/27767969

Belitski, M., \& Desai, S. 2016. What Drives ICT Clustering in European Cities? The Journal of Technology Transfer, 41(3): 430-450. https://doi.org/10.1007/s10961-015-9422-y

Bruque-Camara, S., Vargas-Sanchez, A., \& Hernandez-Ortiz, M. J. 2004. Organizational Determinants of IT Adoption in the Pharmaceutical Distribution Sector. European Journal of Information Systems, 13(2): 133-146. https://doi.org/10.1057/palgrave.ejis.3000490

Cant, M. C., \& Wiid, J. A. 2013. Establishing the Challenges Affecting South African SMEs. The International Business \& Economics Research Journal, 12(6): 707-716. https://doi.org/10.19030/iber.v12i6.7869

Cohen, W. M., \& Levinthal, D. A. 1989. Innovation and Learning: The Two Faces of R \& D. The Economic Journal, 99(397): 569-596. https://doi.org/10.2307/2233763

Coltman, T. R., Tallon, P. P., Sharma, R., \& Queiroz, M. 2015. Strategic IT Alignment: Twenty-Five Years On. Journal of Information Technology, 30(2): 91-100. https://doi.org/10.1057/jit.2014.35

De Haes, S., \& Van Grembergen, W. 2009. An Exploratory Study into IT Governance Implementations and Its Impact on Business/IT Alignment. Information Systems Management, 26(2): 123-137. https://doi.org/10.1080/10580530902794786

Ferneley, E., \& Bell, F. 2006. Using Bricolage to Integrate Business and Information Technology Innovation in SMEs. Technovation, 26(2): 232-241.

https://doi.org/10.1016/j.technovation.2005.03.005 


\section{E-Leadership in Small and Medium-Sized Enterprises in the Developing World}

\section{Maksim Belitski and Bain Liversage}

Gono, S., Harindranath, G., \& Berna Özcan, G. 2016. The Adoption and Impact of ICT in South African SMEs. Strategic Change, 25(6): 717-734.

https://doi.org/10.1002/jsc.2103

Hüsing, T., Dashja, E., Gareis, K., Korte, W. B., Stabenow, T., \& Markus, P. 2015. E-Leadership Skills for Small and Medium Sized Enterprises: Final Report. Brussels: European Commission.

Hüsing, T., Korte, W. B., Fonstad, N., Lanvin, B., Welsum, D., Cattaneo, G., Kolding, M., \& Lifonti, R. 2013. E-Leadership: E-Skills for Competitiveness and Innovation Vision, Roadmap and Foresight Scenarios. Brussels: European Commission.

Korte, W. B., Hüsing, T., \& Dashja, E. (Eds.) 2015. E-Leadership: Digital Skills for SMEs. Brussels: European Commission.

LEAD. 2014. E-Leadership Skills for Small and Medium Sized Enterprises Project. Brussels: European Commission.

Leidner, D., Lo, J., \& Preston, D. S. 2011. An Empirical Investigation of the Relationship of IS Strategy with Firm Performance. Journal of Strategic Information Systems, 20(4): 419-437. https://doi.org/10.1016/j.jsis.2011.09.001

Li, W., Liu, K., Belitski, M., Ghobadian, A., \& O’Regan, N. 2016. ELeadership through Strategic Alignment: An Empirical Study of Small and Medium-Sized Enterprises in the Digital Age. Journal of Information Technology, 31(2): 185-206.

https://doi.org/10.1057/jit.2016.10

Lieberman, E. S. 2005. Nested Analysis as a Mixed-Method Strategy for Comparative Research. American Political Science Review, 99(3): 435-452. https://doi.org/10.1017/S0003055405051762

Lyytinen, K., Yoo, Y., \& Boland Jr., R. J. 2016. Digital Product Innovation within Four Classes of Innovation Networks. Information Systems Journal, 26(1): 47-75. https://doi.org/10.1111/isj.12093

Matzler, K., Schwarz, E., Deutinger, N., \& Harms, R. 2008. The Relationship between Transformational Leadership, Product Innovation and Performance in SMEs. Journal of Small Business \& Entrepreneurship, 21(2): 139-151.

https://doi.org/10.1080/08276331.2008.10593418

Naicker, V., \& Peters, R. 2013. Small Medium Micro Enterprise Business Goals and Government Support: A South African Case Study. South African Journal of Business Management, 44(4): 13-24.
Nkomo, S. M., \& Kriek, D. 2011. Leading Organizational Change in the 'New' South Africa. Journal of Occupational and Organizational Psychology, 84(3): 453-470. https://doi.org/10.1111/j.2044-8325.2011.02020.x

Purvanova, R. K., \& Bono, J. E. 2009. Transformational Leadership in Context: Face-to-face and Virtual Teams. Leadership Quarterly, 20(3): 343-357.

https://doi.org/10.1016/j.leaqua.2009.03.004

Ramamurthy, K., \& Premkumar, G. 1995. Determinants and Outcomes of Electronic Data Interchange Diffusion. IEEE Transactions on Engineering Management, 42(4): 332-351. https://doi.org/10.1109/17.482083

Rogerson, C. M. 2000. Successful SMEs in South Africa: The Case of Clothing Producers in the Witwatersrand. Development Bank Southern Africa, 17(5): 37-41. https://doi.org/10.1080/713661433

Seltzer, J., \& Bass, B. M. 1990. Transformational Leadership: Beyond Initiation and Consideration. Journal of Management, 16(4): 693-703.

https://doi.org/10.1177/014920639001600403

Sun, L., Liu, K., Jambari, D., \& Mitchell, V. 2014. Evaluating Business Value of IT towards Optimisation of Application Portfolio. Enterprise Information Systems, 10(4): 378-399. https://doi.org/10.1080/17517575.2014.939106

Van Wart, M., Roman, A., Wang, X., \& Liu, C. 2017. Integrating ICT Adoption Issues into (e-)Leadership Theory. Telematics and Informatics, 34(5): 527-537. https://doi.org/10.1016/j.tele.2016.11.003

Vargas, M. I. R. 2015. Determinant Factors for Small Business to Achieve Innovation, High Performance and Competitiveness: Organizational Learning and Leadership Style. Procedia-Social and Behavioral Sciences, 169: 43-52. https://doi.org/10.1016/j.sbspro.2015.01.284

Walumbwa, F. O., Avolio, B. J., \& Aryee, S. 2011. Leadership and Management Research in Africa: A Synthesis and Suggestions for Future Research. Journal of Occupational and Organizational Psychology, 84(3): 425-439. https://doi.org/10.1111/j.2044-8325.2011.02034.x

Zahra, S. A., \& George, G. 2002. Absorptive capacity: A Review, Reconceptualization, and Extension. Academy of Management Review, 27(2): 185-203. https://doi.org/10.5465/amr.2002.6587995 


\section{E-Leadership in Small and Medium-Sized Enterprises in the Developing World}

Maksim Belitski and Bain Liversage

Appendix 1. E-leadership domain and capabilities questionnaire protocol

\section{Background of the successful SME}

-When was the business founded and by whom?

- Where is the head office and are there regional offices or representation?

- How many people are employed here?

- What are your core products and services?

- Who are your customers?

- Would you consider your business successful and why?

- How would you describe the leadership style adopted in your business?

- Are you aware of what transformational leadership is and what does it consist of?

- Does your business have a vision, mission, or purpose statement and what does it consist of?

\section{Digital adoption and ICT use}

- Overall, how is ICT used from a strategic point of view in your business? Consider from operational efficiency, customer engagement, and product and service innovation perspectives.

- Has the role of digital been identified within your business?

- Is digital a discussion point at the board level and is there a responsible board representative focused on digital?

- Is digital transformation considered high on the strategic agenda?

-What enterprise systems does your business make use of, if any?

- Does your business make use of mobile applications in day-to- day operations?

- What percentage of investment has been allocated to development and integration of digital technologies?
- Was your website set up with the intention of improving sales or for general information purposes or because other businesses were doing it?

- How often does your business update and enhance its website?

- Does your business make use of social media? If so, which platforms are made use of?

- Do you as a leader make use of social media for business purposes, if so, how active are you?

- Do you think your business is currently benefiting from digital technologies?

-What was the most significant innovation in your business over the last few years and what role did digital play?

- Has the use of digital technology helped your business access new markets?

\section{E-leadership}

- Over the next five years, what sort of leaders do you anticipate your business will need?

- Is there a skills gap regarding digital technology within your business?

- Does your business have a strategy for developing eleaders?

- What are the most relevant e-skills necessary for eleaders to obtain?

- When employing new managers/leaders, what emphasis do you place on their knowledge of and experience in the use of digital technologies.

Citation: Belitski, M., \& Liversage, B. 2019. E-Leadership in Small and Medium-Sized Enterprises in the

(cc) BY

Developing World. Technology Innovation Management Review, 9(1): 64-74.

http://doi.org/10.22215/timreview/1212

Keywords: e-leadership, SMEs, small- and mediumsized enterprises, digital technology, developing country, commercialization 


\section{Author Guidelines}

These guidelines should assist in the process of translating your expertise into a focused article that adds to the knowledge resources available through the Technology Innovation Management Review. Prior to writing an article, we recommend that you contact the Editor to discuss your article topic, the author guidelines, upcoming editorial themes, and the submission process: timreview.ca/contact

\section{Topic}

Start by asking yourself:

- Does my research or experience provide any new insights or perspectives?

- Do I often find myself having to explain this topic when I meet people as they are unaware of its relevance?

- Do I believe that I could have saved myself time, money, and frustration if someone had explained to me the issues surrounding this topic?

- Am I constantly correcting misconceptions regarding this topic?

- Am I considered to be an expert in this field? For example, do I present my research or experience at conferences?

If your answer is "yes" to any of these questions, your topic is likely of interest to readers of the TIM Review.

When writing your article, keep the following points in mind:

- Emphasize the practical application of your insights or research.

- Thoroughly examine the topic; don't leave the reader wishing for more.

- Know your central theme and stick to it.

- Demonstrate your depth of understanding for the topic, and that you have considered its benefits, possible outcomes, and applicability.

- Write in a formal, analytical style. Third-person voice is recommended; first-person voice may also be acceptable depending on the perspective of your article.

\section{Format}

1. Use an article template: .doc .odt

2. Indicate if your submission has been previously published elsewhere. This is to ensure that we don't infringe upon another publisher's copyright policy.

3. Do not send articles shorter than 2000 words or longer than 5000 words.

4. Begin with a thought-provoking quotation that matches the spirit of the article. Research the source of your quotation in order to provide proper attribution.

5. Include an abstract that provides the key messages you will be presenting in the article.

6. Provide a 2-3 paragraph conclusion that summarizes the article's main points and leaves the reader with the most important messages.

7. Include a 75-150 word biography.

8. List the references at the end of the article.

9. If there are any texts that would be of particular interest to readers, include their full title and URL in a "Recommended Reading" section.

10. Include 5 keywords for the article's metadata to assist search engines in finding your article.

11. Include any figures at the appropriate locations in the article, but also send separate graphic files at maximum resolution available for each figure. 


\section{Issue Sponsor}

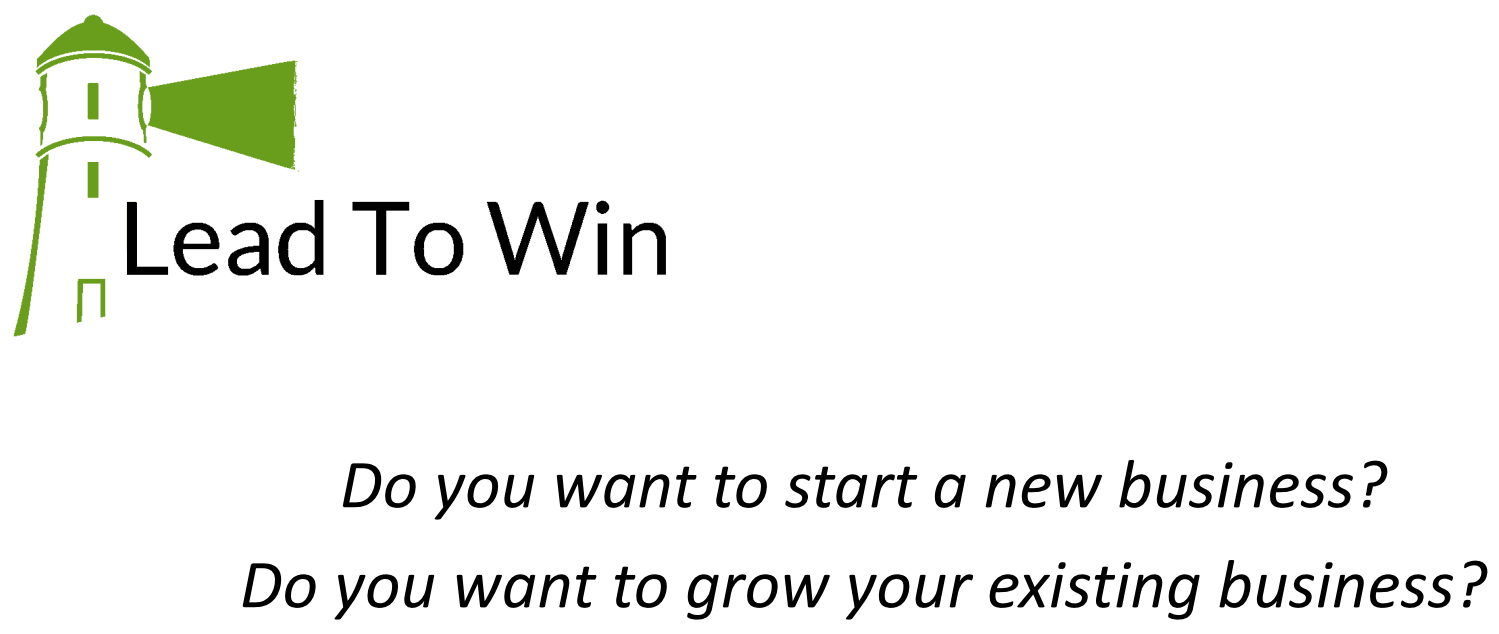

Lead To Win is a free business-development program to help establish and grow businesses in Canada's Capital Region.

Benefits to company founders:

- Knowledge to establish and grow a successful businesses

- Confidence, encouragement, and motivation to succeed

- Stronger business opportunity quickly

- Foundation to sell to first customers, raise funds, and attract talent

- Access to large and diverse business network

\section{Apply Now}

* Twitter

f Facebook

in Linkedin

E Eventbrite

9 Slideshare

- YouTube

-๑ Flickr 


\section{Academic Affiliations and Funding Acknowledgements}
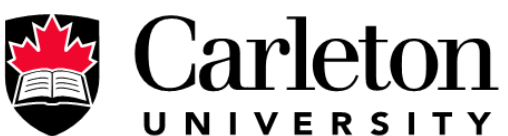

U N I V E R S I T Y

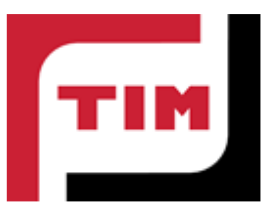

Technology Innovation Management (TIM; timprogram.ca) is an international master's level program at Carleton University in Ottawa, Canada. It leads to a Master of Applied Science (M.A.Sc.) degree, a Master of Engineering (M.Eng.) degree, or a Master of Entrepreneurship (M.Ent.) degree. The objective of this program is to train aspiring entrepreneurs on creating wealth at the early stages of company or opportunity lifecycles.

- The TIM Review is published in association with and receives partial funding from the TIM program. 